\title{
Transcriptome-based analysis of molecular pathways for clusterin functions in kidney cells
}

\author{
by \\ Ghida Saleh Dairi \\ BSc, Umm Al-Qura University, 2010 \\ A THESIS SUBMITTED IN PARTIAL FULFILLMENT \\ OF THE REQUIREMENTS FOR THE DEGREE OF \\ MASTERS OF SCIENCE \\ in \\ THE FACULTY OF GRADUATE AND POSTDOCTORAL STUDIES \\ (Experimental Medicine)
}

THE UNIVERSITY OF BRITISH COLUMBIA

(Vancouver)

May 2016

(C) Ghida Saleh Dairi, 2016 


\begin{abstract}
Background: Clusterin (CLU) is a chaperone-like protein. Our previous studies have demonstrated that CLU protects kidney from ischemia-reperfusion injury (IRI) and enhances renal repair after IRI; however, the molecular pathways for its functions in the kidney are not fully understood. This study was designed to investigate CLU-mediating pathways in kidney cells by using bioinformatics analysis.
\end{abstract}

Materials and Methods: An in vitro model of kidney tissue using CLU null renal tubular epithelial cells (TECs) was established for this research project. An immortalized CLU null TEC cell line was generated from a CLU knockout (KO) mouse, and was stably expressing pHEX6300 plasmid containg human CLU cDNA (TEC-CLU ${ }^{\text {hCLU }}$ ), so that this cell line constitutively expresses human CLU protein, whereas control cell line (TEC-CLU ${ }^{-/}$) was generated from the same parental CLU null TEC cell line by expressing empty pHEX6300. Both TEC-CLU ${ }^{\mathrm{hCLU}}$ and TEC-CLU ${ }^{-/-}$cell lines were exposed to either normoxia or hypoxia (1\% O2). Transcriptome profiling with a significant 2 -fold change $(\mathrm{FC})(\mathrm{FC} \geq 2, \mathrm{p} \leq$ 0.05)was performed using SurePrint G3 Mouse Gene Expression $8 \times 60 \mathrm{~K}$ microarray, and the signaling pathways was ranked by using Ingenuity pathway analysis (IPA).

Results: Here, we showed that compared to CLU null TEC-CLU ${ }^{-/-}$controls ectopic expression of human CLU in CLU null kidney cells (TEC-CLU ${ }^{\text {hCLU }}$ ) promoted cell growth but inhibited migration in normoxia, and enhanced cell survival in hypoxia. CLU affected expression of 3864 transcripts (1893 up-regulated) in normoxia and 3670 transcripts (1925 up-regulated) in hypoxia. CLU functions including cell proliferation, survival and adhesion 
in normoxia were associated mostly with AKT2 dependent PI3K/AKT, PTEN, VEGF and ERK/MAPK signaling and as well with GSK3B-mediated cell cycle progression. In addition to unfolded protein response (UPR) and/or endoplasmic reticulum (ER) stress, CLUenhanced cell survival in hypoxia was also associated with Foxo3/PIK3CD/MAPK1dependent PI3K/AKT, HIF- $\alpha$, PTEN, VEGF and ERK/MAPK signaling

Conclusion: Our data showed that CLU functions in kidney cells were mediated in a cascade manner mainly by PI3K/AKT, PTEN, VEGF and ERK/MAPK signaling, and specifically by activation of UPR/ER stress in hypoxia, providing new insights into the protective role of CLU in the kidney. 


\section{Preface}

This thesis has been written in partial fulfillment of the requirement for the degree of Master of Science in Experimental Medicine. I have written this thesis under the direction and supervision of Dr. Caigan Du, Dr. Colin Collins and Dr. Christopher Ong from September 2013 to March 2016. Dr. Caigan Du, Dr. Colin Collins and Dr. Christopher Ong reviewed this thesis. All the experimental works and analysis of this research project was performed by Ghida Dairi in Vancouver Prostate Centre.

Microarray was done at Laboratory for Advanced Genome Analysis at Vancouver Prostate Centre by Miss. Anne Haegert. The CLU-GFP plasmid was used in this research project was kindly provided by Dr. Martin Gleave's group at Vancouver Prostate Centre.

This thesis is published in Journal of Cellular Physiology. In addition, thesis's results were presented as poster presentation at UBC Urology Department Research Day (June, 2015) and Experimental Medicine Student Research Day (Nov, 2015) and the abstract was published in American Journal of Transplant (online). 


\section{Table of contents}

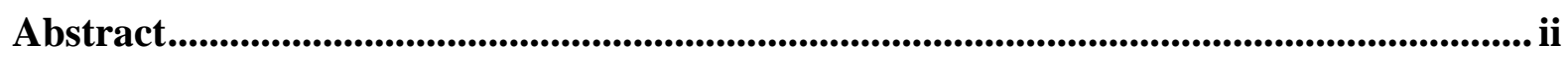

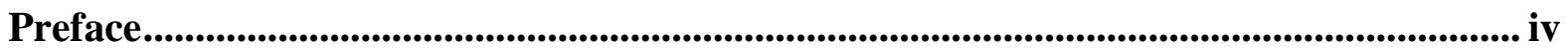

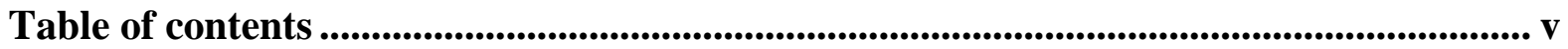

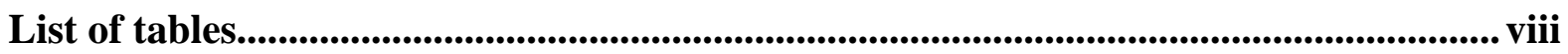

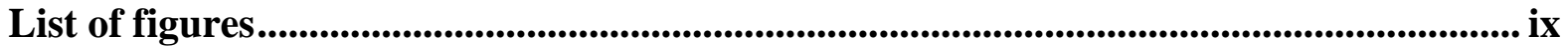

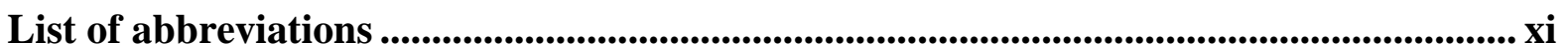

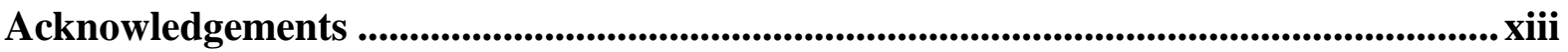

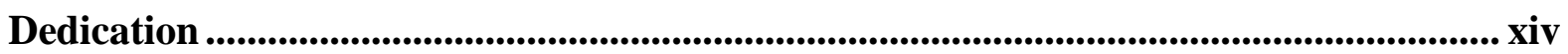

Chapter 1: Introduction and background ....................................................................... 1

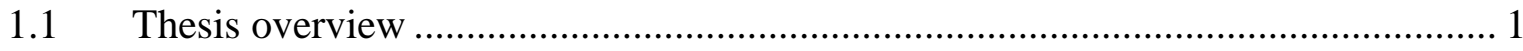

1.2 The embryological origin and structure of the kidney ..................................... 2

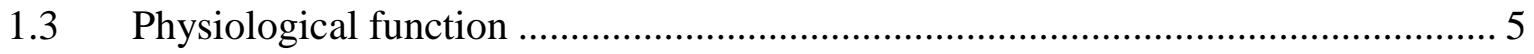

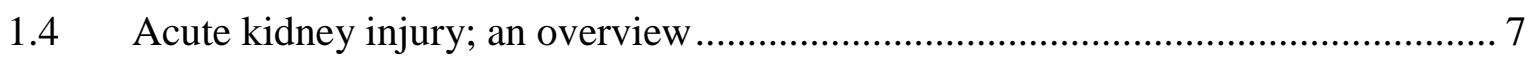

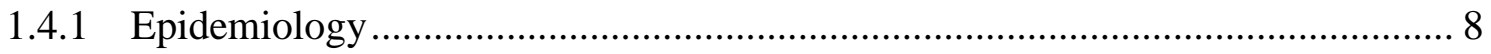

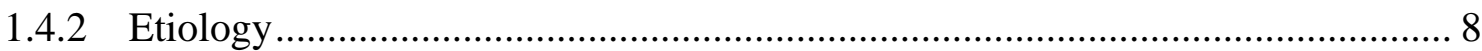

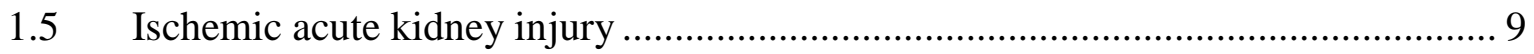

1.5.1 Consequences of ischemia at tubular epithelial cells level ............................. 10

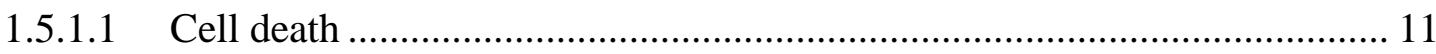

1.5.1.2 Transcriptional reprograming in response to hypoxia ............................. 13

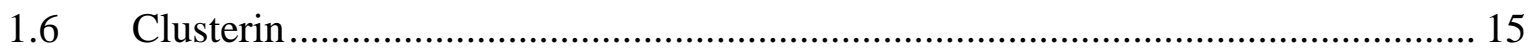

1.6.1 Clusterin gene, cellular localization and structure ..................................... 16 


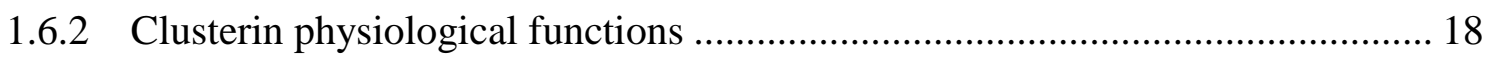

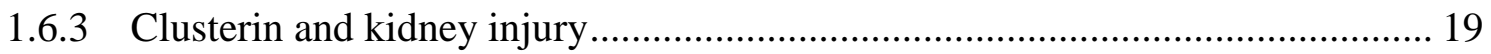

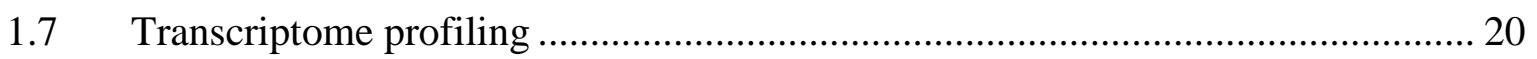

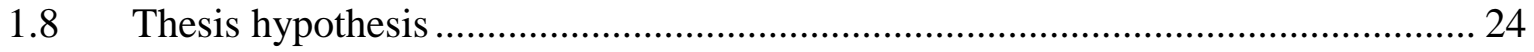

Chapter 2: Materials and methods................................................................................. 25

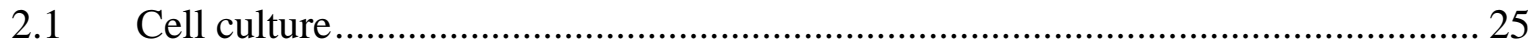

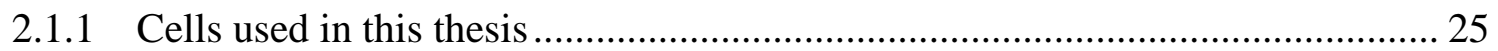

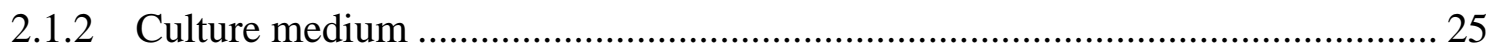

2.1.3 Coating dishes with collagen ...................................................................... 26

2.1.4 Induction of hypoxia in cell culture ........................................................... 26

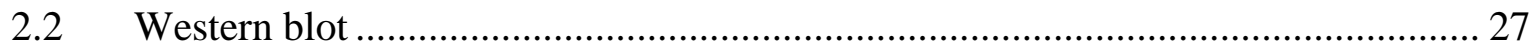

2.3 Cellular localization of clusterin by confocal microscopy ………………............ 29

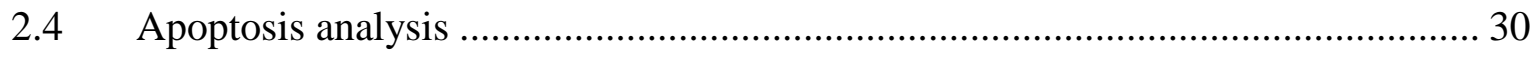

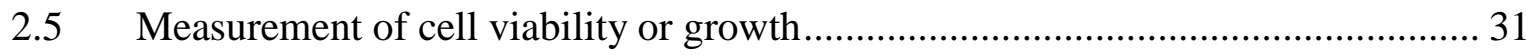

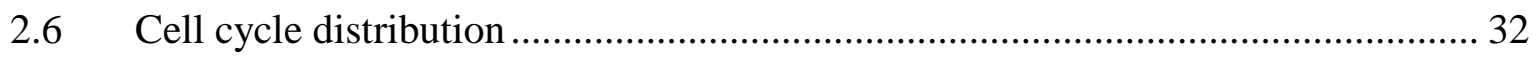

2.7 Cell migration by real time cell analyzer ……………........................................ 32

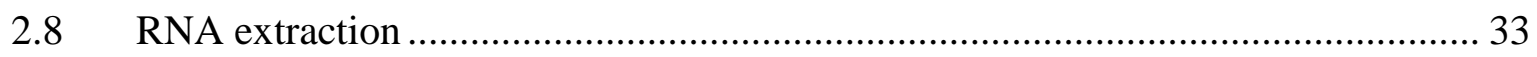

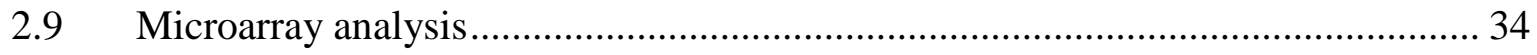

2.10 Microarray data analysis .................................................................................. 35

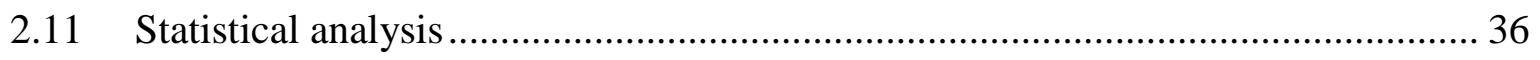

Chapter 3: Results................................................................................................................................. 37

3.1 Ectopic expression of human clusterin protein in clusterin in null tubular epithelial

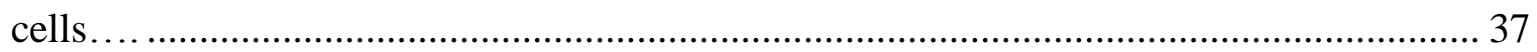


3.2 Regulation of clusterin gene expression (transcriptome) by clusterin expression in tubular epithelial cells . 40

3.3 Signaling pathways mediating clusterin-dependent cell survival under normoxia 42

3.4 Signaling mediating clusterin-dependent cell proliferation in normoxia .............. 45

3.5 Signaling pathways for inhibition of clusterin in cell migration in normoxia........ 50

3.6 Signaling pathways mediating clusterin-dependent cell survival in hypoxia........ 53

3.7 Interaction between genes mediating clusterin functions ............................... 56

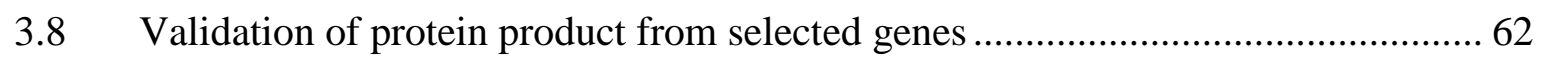

Chapter 4: Discussion and conclusion.....................................................................64

Chapter 5: Questions for next studies .............................................................................6 69

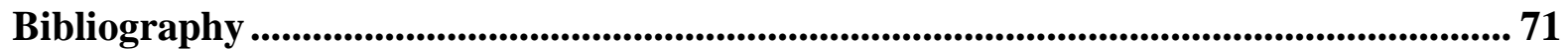




\section{List of tables}

Table 3.1 Cell survival/death pathways associated with clusterin expression in tubular epithelial cells in normoxia...

Table 3.2 cell proliferation pathways associated with clusterin expression in tubular epithelial

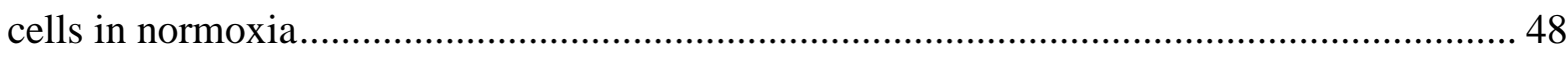

Table 3.3 Cell cycle pathways associated with clusterin expression in tubular epithelial cells

in normoxia

Table 3.4 Cell migration pathways associated with clusterin expression in tubular epithelial cells in normoxia.

Table 3.5 Cell death/survival pathways associated with clusterin expression in tubular epithelial cells in hypoxia 


\section{List of figures}

Figure 1.1 Embryological development of kidney ............................................................ 4

Figure 1.2 Embryological development and structure of the nephron..................................... 5

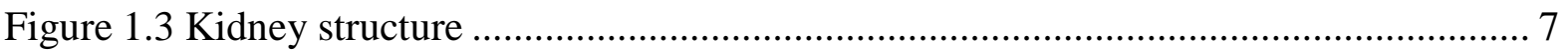

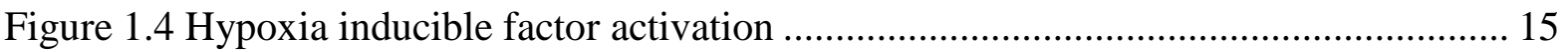

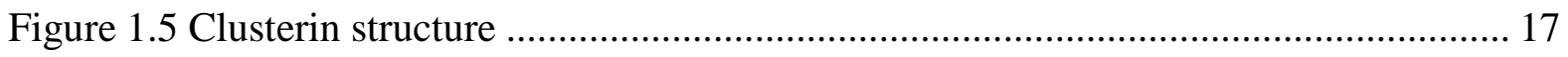

Figure 1.6 Schematic of one color gene expression microarray procedure ............................ 22

Figure 3.1 Ectopic expression of human clusterin isoform1 in tubular epithelial cells from

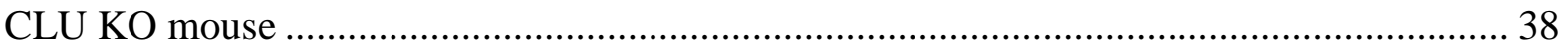

Figure 3.2 Cellular localization of clusterin in tubular epithelial cells under hypoxia and

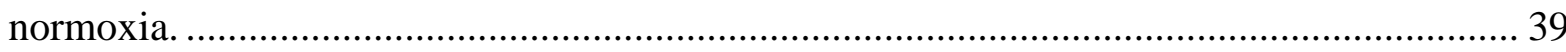

Figure 3.3 Clusterin-induced transcriptome of tubular epithelial cells in both normoxia and

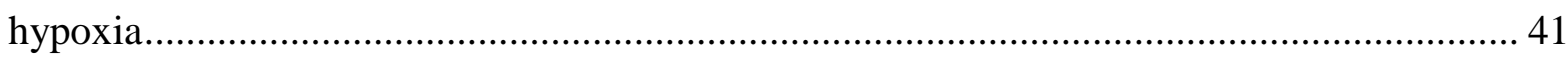

Figure 3.4 Clusterin- induced cell survival in normoxia .................................................... 43

Figure 3.5 Clusterin-induced tubular epithelial cells growth or proliferation in normoxia.... 46

Figure 3.6 Clusterin-induced tubular epithelial cells division in normoxia............................ 47

Figure 3.7 Clusterin-restrained tubular epithelial cells migration in normoxia....................... 51

Figure 3.8 Clusterin-enhanced tubular epithelial cells survival in hypoxia............................ 54

Figure 3.9 Network analysis of genes mediating clusterin cell survival function in normoxia

Figure 3.10 Network analysis of genes mediating clusterin cell prolifration function in

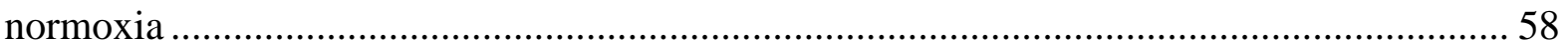

Figure 3.11 Network analysis of genes mediating clusterin cell cycle function in normoxia 59 
Figure 3.12 Network analysis of genes mediating clusterin cell migration function in normoxia ... 60

Figure 3.13 Network analysis of genes mediating clusterin cell survival function in hypoxia 61

Figure 3.14 Confirmation of selected genes by western blot.......................................... 63

Figure 4.1 Association of clusterin functions with signaling pathways in tubular epithelial cells . 68

Figure 5.1 Schematic of next research hypothesis. 70 


\section{List of abbreviations}

AKI- Acute kidney injury

ATP-Adenosine triphosphate

AKT- Protein kinase

Bad- Bcl-2-associated death promoter

Bax- Bcl-2-associated X protein

BCL2- B-cell lymphoma

CLU- Clusterin

CLE- Clusterin element

cRNA- Complementary RNA

DNA- Deoxyribonucleic acid

ER- Endoplasmic reticulum

ERN1- Endoplasmic Reticulum To Nucleus Signaling 1

Foxo- Forkhead box o

GFR- Glomerular filtration rate

GSK3B- Glycogen syntheses kinase 3 beta

HSF- Heat shock factor binding element

HRE- Hypoxia responsible element

HIF- Hypoxia inducible factor

HDL- High density lipoprotein

IR- Ischemia/reperfusion

IRE1- Inositol-requiring enzyme 1

IPA- ingenuity pathway analysis 
LDL- Low density lipoprotein

MLKL- Mixed Lineage Kinase Domain-Like

mRNA- Messenger RNA

NF-кB -nuclear factor kappa-light-chain-enhancer of activated B cells

nCLU- nuclear clusterin

PI3K- Phosphatide 3-kinase

PHD- Prolyl hydroxylase domain

RIP- Receptor-interacting protein kinase

RNA- Ribonucleic acid

sCLU- Secreted clusterin

TEC- Tubular epithelial cell

TNF- Tumor necrosis factor

TLR-Toll like receptor

UPR- Unfolded protein response

VHL- Von Hippel-Lindau

XBp1- X-box binding protein 1 


\section{Acknowledgements}

First of all, all praises go to Allah most merciful for his guidance.

I would like to express my deepest gratitude to my supervisor, Dr. Caigan Du for his guidance, encouragement, advice and support he provided throughout my time as his student. I have been so lucky to have a supervisor who cared so much about my work and my career dreams. I would like to extend my thanks to all of my committee members, Dr. Christopher Ong and Dr. Colin Collins. It never would have been possible for me to take this work to completion without their direction and encouragement. Also I would like to thank all members in Du's laboratory, in particular Miss. Qiunong Guan for her technical expertise and support.

I am truly grateful to my father, Dr. Saleh and my mother, Nafesa for their immeasurable love and support. They have always encouraged me to explore my potential and pursue my dreams no matter how difficult it seems. They help me a lot to reach this stage in my life. Sweet thanks to my brothers Dr. Khalid, Dr. Mohammad, Dr. Abdulrahman and my sister, Ghadeer for their everlasting supports.

I would like to thank my sponsoring institution, Ministry of Higher Education in Saudi Arabia, and Saudi Arabian Cultural Bureau in Canada for giving me this unique opportunity by financially supporting my education over the course of the program.

At last I wish to thank many other people whose names are not mentioned here but this does not mean that I have forgotten their help. 


\section{Dedication}

I would like to dedicate my thesis to the persons who sacrifices their life and taught me to trust Allah, believed in hard work and where there is a will, there is a way... My parents

To all those who believed in me and supported me ... My siblings and my friends

To the reason behind my happiness ... My nephews, Ahmed and Abdulaziz 


\section{Chapter 1: Introduction and background}

\subsection{Thesis overview}

Aerobic respiration in the mitochondria requires oxygen $\left(\mathrm{O}_{2}\right)$ to generate adenosine triphosphate (ATP) that is an essential factor for all mammalian cells in order to perform their physiological and biological functions." Hypoxia/ischemia" is a term that describes the condition of a reduction of the oxygen amount delivered to the organ ${ }^{1}$. A deficiency of oxygen level received by the organ or particularly the cell will likely induce a cellular injury which eventually affects the functions of the organ ${ }^{2}$. Indeed, $70-80 \%$ of the kidney cells are highly susceptible to the oxygen level. Therefore, in some cases a reduction of the oxygen level received by the kidney is mostly associated with organ and/or cellular injury ${ }^{3}$.

Hypoxia/ischemia-reperfusion(IR) in the kidney can give rise to acute kidney injury (AKI), a serious disease that may progress into a chronic kidney disease (CKD) and eventually kidney dysfunction or end-stage renal disease (ESRD) ${ }^{4,5}$. One of the critical aspects of the ischemic AKI is the ability of the kidney cell to adapt to the hypoxia situation. Nowadays, there is no doubt that clusterin (CLU) is a glycoprotein with cyto-protective properties against hypoxia in kidney cells ${ }^{6}$, and enhances renal tissue repair after IR injury (IRI) ${ }^{7}$. Thus, understanding of CLU-mediated signaling pathways in kidney cells will provide insight into how CLU mediates resistance against IRI and tissue repair after IRI, which may lead to the development of the therapeutic strategies that mimic the beneficial effect of CLU to prevent ischemic AKI and to accelerate its repair. 
Our goal in my graduate research project is to reveal and rank the signaling pathways affected by CLU in kidney cells under both normoxic and hypoxic conditions. We use the genomic (transcriptome profile) combined with functions analysis for better understanding of CLU-dependent signaling pathways in kidney cells. Our hypothesis is that the expression of CLU in kidney cells affects cellular signaling pathways that regulate the expression of certain genes, leading to cell survival/death, cell proliferation (cell cycle) and cell migration

\subsection{The embryological origin and structure of the kidney}

The embryological development of the urinary system contains kidneys, ureters, urinary bladder and urethra ${ }^{8}$. In fact, there are three developmental systems of the kidney; pronephros, mesonephors and metaephors, respectively. In addition, all of these phases are indeed originate from one source known as intermediate mesoderm. Intermediate mesoderm originates from mesoderm, one of the basic germ layers ${ }^{8}$.

Pronephros is the first phase of the kidney development, however, is rudimentary and nonfunctional. It develops at the beginning of the 4th week of the gestational period and in the mid of the 4 th week as they forming they regressing ${ }^{8}$. All this pronephros is a solid cell that forming and joining the pronephros ducts. At the end of the 4th week most of the pronephros is degenerated ${ }^{8}$.

Mesonephors are an interim kidney until permanent kidneys are fully developed and they consist of two portions; mesonephric ducts and mesonephors ${ }^{8}$. At $4^{\text {th }}$ week as the pronephros are regressing the mesonephros are begin to develop and about 40 mesonephric tubules are 
produced and they become fully developed ${ }^{8}$. After that, the mesonephros start to regress and by the end of the $5^{\text {th }}$ week there is a massive regression in both of the mesonephric tubules or ducts and mesonephros while only 20 pairs of tubules are remaining. At the end of the first trimester, mesonephros regress and give rise to male/female genital organ ${ }^{8}$.

Metanephros is the last phase of embryological kidney development and they are a definitive permanent kidney. It has two functional components; the collecting portion and the excretory portion. These two portions are derived from two different sources of intermediate mesoderm $^{8}$. First of all, the collecting portion derived from metanephric diverticulum (ureteric bud) ${ }^{8}$. The excretory portions derived from metanephrogenic blastemal (a mass of the mesenchyme tissue) ${ }^{8}$. They begin to develop early in 5 th week when the mesonephros are regressing massively and begin to function in the end of the 9th week while all mesonephros are regressed totally. So, it takes 5 weeks of metanephros to develop ${ }^{8}$. Briefly, formation of the metanephros or the functioning kidney begins (5th week) when the uretic buds sprouts from the distal portion of the mesonephric ducts. After 4 days the renal pelvis is develop. During the 6th week the uretic bud bifurcates and branches until 32 weeks to form a major and minor calyx. By that time 1 to 3 million branches are formed and known as collecting ducts of future kidney ${ }^{8}$. For detail, please see Figure1.1. 


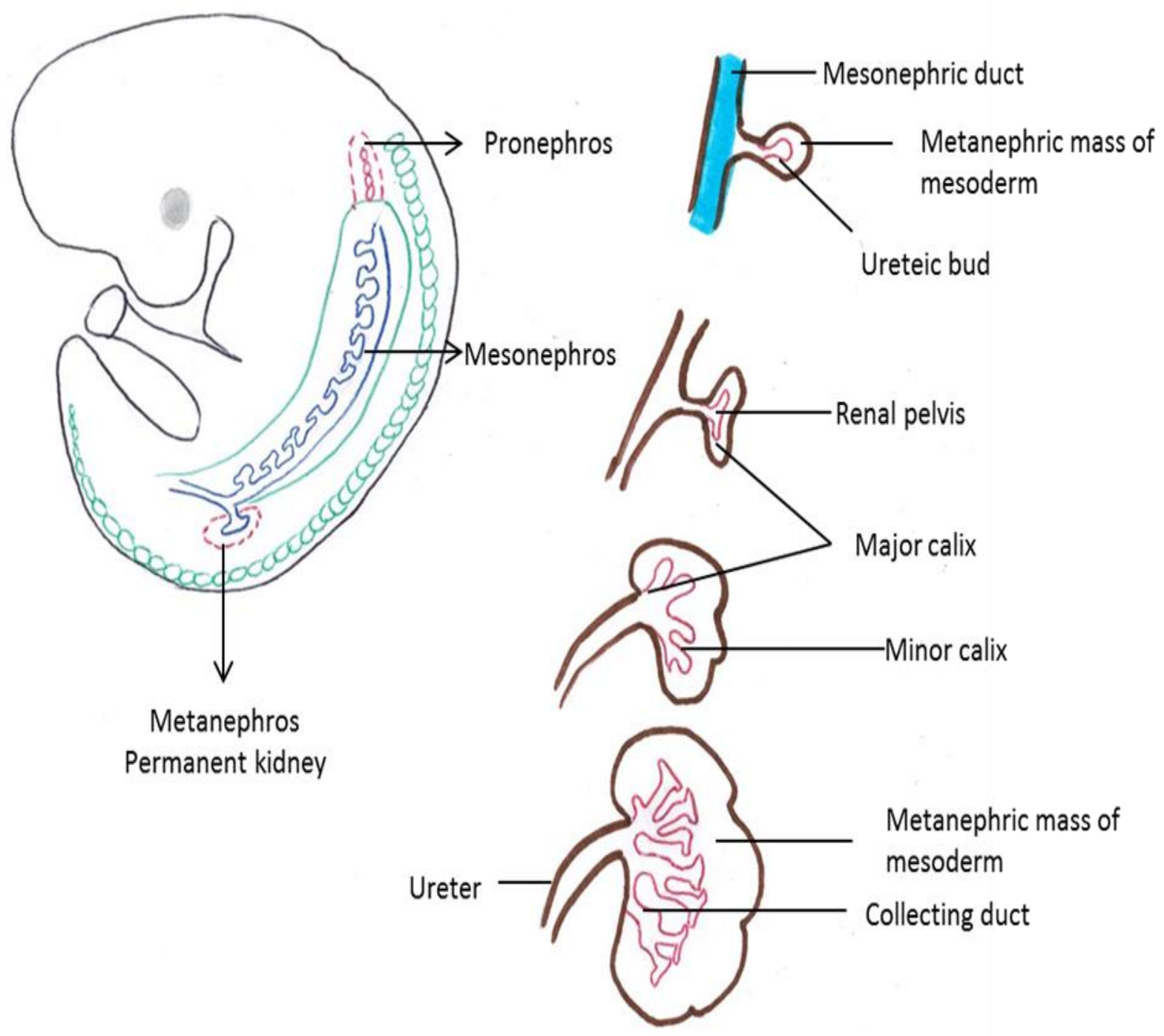

Figure 1.1 Embryological development of kidney

The second component of the metanephros is the execratory portion that known as nephron ${ }^{8}$. The process of the development of the nephron called nephrogenesis ${ }^{8}$. Each newly collecting duct is covered by metanephric tissue caps at the distal end which then differentiates into small vesicles called renal vesicles. These vesicles give rise to $\mathrm{S}$ shaped tubule which then 
expand and form a cup liked structure called Bowman's capsule ${ }^{8}$. This capsule acquires a tuft of capillaries known as glomerulus ${ }^{8}$. The other end of this $\mathrm{S}$ shaped tubules continuous lengthening to form proximal convoluted tubule then loop of Henle and distal convoluted tubule ${ }^{8}$. Indeed, the formations of the nephrons continue until the birth ${ }^{8}$. For detail, please see Figure1.2.

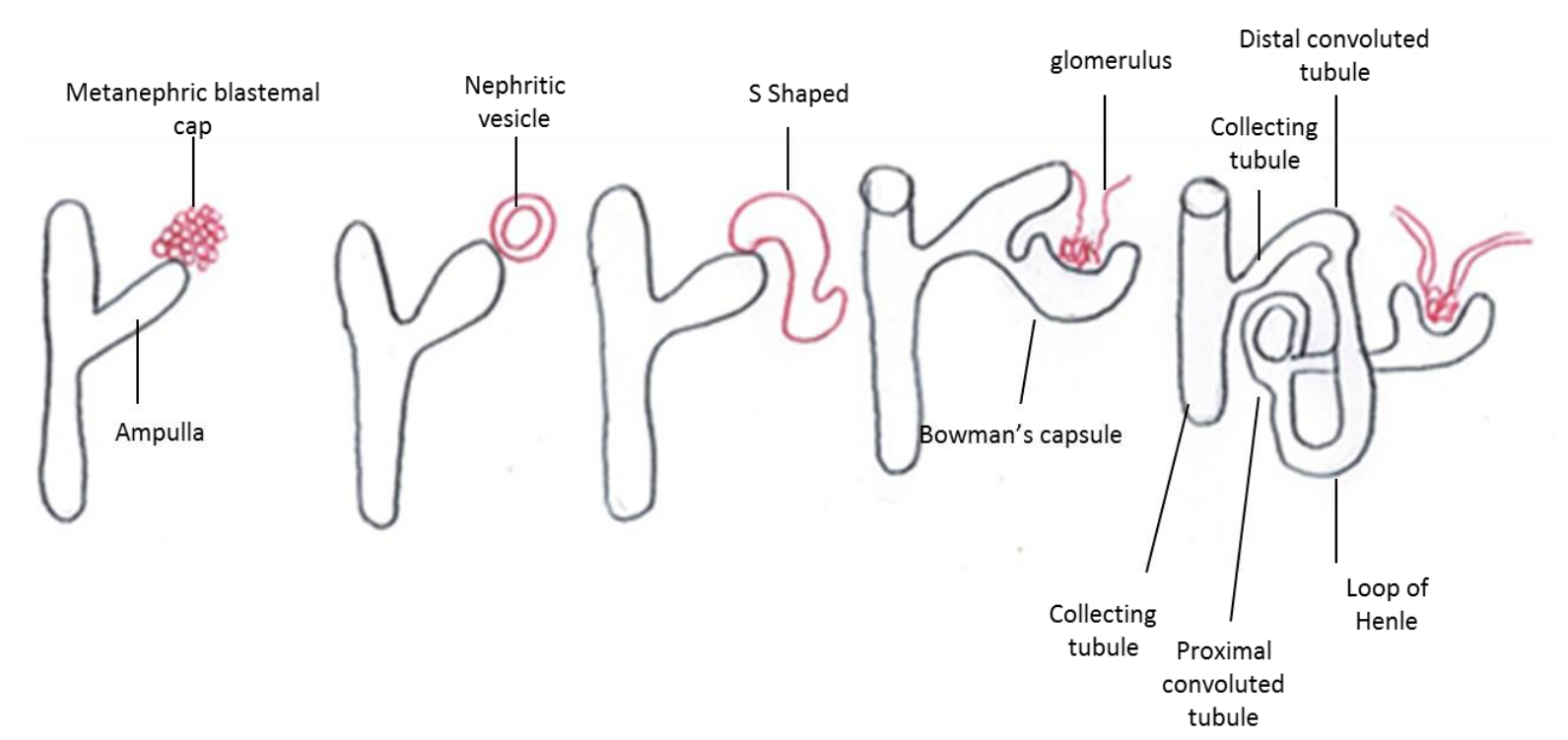

Figure 1.2 Embryological development and structure of the nephron

\subsection{Physiological function}

The kidney is one of the primary execrated organs in our body and they count for $2 \%$ of our body weight ${ }^{9}$. It is bean-shaped and is highly specialized organ that plays a vital role in maintaining fluids homeostasis by multi functions including, filtering the blood, regulating the blood $\mathrm{pH}$, execrating urine and waste products, regulating hormones and vitamins as well 
as various substances according to specific body needs 9 . This regulatory function is an essential mechanism to maintain the internal environment of our body cells highly stable in order to perform their functions. Thus, at least one functioning kidney is needed otherwise the death can occur within few days ${ }^{9}$.

Each kidney mainly divided into two major part including medulla and cortex (Figure 1.3) and only $10 \%$ of the blood supply reach the medulla whereas the rest to the renal cortex, which contains the majority of the glomeruli ${ }^{9}$. Approximately about $25 \%$ of the cardiac output or in other words, $1100 \mathrm{ml}$ of blood per minute is filtered by the kidneys ${ }^{9}$. This filtration occurs in the functional unit of the kidney which known as nephron to produce urine. Our kidney is composed of approximately 1,000,000 nephron ${ }^{9}$. Glomerular filtration rate (GFR), urine output and creatinine/urea are using as a parameter to assess the kidney function ${ }^{9}$. According to the fluid flow, each nephron is mainly composed of three major parts: the glomerular capsule, renal tubule and collecting ducts $^{9}$ as illustrated in Figure1.2. $70 \%-80 \%$ of the nephron is lined with tubular epithelial cells (TECs) ${ }^{9}$. Due to the unique histological structure of these cells, most of the reabsorptions and secretions occur through it $^{9}$. All of these cells are truly metabolically active and therefore they rely on the aerobic metabolism process to perform their functions, in a particular oxygen molecule ${ }^{9}$. 


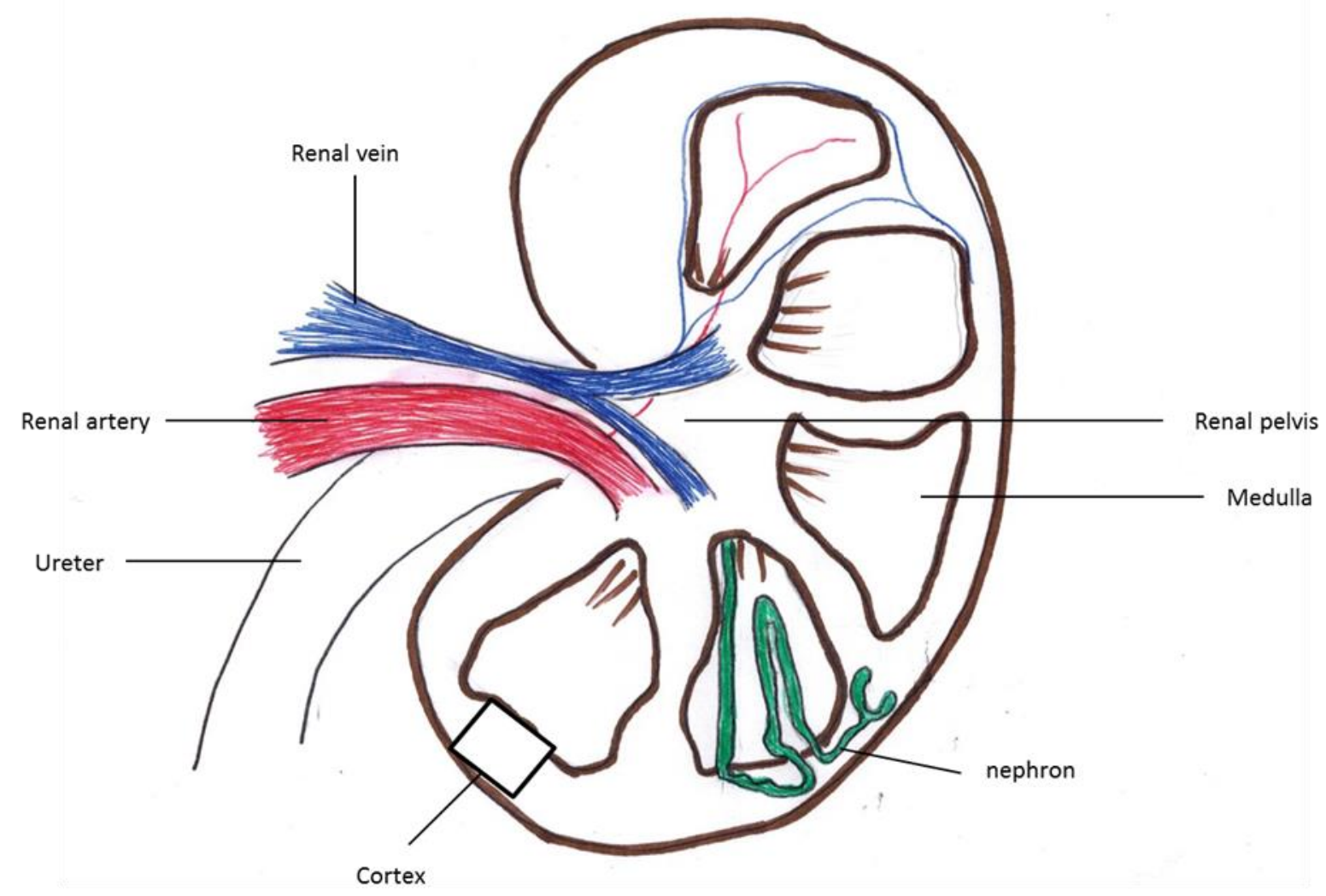

Figure 1.3 Kidney structure

\subsection{Acute kidney injury; an overview}

Acute kidney injury (AKI), previously recognized as "acute renal failure", is a complex disease described as" an abrupt reduction in kidney functions within 48 hours" $^{10}$. It diagnoses mainly by increases in serum creatinine, changes in urine output, decreases in GFR and other diagnostic criteria. However, sensitive and specific markers to diagnose AKI precisely are currently unavailable ${ }^{10}$. 
Numerous clinical studies have demonstrated that AKI is an important contributor to induce CKD and $\mathrm{ESRD}^{11-13}$. Furthermore, it has been strongly reported that AKI patients has a high rate of both mortality and morbidity ${ }^{14}$. However, the pathogenesis of AKI and the transition from AKI to CKD and ESRD are still unclear.

In spite of the massive researches devoted on the AKI, there is no effective and preventive treatment available so far. Renal replacement therapy is the only therapy that use to replace the kidney function and intended to be a life-extending therapy ${ }^{15}$.

\subsubsection{Epidemiology}

Many studies have denoted that AKI is a rife serious disease which associated with a significant rate of morbidity and mortality, and the incidence of AKI remains increasing ${ }^{5,16}$. Hospitalized patients are highly susceptible to develop AKI and according to the previous studies, the average of AKI among hospitalized patients recorded to be between $3.2 \%$ and $20 \%{ }^{17-19}$. While the average in intensive care units (ICUs) recorded to be between $22 \%$ $67 \%^{20,21}$. The mortality rate of ICUs patients who need renal replacement therapy has been reported to exceed $50 \%{ }^{14}$. There are significant numbers of survivors from AKI stayed on the renal replacement therapy (dialysis) ${ }^{22}$. All in all, the worldwide incidence of AKI is poorly unknown.

\subsubsection{Etiology}

According to the pathogenic categorization, AKI classified into three types ${ }^{23}$ :

(i) renal or intrinsic; (ii) post-renal; (iii) pre-renal. 
Intrinsic or renal-AKI is most often caused by different insults including inflammation, damage to the glomerular membrane, autoimmune reactions, drug toxicity. While the postrenal type occurs mostly due to obstructions on the urinary tract ${ }^{23}$.

$60 \%-70 \%$ of all AKI cases were associated with pre-renal or ischemic $\mathrm{AKI}^{24}$. For instance, hypotension which caused by blood loss due to surgical interventions or trauma, heart failure, narrowing of renal arteries and other causes ${ }^{23}$.

\subsection{Ischemic acute kidney injury}

AKI caused by transient ischemia/hypoxia counts for approximately $1 / 3$ of patients requiring therapy ${ }^{25}$. IRI is a common reason for ischemic AKI and it has been well studied ${ }^{26}$. It is unavoidable event after kidney surgical interventions as well as during organ transplantation. It occurs when oxygenated blood supply in whole or to part of the kidney is interrupted decreased and then following by restoration of blood supply and re-oxygenation, resulting in tissue hypoxia ${ }^{27}$. Indeed, IRI results in functional and structural changes in the kidney ${ }^{26}$. However, the exact molecular mechanisms of ischemic AKI are not fully understood.

More than 26 different cell types are located in our kidney such as podocytes, multiple types of TEC, glomerular cell and others, each has different function ${ }^{28}$. However, the sensitivity of these cells to the reduction of oxygen is not equal ${ }^{2,28}$. TECs are highly susceptible cells to ischemia/hypoxia ${ }^{29}$ and therefore they are consider as the major cells involved in IRI in the kidney $^{25}$. Extensive evidence suggests that detachment, dysfunction and death of these cells is principally linked to clinical picture of ischemic AKI ${ }^{30}$. These features make the TECs 
well-suited for studying and identifying which pathways in kidney are affected in response to hypoxia.

\subsubsection{Consequences of ischemia at tubular epithelial cells level}

The first critical change induced by the ischemia and associated with AKI is the decrease in the amount of oxygen delivery to the kidney cells ${ }^{27}$. This will affect and switch cellular metabolism from aerobic to anaerobic ${ }^{31}$. The anaerobic metabolism cannot meet the need of kidney TEC and as a consequence, the ATP levels rapidly drop. Moreover, the intracellular $\mathrm{pH}$ will be more acidosis due to the accumulation of lactic acid ${ }^{31}$.

Thus, changes on both ATP and intracellular $\mathrm{pH}$ levels will lead to a defect on the cellular electrolytes homeostasis by destabilizing the lysosome membrane, which then will lead to a leaking of vinous hydrolyses causing changing of the cell structure ${ }^{32}$, and by suppress the ionic pumps $\left(\mathrm{Na}^{+} / \mathrm{K}^{-}\right.$ATPase pump) ${ }^{33}$. Along with less $\mathrm{Na}^{+}$ions transport out of the cell, the intracellular $\mathrm{Ca}_{2}^{+}$levels are also increased due to the stop of pumping $\mathrm{Ca}_{2}{ }^{+}$out of the cells as well as inability of the endoplasmic reticulum (ER) to reuptake them. Numerous studies have linked the over loaded of intracellular $\mathrm{Ca}_{2}{ }^{+}$with the opining of the mitochondrial transition pore which primarily linked to cell death ${ }^{34}$.

Overall, during hypoxia major biological signaling pathways are involved. Cell death by either apoptosis, necrosis or/and necroptosis is mainly take place in kidney cell (i.e.TECs) and considers as the major cause of ischemic $\mathrm{AKI}^{25,35}$. Transcriptional re-programing which 
controlled by hypoxia inducible factor ( HIF ) is a defense mechanism by which the TEC is adapted to hypoxia ${ }^{27}$

\subsubsection{Cell death}

Hypoxia phase activates various types of cell death in the kidney cell, namely, necrosis, apoptosis, necroptosis whereas some cells undergo sub-lethal injury ${ }^{26}$. In addition, it has been reported that the decline in renal function associated with ischemic AKI is linked to the cellular injury and death ${ }^{26}$. Therefore, protecting the kidney cells from death during ischemia/hypoxia will probably improve the ischemic AKI outcome.

Necrosis is one of the cell death type occurs in kidney cells during hypoxia and it is characterized by "cell and organelle swelling which cause a rupture of cell membranes and leads to leaking of all intracellular contents" ${ }^{36}$. Many studies have described the renal TEC necrosis as a "pathognomonic lesion of ischemic $\mathrm{AKI}^{\text {", }} 37$. However the amount of necrosis detected in human kidney tissue fails to predict and diagnose the renal function as well as the need for treatment ${ }^{37}$. Therefore, due to the lack of correlation between cell necrosis and kidney function, an alternative forms of cell death shows to be an important contributor to kidney failure ${ }^{26}$.

Interestingly, researchers have largely identified that renal cell death also includes apoptosis, not only necrosis ${ }^{25}$. Additionally, this type of the cell death correlates more better with the kidney dysfunction and ischemic AKI than necrosis, in mouse models ${ }^{38,39}$. 
Apoptosis is "a process of programmed cell death that defined by cell shrinkage, cell detachment, nuclear DNA fragmentation and including other morphological chanagies "26 A 11 these cellular morphologic changes of apoptosis enable us to distinguish between cell necrosis and apoptosis ${ }^{26}$.

During the hypoxic stress, in renal cells as well as in non-renal cells, the mitochondria plays a vital role in intrinsic and extrinsic apoptotic initiation signals. Furthermore, the balance between these signals regulates the cell fate and controls whether or not the cells die by opining the outer mitochondrial membrane. The permeabilization of this membrane is regulated by B-cell lymphoma 2 (BCL2) family proteins. Hypoxia stress induces permeabilization of the mitochondrial membrane which allow pro-apoptotic proteins for instance, cytochrome $c$ to activate caspase-dependent and independent pathways ${ }^{40}$. Hence, protecting the mitochondrial membrane from "leaking" is important. A significant body of evidence shown that, Bax and Bak ( primary BCL2 members) increase membrane permeability and causing activation of the pro-apoptotic signals, in renal TEC ${ }^{41}$. In addition, results from in vivo studies shown that Bid( another BCL2 member) knockout delays death from kidney failure induced by renal IRI ${ }^{42}$.

Necroptosis is a type of cell death that is recently identified and defined as "a controlled cell death with morphological features of necrosis" ${ }^{43}$. However, this type represents neither apoptosis nor necrosis. It is highly orchestrated regulated necrosis that triggers by activation of cell death receptor for instance, tumor necrosis factor (TNF) or toll like receptor (TLR) and interferons(IFN). Receptor-interacting protein kinase 3 (RIP3) and mixed lineage kinase 
domain-like protein (MLKL) are the key markers for necroptosis ${ }^{44,45}$. The molecular mechanism of this type is still not fully understood. It has been documented that activation of the extracellular receptor (death receptors, TLR, IFN) leads to recruit RIP1 which subsequently bind to and auto phosphorylates RIP 3 by RIP homotypic interaction motif. Both RIP1and RIP3 form a complex called necrosome ${ }^{46}$. Activated RIP3 then phosphorylates MLKL which translocate to the membrane and disrupt the plasma membrane resulting in same morphological features of necrosis ${ }^{47}$. Interestingly, necroptosis has been identified to play a role in pathogenesis of ischemic $\mathrm{AKI}^{45,48}$. It was first determined by Linkerman et al. in mice model of renal IRI while the exact mechanism behind the role of necroptosis in ischemic AKI still not yet investigated ${ }^{48}$.

Regardless the complexity of understanding the ischemic AKI molecular pathogenesis, extensive evidence show that cell death is linked to the pathogenesis of ischemic AKI ${ }^{38,39}$. Therefore, prevention or at least minimization of the cell death induced by hypoxic stress likely would be expected to improve the ischemic AKI outcome.

\subsubsection{Transcriptional reprograming in response to hypoxia}

The transcriptional reprogramming is a consequence of the IR that causes ischemic AKI. This process should be considered as a defense and adaptive mechanism and not as an injury. The ischemic/hypoxia period is associated with significant alterations in the transcription control of the gene expression ${ }^{27}$. 
These alterations mainly occur through activation of HIF signaling cascade ${ }^{35}$. The HIF is a nuclear transcription factors of HIF $\alpha$ and HIF $\beta$ subunits ${ }^{1}$. These two subunits dimerized in nucleus and activate transcription ${ }^{49}$. HIF has an oxygen-sensitive $\alpha$ subunit and a constitutively expressed $\beta$ subunit ${ }^{1}$. The HIF $\alpha$ subunit regulate HIF activation, the stabilized $\mathrm{HIF} \alpha$ is allowed to translocate into the nucleus and dimerizes with the $\beta$ subunit and act to activate transcription of hypoxia adaptation genes ${ }^{49}$.

Under normal physiological environment "normoxia" and with presence of oxygen, von Hippel-Lindau (pVHL) is a proteins that control the level of HIF ${ }^{49}$. pVHL "is a tumor suppressor protein has a ubiquitin ligase proprieties to act on $\alpha$ portion of HIF and mediates its degradation "50. Along with assistance of Prolyl hydroxylase domain (PHD) and presence of $\mathrm{O} 2$ the VHL binds to HIF $\alpha$ and recruit ubiquitin to help degrade the whole complex ${ }^{50}$. All three PHDs types are found to be expressed in renal TEC ${ }^{50}$. PHDs are an oxygen-sensing enzymes that need oxygen to hydroxylase $\mathrm{VHL}^{49}$.

In contrast, depletion on the level of oxygen (hypoxia) is associated with inhibition of PHD enzyme leads to transcriptional reprograming. Briefly, decreasing of oxygen level will lead to inactivation of PHD which results in accumulation of HIF $\alpha$ which then translocate into the nucleus $^{49}$. In the nucleus, HIF $\alpha$ bind with HIF $\mathrm{b}$ and form a heterodimer that alters the gene expression and induce transcription of numerous genes and eventually controls many signaling pathways in order to maintain the cell a live ${ }^{49}$. For detail, please see Figure 1.4. 


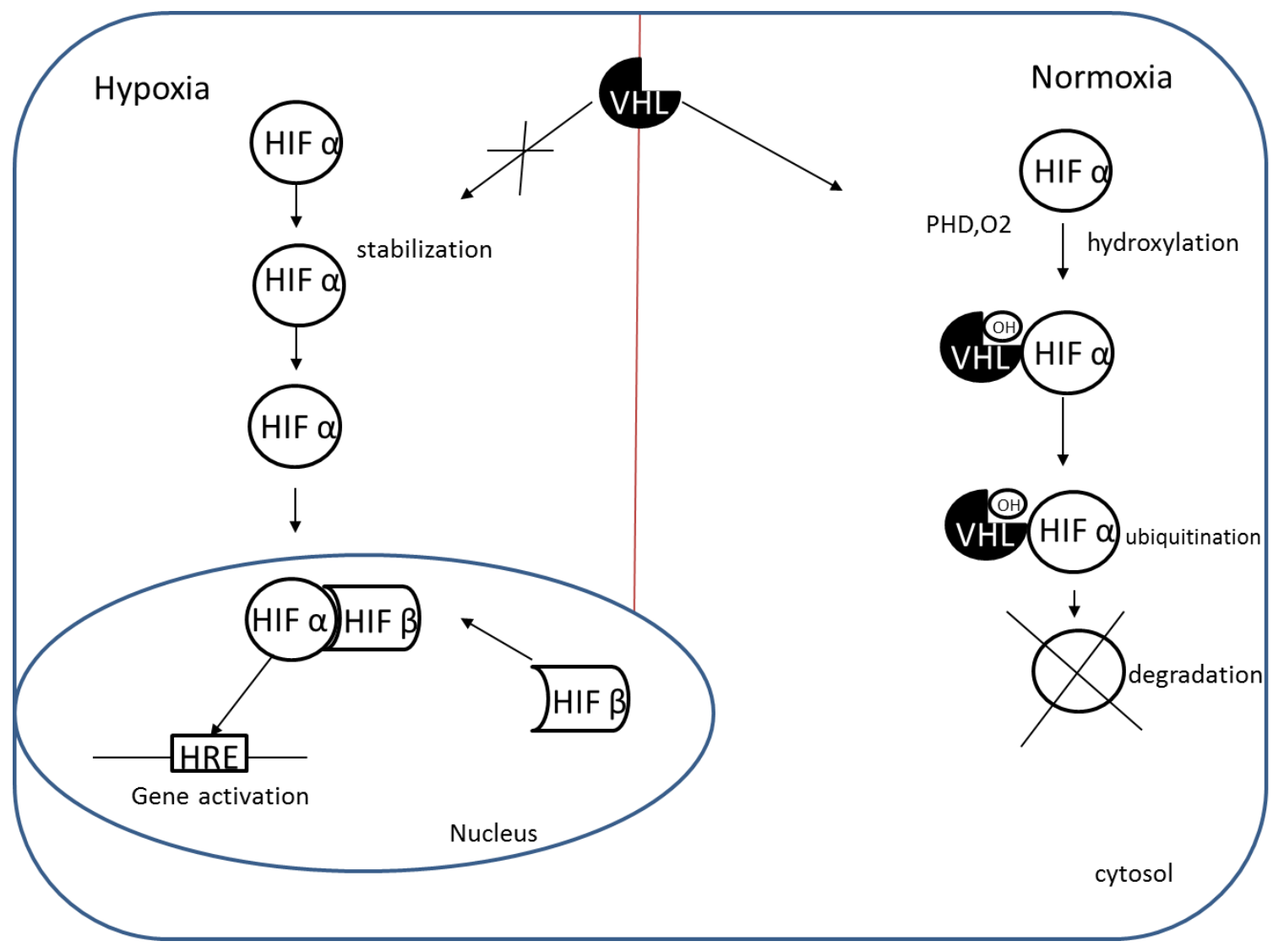

Figure 1.4 Hypoxia inducible factor activation

\subsection{Clusterin}

Clusterin (CLU) is a secreted glycoprotein vastly distributed in human body fluids. It was first found out in fluid of ram rete testes by Blaschuk, Burdzy, and Fritz in 1983, and then it is named due to its ability to induce clustering of Sertoil cells and erythrocytes. Numerous researchers have identified that CLU is an extracellular protein as well as intracellular with a multifunctional properties ${ }^{51}$. It expresses in many cell types including epithelial secretory cells and non-epithelial secreted cells ${ }^{52,53}$. However, the exact cellular localizations of this protein are not fully understand. 


\subsubsection{Clusterin gene, cellular localization and structure}

CLU is a single copy gene can translate into multiple proteins, not only a single protein. This gene is located in humans, at chromosome $8(8 \mathrm{p} 21-\mathrm{p} 12)$ and organized in 9 exons and 8 introns and the first exon is alternative ${ }^{54,55}$. As a result of alternative splicing process in exon 1 and 2, mainly CLU gene can be transcribed into two mRNA isoforms, or more. The translated protein from each of these isoforms has a completely different functions and cellular localization ${ }^{56}$. Till date, two isoforms of this protein have been well defined in humans: isoform 1 encoding the pre-secreted CLU (sCLU) and has ER targeting signal in exon 2, and isoform 2 which give rise to nuclear CLU (nCLU) protein and has nuclear targeting signal ${ }^{57,58}$.

After the translation, nCLU protein is directly target the nucleus and translocate there ${ }^{57}$, whereas, pre-sCLU is transfer to ER for glycosylation and then to Golgi bodies for maturation by inducing a cleavage between Arg-205 and Ser-206 amino acid residues to end up with a mature sCLU $(\sim 70 \mathrm{kDa}){ }^{59,60}$. This mature sCLU form is a secreted heterodimeric protein which is structurally composed of two $40 \mathrm{kDa}$ subunits $(\alpha \text { and } \beta)^{59,60}$. These two subunits are linked by five disulphide bridges and each has many large molten domains, amphipathic regions and coiled-coil $\alpha$-helices ${ }^{59,60}$ as shown in Figure1.5. 


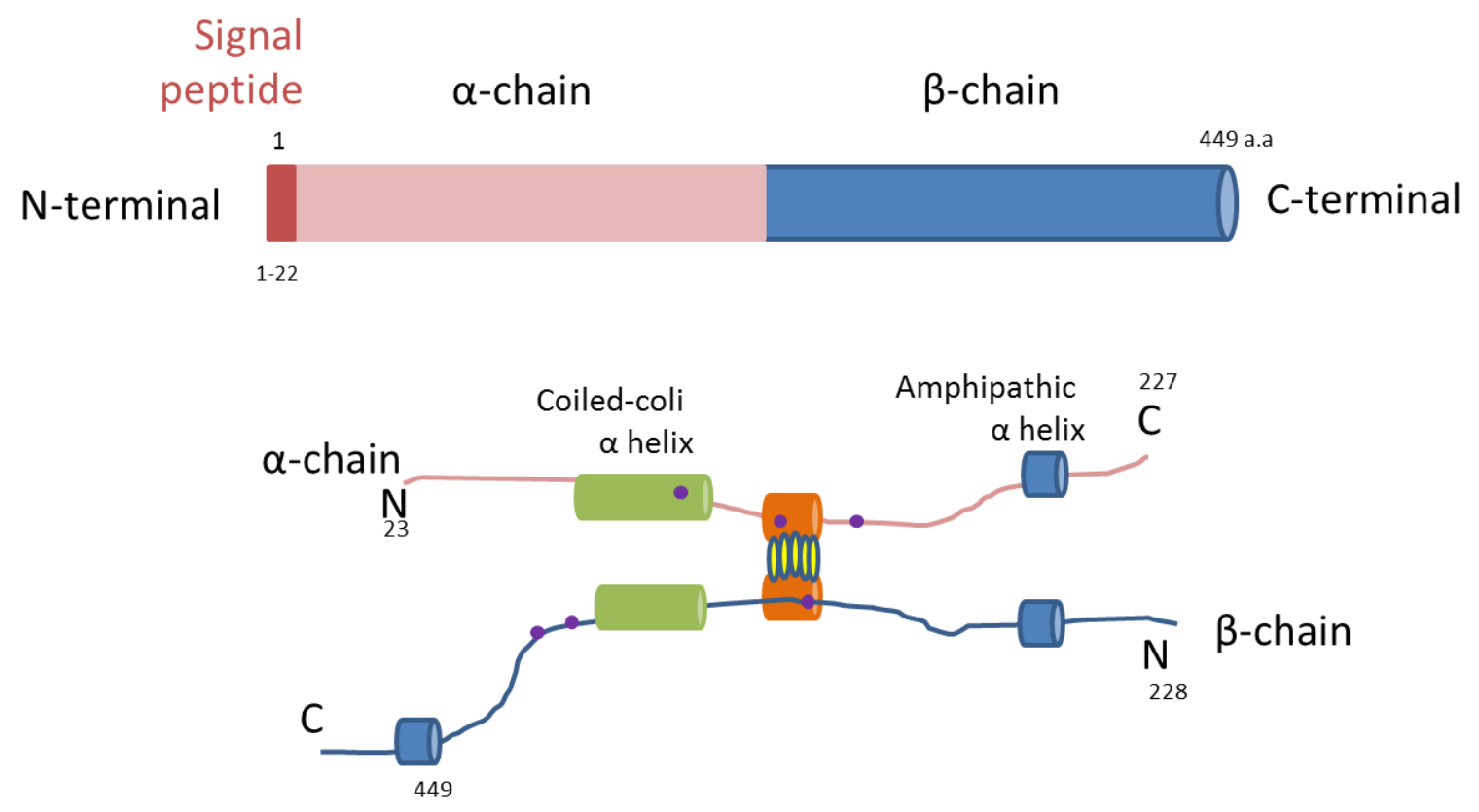

Figure 1.5 Clusterin structure

Interestingly, in response to a particular stress situation, sCLU can skip the secretion process and re-trans localized into the cytosol ${ }^{61}$. However, the inducible mechanism of CLU expression is poorly described. It has been documented that CLU promotor has ' clusterin element' (CLE), heat shock factor binding element (HSF) ${ }^{62}$ and hypoxia inducible factor (HIF ) binding elements ${ }^{63}$.

Murine CLU gene is a single copy gene which transcribed to only one mRNA isoform, due to lack of alternative splicing. This gene is located in chromosome 14 and composed of 9 exons and 8 intron $^{64}$. sCLU is the only CLU isoform has been identified in mice ${ }^{64}$. Indeed, there is $75 \%$ homology of mouse CLU to human sCLU at amino acid level. In addition, both of the mouse CLU and human sCLU have the same ER-targeting signal peptide and the 
maturation cleavage $\operatorname{site}^{64}$. In the kidney, CLU was localized in the same way in human as that in mice ${ }^{65}$. Therefore, all these sharing features and $75 \%$ similarity between human sCLU and mice CLU can enable them to perform the same function and most likely CLU in mice can serve as a counterpart for sCLU in human, predominately in the experimental study of kidney diseases ${ }^{65}$.

\subsubsection{Clusterin physiological functions}

CLU is a major glycoprotein founds in human fluids such as plasma, urine, semen and including others ${ }^{53}$. Many cell types are produce and secrete CLU protein ${ }^{52,53}$. In human, this protein expression is up regulated following many pathophysiological insults including neuropathologies ${ }^{66,67}$, cancer $^{56}$ and kidney disease ${ }^{68}$. As well as in rodent, renal CLU also is upregulated following different insult, such as IRI ${ }^{6}$.

The two CLU isoforms (nCLU and sCLU) have been found to have different biological functions. The nCLU isoform is localizing in the nucleus without glycosylation and functioning as pro-apoptotic which induce cell death ${ }^{51}$. While sCLU isoform found to be associate with many functions. In the blood stream, sCLU has been reported to induce cell $\operatorname{aggregation}^{69,70}$, inhibit complement cytolysis activity ${ }^{71,72}$, bind to low-density lipoprotein (LDL) and high-density lipoprotein (HDL) $)^{73,74}$ and function as an extracellular chaperone protein $^{75}$. Thus, circulating sCLU serves as inhibitor of the complements as well as regulator of lipid transport and mediates clearance of misfolded proteins as well as cellular debris. In the cell cultures (in-vitro), the intracellular sCLU has been reported to play roles in some major cell survival/death signaling pathways such as PI3K/Akt and $\mathrm{NF}-\kappa \mathrm{B}^{76,77}$. It has been 
proposed to influence transcription and promotes NF- $\mathrm{BB}$ pathway ${ }^{77}$ and also it plays role as an anti-apoptotic molecule which prevents apoptosis after TNF- $\alpha, \mathrm{H}_{2} \mathrm{O}_{2}$ or gentamicin through activation of magalin-PI3K /Akt pathway ${ }^{78,79}$

\subsubsection{Clusterin and kidney injury}

CLU is an apical secreted glycoprotein in kidney $\mathrm{TECs}^{80}$ and is observed and detected in both live and apoptotic cells after renal injury ${ }^{81}$. Interestingly, under hypoxia /ischemia environment the expression of sCLU is increased in renal TECs which strongly supports the hypothesis of relocalization of sCLU into cytosol ${ }^{6,7}$. In order to study the CLU effects in the kidney, CLU knock out (CLU KO) mice and TEC cells derived from this mice have been used by our research groups ${ }^{6,7}$. In fact, there are no significant differences between CLU KO mice and wild type (WT) mice in terms of phenotype, organ morphogenesis, organ differentiation and organ weight during postnatal period. However, CLU KO mice were subjected to IRI shows an impairment in kidney repair, suggesting that CLU is an important protein that contributes to repair process in kidney after injury ${ }^{65,82}$. In mice, CLU is upregulated following IRI in kidney tubular cells, and deficiency in CLU expression worsens renal IRI outcome by increasing the number of tubulars damage and affects renal function profile (increases serum creatinine and blood urea nitrogen(BUN)) ${ }^{6}$. A further study shows that lack of CLU reduces renal tissue repair after IRI and accelerates renal damage by inducing renal fibrosis while expression of CLU improved renal recovery after $\mathrm{IRI}^{7}$. In kidney TEC cultures, ectopic expression of CLU was associated with decreases cell apoptosis and favor cell survival under hypoxia condition, increases cell proliferation with inducing normal cell cycle and suppresses cell migration ${ }^{7}$. 
Overall, CLU is an anti-apoptotic molecule and up regulation of CLU expression is an important mechanism of defense against IRI. Hence, CLU plays an important role in maintaining renal tissue homeostasis against hypoxic injury. The intrinsic signaling pathways by which CLU can mediate resistance against IRI clearly complicated and are not fully defined.

\subsection{Transcriptome profiling}

Ischemic $\mathrm{AKI}$ is one of the consequences of multiplex signaling pathways that regulates and promotes cell death/survival, cell proliferation and cell migration. In addition, CLU is an important protein playing a role in IRI $^{6}$. To further understand all of these signaling pathways that are involved in these processes, a method that simultaneously reveals these pathways and the gene-associated and expressed with these events would strongly be helpful. Transcriptome is a term described all of the cellular $\mathrm{mRNA}^{83}$. Therefore, transcriptome profiling is used to study the whole mRNA activities. Protein is a functional unite of the cell and is synthesized from DNA by two main process namely, transcription and translation ${ }^{83}$. Transcription is the process by which the RNA polymerase enzyme uses the DNA sequence as a templet to copy the gene information into $\mathrm{mRNA}^{83}$. Hence, DNA transcribed into mRNA is called gene expression and it is controlled by the protein called transcription factors which bind to DNA and either enhance or suppress the transcription of the specific

gene $^{83}$. Translation is the subsequent process by which the mRNA is translated into protein, if is not degraded ${ }^{83}$. 
In situ oligonucleotide gene expression microarrays are the tools that have been used to provide the wide picture of all transcriptional activity, not only one genes as the traditional biological tools ${ }^{84}$. This technique has been developed by Dr. Brown PO and his colleagues in Stanford University in the mid of 1990s , and over the time many subtle changes were entered into the microarray gene-expression tool by Spellman, P. T. et al,1998 and Perou, C. M. et al,2000. Since then it has been used in many different research fields such as kidney diseases, cancer and including others for many different purposes.

The main concept behind the microarray technology is DNA hybridization ${ }^{85}$. mRNA is extracted from the sample either tissue or cell and then reversed-transcribed into DNA. This DNA is further will be labeled with a fluorescent dye and hybridized on the array or the chip and finally scanned by high resolution scanner ${ }^{85}$. For detail, please see Figure 1.6. 

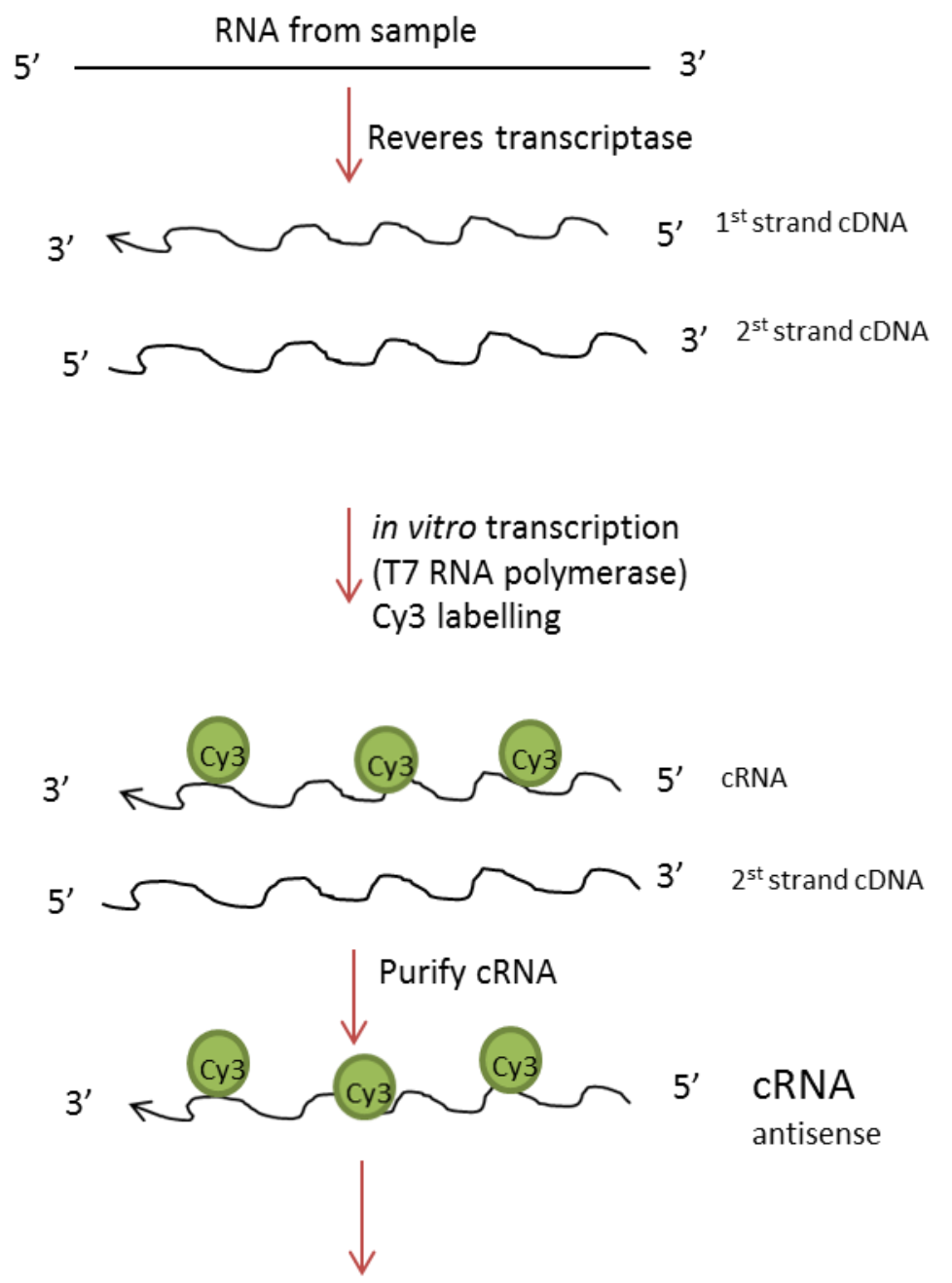

Hybridization, washing

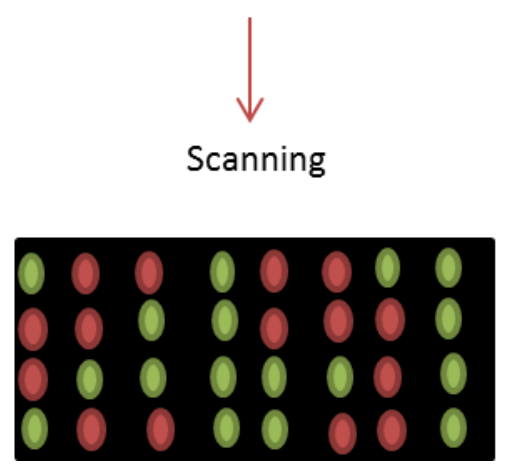

Figure 1.6 Schematic of one color gene expression microarray procedure 
The intensity of the dye (usually fluorescent) will quantified by scanning the chips to represent the amount of the gene expression ${ }^{85}$. There is direct proportion between the fluorescent intensity and the amount of mRNA. However, these quantifications analysis do not provide a truly accurate concentrations of the mRNA (particular gene), yet are used to compare the mRNA level between the experimental conditions ${ }^{85}$. In order to fairly compare between genes or arrays, normalization step for the intensity raw values suggested to be done $^{85}$

Microarray-based gene expression generates a vast quantity of data, however, a significant challenge exists in analyzing these data with many bioinformatics tools/software's to meet all of the needs of microarray researcher ${ }^{86}$.

In situ oligonucleotides microarray has been extensively used to study the gene expression profile due to its high sensitivity and specificity proprieties ${ }^{87}$. It is also a fast and easy tool to study the whole transcriptional activity of hundreds of thousands of genes in only one single experiment ${ }^{87}$. Despite its wide use, it has a few disadvantages such as a need for an expensive specialized equipment for hybridization, labeling, washing, scanning and all the quantitation process. In addition, the microarray chips are still expensive which may cause difficulties to increase the sample size. A collection of many software's are highly needed to profile the gene expression data while a few of gene functions are identified ${ }^{87}$. Finally, as long as the protein is the functional molecule of the cell, all of the gene expression/mRNA data generated by the microarray are still needed to be confirmed on protein level ${ }^{83}$. 
One of the substantial and major questions answered by the gene expression profile is: - what gene is expressed and to what level and in which pathway is involved ${ }^{86}$. This profile represents the mRNA expressed in a cell or tissue ${ }^{86}$. It has been assumed that a relative level of mRNA transcripts may indicate the cellular responses to a specific condition, therefore, microarray gene expression generates an expression profile that been used to study the gene expression levels that reflect the cellular response to any experimental situations ${ }^{88,89}$. Beyond studying the expression levels of individual genes under different conditions, this mRNA profile can be combined with any functional analysis software to reveal cell pathways that are involved in the study such as cell survival/death, cell proliferation, cell cycle, cell migration and others ${ }^{86}$. All of these features make this technology more powerful than the traditional tools particularly in the study of gene expression area.

\subsection{Thesis hypothesis}

We hypothesized that cellular CLU can regulate the gene expression and cell fate in kidney TECs via many signaling pathways in bothnormoxia and hypoxia. To approach this hypothesis we had three main objectives:

1- Investigate whether CLU can affect the TECs gene expression by using a genome-wide analysis such as gene expression using microarray.

2- Using gene expression microarray data to identify the CLU-mediated pathway(s) that lead to specific functions in response to normoxia and 24 h-hypoxia.

3- Rank the pathways mediating CLU functions in kidney TECs. 


\section{Chapter 2: Materials and methods}

\subsection{Cell culture}

\subsubsection{Cells used in this thesis}

In order to understand the CLU functions in kidney TECs, In order to understand the CLU functions in kidney cell, an in vitro model of kidney tissue using CLU null renal tubular epithelial cells (TECs) was established for this research project. An immortalized CLU null TEC cell line was generated from a CLU knockout (KO) mouse, and was stably expressing pHEX6300 plasmid containing human CLU cDNA (TEC-CLU ${ }^{\text {hCLU }}$ ), so that this cell line constitutively expresses human CLU protein, whereas control cell line (TEC-CLU ${ }^{--}$) was generated from the same parental CLU null TEC cell line by expressing empty pHEX6300 as described previously ${ }^{6}$.

\subsubsection{Culture medium}

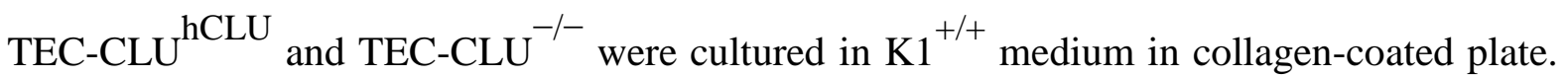
$\mathrm{K}^{+/+}$medium is a $(50: 50)$ mixture of Dulbecco's modified Eagle's medium (DMEM) and Ham's F12 (Invitrogen-GIBCO, Burlington, ON). it is supplemented with 5\% bovine calf serum, hormone mix (5 $\mu \mathrm{g} / \mathrm{ml}$ of insulin, $34 \mu \mathrm{g} / \mathrm{ml}$ of triiodothyronine), $5 \mu \mathrm{g} / \mathrm{ml}$ of transferrin, $1.73 \mathrm{ng} / \mathrm{ml}$ of sodium selenite, and $18 \mathrm{ng} / \mathrm{ml}$ of hydrocortisone), and $25 \mathrm{ng} / \mathrm{ml}$ of epidermal growth factor (EGF) (Sigma, St. Louis, MO) as describe previously ${ }^{6} . \mathrm{K} 1^{-/-}$ medium was used to arrest the cell division in cell cycle assay. It is $\mathrm{K} 1^{+/+}$medium without addition of serum and growth factors. Both (TEC-CLU ${ }^{\text {hCLU }}$ ) and (TEC-CLU ${ }^{-/}$) were 
grown and maintained in complete $\mathrm{K}^{+/+}$medium with zeocin as a selective antibiotic (up to $500 \mu \mathrm{g} / \mathrm{ml})$.

\subsubsection{Coating dishes with collagen}

Advanced BioMatrix's collagen solution, PureCol: is a purified bovine collagen solution that contains about $97 \%$ type 1 collagen. As it was required for attachment of TECs, it was used to coat the dishes, 6 wells and 96 wells plates before culturing the cells ineach experiment. Collagen solution was diluted with PBS with ratio of (nearly1:30) and completely mixed. Then, appropriate amount of this mixture was added to cover the whole culture surface. All the collagen-coated dishes or plates were kept in a $\mathrm{CO} 2$ incubator at $37^{\circ} \mathrm{C}$ overnight and then all the remaining mixture was aspirated.

\subsubsection{Induction of hypoxia in cell culture}

Hypoxia in culture of TECs in complete $\mathrm{K} 1^{+/+}$medium was induced by $24 \mathrm{~h}$ incubation in a humidified hypoxic chamber (Coy Laboratory Products, Inc., Grass Lake, MI, USA), which was supplied with a several gases including of $1 \% \mathrm{O}_{2}, 5 \% \mathrm{CO}_{2}$ and $94 \% \mathrm{~N}_{2}$ at $37^{\circ} \mathrm{C}$. The humidified $\mathrm{CO}_{2}$ incubator which has 5 percent $\mathrm{CO}_{2}$ and 95 percent air or about 20 percent $\mathrm{O}_{2}$ at $37^{\circ} \mathrm{C}$ was used for identical (twin culture) incubation which were grown as normoxia controls. 


\subsection{Western blot}

- Protein Sample Preparation:

Cells $\left(1.5 \times 10^{6}\right.$ cells $)$ were seeded in $60 \mathrm{~mm}$ Petri dish and were treated with either hypoxia or normoxia for $24 \mathrm{~h}$. Then the total proteins were extracted from the cells by gently disrupting the cell pellet in the lysis buffer (10mM HEPES (pH7.9), $10 \mathrm{mM} \mathrm{KCl,0.1} \mathrm{mM} \mathrm{EDTA,} 0.1$ mM EGTA, 0.1\% NP-40, 1mM DTT, 0.5mM phenylmethylsufony) containing protease inhibitor cocktail (Roche, Mannheim, Germany).The protein concentration was determined using Bradford assay using Bio-Rad dye reagent (Bio-Rad, Hercules, CA) using bovine serum albumin (BSA) as a standard reference. After determination of protein concentration, sample buffer was added to extracted protein and was boiled for 5 min prior loading the samples. Sample Buffer contains 40 mM Tris-HCl (pH 6.8),10\% SDS, 20\%Mercaptoethanol, 4 mM EDTA and 0.04\% Bromophenol Blue.

\section{- $\quad$ Protein separation by SDS PAGE}

A sodium dodecyl sulfate-polyacrylamide gel electrophoresis (SDS-PAGE) gel has been widely used to detect the protein of interest in a combination with Western blot ${ }^{90}$. SDS is a strong anionic detergent that binds to the denatured protein through their hydrophobic region and then they become negatively charged ${ }^{90}$. In addition, polyacrylamide gel has a high capacity to separate the protein due to the existence of polyacrylamide compound ${ }^{90}$. Therefore, SDS-PAGE is used to separate proteins according to their molecular size, not their charge $^{90}$. Only $100 \mu \mathrm{g}$ of protein from each samples was loaded and separated using gel electrophoresis on a $10 \%$ (SDS-PAGE), according to the molecular size of the target protein. 
- Transferring the proteins in SDS-PAGE into a nitrocellulose membrane (Western blotting)

The membrane was kept in transferring buffer for 30 min. Transferring Buffer contains 25 mM Tris-Base, $192 \mathrm{mM}$ Glycine and 20\% Methanol. Then the transfer of the proteins in the gel onto nitrocellulose membranes(Bio-Rad Lab, Hercules, CA, USA), was done by using wet transfer electro-blotting procedure followed by blocking the membrane with blocking buffer (LI-COR, USA) for $1 \mathrm{~h}$ at room temperature in shaker to prevent non-specific binding of the antibodies in next steps. After the blocking step, the membrane was probed with a primary antibody at $4{ }^{\circ} \mathrm{C}$ overnight. After overnight incubation, the membrane was washed for three times with Tris-buffered saline tween (TBST) and 10 min each and then incubated with a secondary antibody. The blotted membrane was scanned by Odyssey infrared imaging system (LI-COR, USA) and the protein band was visualized. In order to confirm the equal protein loading in each sample, the plots were re-probed with anti-glyceraldehyde 3phosphate dehydrogenase (GAPDH) (Epitope Biotech Inc) and scanned and visualized using same Odyssey infrared imaging system.

\section{- Antibodies used in this thesis}

Primary antibodies used in this study were: goat polyclonal anti-CLU- $\alpha$ (C-18, Santa Cruz Biotech, Santa Cruz, CA, USA), goat polyclonal anti-AKT2 (D-17, Santa Cruz Biotech), rabbit polyclonal anti-FOXO3a (phospho-ser253) (\#9466), Cell Signaling Technology, New England Biolabs, Ltd., Whitby, ON, Canada), rabbit polyclonal anti-IRE1 (phospho-ser724) (Biorbyt, Cambridge, UK), rabbit polyclonal anti-p21 (C-19, Santa Cruz 397 Biotech, Santa 
Cruz, CA, USA), mouse monoclonal anti-GSK3 $\beta$ ( \#610201), (BD transduction laboratories, BD Biosciences) and mouse monoclonal anti-glyceraldehyde 3-phosphate dehydrogenase (GAPDH) (clone GA1R, Epitope Biotech Inc., Vancouver, BC, Canada).

Secondary antibodies were: IRDye 680RD donkey (polyclonal) anti-goat IgG, IRDye 680RD mouse (polyclonal) anti-rabbit IgG and IRDye $800 \mathrm{CW}$ goat (polyclonal) anti-mouse IgG (LICOR Biosciences, Lincoln, NE, USA).

\subsection{Cellular localization of clusterin by confocal microscopy}

To determine the cellular localization of CLUprotein, CLU null TECs were transfected with

EGFP-N1 vector containing human CLU isoform 1-GFP cDNA as described previously ${ }^{91,92}$. The expression of CLU-EGFP was examined with the confocal microscope. The CLUEGFP plasmid was kindly provided by Dr. Martin Gleave's group at Vancouver Prostate Centre(Vancouver, BC, Canada), and was made by Dr. Na Li several years ago ${ }^{91}$.Briefly, EGFP-N1 vector was used for this plasmid construction and XhoI and BamH1 enzymes were used for sub cloning ${ }^{92}$.

CLU null TECs were transfected with EGFP-N1 vector containing human CLU-GFP isoform 1 cDNA by using the Lipofectamine 2000 (Invitrogen, USA), according to manufacturer's protocols. Cells were seeded in 6 wells plate with $0.3 \times 10^{6} /$ well and grown on collagencoated glass coverslips and maintained in $\mathrm{K}^{+/+}$medium overnight for $80 \%$ confluency. Then, both of CLU-GFP plasmid and the Lipfectamine 2000 reagent were diluted with Opti$\mathrm{MEM}^{\circledR}$ (Invitrogen-GIBCO, USA), and incubated for $5 \mathrm{~min}$ at room temperature. After the 5 
min incubation, diluted DNA and lipfectamine were combined and mixed gently together, and incubated for $20 \mathrm{~min}$ at room temperature. $\mathrm{K} 1^{+/+}$medium was aspirated and the cells were washed twice with Opti-MEM ${ }^{\circledR} .100 \mu \mathrm{l}$ of the mixture was added to each well and incubated for $5 \mathrm{~h}$ at $37^{\circ} \mathrm{C}$ in a $\mathrm{CO}_{2}$ incubator. After that, $1 \mathrm{ml}$ of $\mathrm{K}^{+/+}$medium was added to each well and incubated overnight, then the medium was replaced with complete $\mathrm{K} 1^{+/+}$ medium and incubated for $2 \mathrm{~h}$.

Follow the transfection, TECs in 6-wells plate were either exposed to $1 \% \mathrm{O}_{2}$ (hypoxia) in a humidified hypoxic chamber (Coy Laboratory Products, Inc., Grass Lake, MI, USA) or kept in a $\mathrm{CO}_{2}$ incubator (nomoxia) for $24 \mathrm{~h}$. Medium was aspirated and cells were washed gently with warm PBS, followed by fixing with $4 \%$ formaldehyde solution for 20 min and rinsing with PBS. The nuclei in cell cultures were stained with 4',6-diamidino-2-phenylindole (DAPI, Cell Signaling Technology, Danvers, MA, USA). The transfected cells (green: CLUGFP; blue: DAPI-stained nuclei) in cell cultures were visualized using a Zeiss LSM 780 confocal microscope (Carl 176 Zeiss, Thornwood, NY, USA).

\subsection{Apoptosis analysis}

Apoptosis in TEC cultures was induced by exposing cells to $1 \% \mathrm{O}_{2}$ in a humidified hypoxic chamber (Coy Laboratory Products, Inc.) as mentioned previously and was measured by using fluorescence-activated cell sorting (FACS) analysis. Cells were trypsinzed and then incubated with annexin-V conjugated with phycoerythrin (annexin-V-PE) for early apoptosis and 7-amino-actinomycin D (7-AAD) for late apoptosis following the manufacturer's protocol (BD Biosciences Canada, Mississauga, ON, Canada). Shortly, TEC were incubated 
briefly with trypsin-EDTA solution (Sigma-Aldrich Canada, Oakville, ON, Canada) as a result cells were released. These cells were incubated with annexin-V-PE and 7-AAD in 1x binding buffer for $15 \mathrm{~min}$. The fluorescence intensity of positively stained apoptotic cells was measured by a flow cytometry and analyzed compared with background controls using FlowJo software (Tree Star Inc., Ashland, OR, USA). Thus, in FACS graph, the lower left quadrant represents the non-stained non-apoptotic (viable) cells, whereas the upper left quadrant for necrotic cells (7-AAD positive only), the upper right represents the late apoptotic cells (both annexin-V and 7-AAD positive), and lastly early apoptotic cells in the lower right quadrant (annexin-V positive only). The cell death in cultures, measured by FACS analysis, was also confirmed by the trypan blue exclusion assay using a $\mathrm{TC} 10^{\mathrm{TM}}$ automated cell counter (Bio-Rad Laboratories Canada, Mississauga, ON, Canada).

\subsection{Measurement of cell viability or growth}

Cell viability or growth was determined using 3-(4,5-dimethylthiazol-2-yl)-2,5diphenyltetrazolium bromide (MTT) assay. Briefly, cells were seeded in 96-well plates at a density of 2 or $2.5 \times 10^{3}$ cells/well and incubated in $5 \% \mathrm{CO}_{2}$ atmosphere at $37^{\circ} \mathrm{C}$. After 0,24 and $48 \mathrm{~h}$ of incubation, $10 \mu \mathrm{L}$ of $0.5 \mathrm{mg} / \mathrm{mL}$ of MTT (Sigma-Aldrich Canada, Oakville, ON, Canada) was added to each well for $4 \mathrm{~h}$. The resulting formazan crystals were dissolved in $100 \mu \mathrm{L}$ DMSO (Sigma-Aldrich Canada), and the optical density (OD) at $562 \mathrm{~nm}$ was measured using an ELx808 Ultra Microplate Reader (BioTek, Winooski, VT, USA). Finally, the cell viability in each well at those different time points was calculated, and was also confirmed by the trypan blue exclusion assay in separate experiments. In trypan blue exclusion assay, the numbers of viable cells (trypan blue negative) were counted using a 
$\mathrm{TC} 10^{\mathrm{TM}}$ automated cell counter (Bio-Rad Laboratories Canada, Mississauga, ON, Canada), and were presented as an average of at least three determinants in each experiment.

\subsection{Cell cycle distribution}

TECs $\left(1 \times 10^{6}\right.$ cells/well) were seeded in 6 -well plates in complete $\mathrm{K}^{+/+}$medium for $24 \mathrm{~h}$, followed by the incubation in serum and growth factor-free $\mathrm{K} 1^{-/-}$medium overnight to synchronize the cell growth. The cell cycle phases were examined at different time points $(0$, 6,12 and $24 \mathrm{~h}$ ) after changing the $\mathrm{K} 1^{-/-}$medium back to the complete $\mathrm{K} 1^{+/+}$medium. Cells at each time point were harvested by a brief trypsinization and centrifugation, and finally washed twice with ice-cold PBS.

The staining with propidium iodide (PI)(Invitrogen Canada, Burlington, ON, Canada) was performed as follows: cells were fixed with ice-cold $70 \%$ ethanol overnight, followed by treatment with $80 \mu \mathrm{g} / \mathrm{mL}$ of DNase-free RNase, $0.05 \%$ TritinX-100 and staining with 40 $\mu \mathrm{g} / \mathrm{mL}$ of PI at $37^{\circ} \mathrm{C}$ for $30 \mathrm{~min}$. The PI intensity indicating the DNA content was detected by FACS, and was used to distinguish the stained cells in different phases (Sub G1, G1, S, or G2/M) of the cell cycle by using FlowJo software (Tree Star Inc.). This experiment was performed twice.

\subsection{Cell migration by real time cell analyzer}

This assay was done with collaboration with Dr. Paul Rennie laboratory at Vancouver Prostate Centre. The cell migration in culture was monitored using a real time cell analyzer (RTCA) system (xCELLigence RTCA - ACEA Biosciences, San Diego, CA, USA). Cells 
were grown in CIM-16 plates that were used to measure the changes in electrical impedance as the cells migrate through the micro-gold prorated membranes of the upper chamber towards the lower chamber ${ }^{93}$. After starvation in $\mathrm{K}^{-1-}$ medium overnight, TEC-CLU ${ }^{\text {hCLU }}$ or $\mathrm{TEC}^{-\mathrm{CLU}^{-/}}$cells $\left(1\right.$ or $2 \times 10^{4}$ cells/well) in $\mathrm{K}^{-/-}$medium were seeded in the upper chamber of the CIM-16 plates, followed by addition of $160 \mu \mathrm{L}$ of complete $\mathrm{K} 1^{+/+}$medium to the lower chamber. After assembling both the upper and lower chambers, the rate of cell migration was recorded every $5 \mathrm{~min}$ for a period of $48 \mathrm{~h}$, and the background reading of each well was performed using $30 \mu \mathrm{L}$ of $\mathrm{K}^{-/-}$medium. The cell migration results were graphed as cell index value vs. time (min) using RTCA 2.0 software (ACEA Biosciences).

\subsection{RNA extraction}

Total RNA was extracted from cells using mirVana ${ }^{\mathrm{TM}}$ isolation kit (Ambion, Austin, TX, USA) according to the manufacturer's instruction. Briefly, total RNA was extracted from cells exposed to hypoxia and cells were cultured under normal condition. Culture medium was aspirated and discarded. Cells were trypsinzed, washed with PBS and centrifuged at 2000x $\mathrm{g}$ for $5 \mathrm{~min}$ then the supernatant was discarded. The pellet (cells) was disrupted in lysis binding buffer and (1/10 volume) of miRNA homogenate additive was added and gently vortexed for 10 seconds and incubated on ice box for $10 \mathrm{~min}$. Acid phenol chloroform was added to the lysate. Then, lysates were centrifuged for maximum speed $(10,000 \times \mathrm{g})$ for $10 \mathrm{~min}$ and two different layers were observed. Only the upper phase was collected and $1.25 \times$ of this collected volume of $100 \%$ ethanol was added. After that, the lysate/ethanol sample was placed into the filter. The filter was washed a few times with the wash solution 1 and 2, and was dried by centrifugation for $1 \mathrm{~min}$. Finally, the RNA was eluted with heated 
elution solution. Three separate samples from each group were performed. RNA samples were sent to the Laboratory for Advanced Genome Analysis at Vancouver Prostate Centre for RNA quality examination and microarray analysis.

The quality of RNA Integrity Number (RIN) and the quantity of extracted RNA samples were assessed using Agilent 2100 bioanalyzer with an RNA 6000 Nano kit and Ladder (Agilent Technologies, Santa Clara, CA, USA) prior to microarray analysis. RNA samples with a RIN value of greater than or equal to 8.0 were deemed to be acceptable for microarray analysis.

\subsection{Microarray analysis}

- RNA amplification and labeling

100 ng of total RNA from each sample was used to generate cyanine-3 (Cy3) labeled cRNA using One-Color Microarray-Based Gene Expression Analysis Low Input Quick Amp Labeling v6.0 kit (Agilent Technologies) following manufacture's protocol. In brief, total RNA was transcribed into complementary DNA (cDNA) by the action of reverse transcriptase anzyme and then this cDNA was transcribed into complementary RNA (cRNA) and then labeled with cyanine-3 (Cy3). NanoDrop ND-1000 UV-VIS Spectrophotometer version 3.2.1 was used to quantify the Cy3-labeled cRNA.

- Microarray hybridization

The purified Cy3-labeled cRNA samples were subsequently hybridized on Agilent SurePrint G3 Mouse Gene Expression $8 \times 60 \mathrm{~K}$ Microarrays/Slides (Design ID 028005) (Agilent 
Technologies). Briefly, array chips were incubated at $65^{\circ} \mathrm{C}$ for $17 \mathrm{~h}$. Then they were washed to eliminate cross-reaction and scanned with the Agilent DNA Microarray Scanner at a 3 um scan resolution (Agilent Technologies).

\section{- Data acquisition and processing}

Agilent Feature Extraction software (version 11.0.1.1) (Agilent Technologies) was used to analyze acquired array image. Quantile normalization and subsequent data processing were performed using the Agilent GeneSpring 12.0 software package (Agilent Technologies).

To identify the significantly regulated gene in the data processing, fold changes (FC) between the compared groups and $\mathrm{p}$ values from statistical analysis with t-test were calculated. The t-tests were performed on normalized data that had been log transformed and the variances were not assumed to be equal between sample groups. After that, the gene lists were uploaded into Ingenuity Pathway Analysis (IPA) software (Ingenuity Systems, Redwood City, CA, USA) to examine gene enrichment pathways.

\subsection{Microarray data analysis}

\section{- Ingenuity pathway analysis (IPA)}

IPA software is used to analyze and understand data from many different sources such as gene expression microarray ${ }^{94}$. It is a powerful tool that is based on Ingenuity knowledge which is linked to the literatures ${ }^{94}$. IPA was used to analyze the signaling pathways specific for CLU functions by comparing microarray-generated transcriptome of CLU-expressing TEC-CLU ${ }^{\text {hCLU }}$ with that of CLU negative TEC-CLU ${ }^{-/-}$control. After uploading differentially expressed genes which were detected by microarray to IPA using core analysis option, 
especially "cell survival/death, cell proliferation, cell cycle, cell migration" were used as the keywords to search for all the genes related to these cellular functions. After that, we imported the genes associated with "cell survival/death, cell proliferation, cell cycle, cell migration" separately into the "Canonical Pathway" frame of the IPA software to determine which signaling pathways were regulated by the expression of CLU in kidney cells.

\section{- String software}

String v10. database (http://string-db.org/) was used to generate a network analysis of candidates genes. String (Search Tool for the Retrieval of Interacting Genes/Proteins) "is a database of known and predicted protein-protein interaction" ${ }^{\prime 95}$. These interactions based on direct and indirect associations ${ }^{95}$.

\subsection{Statistical analysis}

Comparisons between groups were done by using either analysis of variance (ANOVA) or $t$ tests (two-tailed distribution) in Prism GraphPad software (GraphPad Software, Inc., La Jolla, CA, USA). Data form separate experiment were collected and used for statistical analysis. Only data were shown a $p$ value of $\leq 0.05$ was considered significant. 


\section{Chapter 3: Results}

\subsection{Ectopic expression of human clusterin protein in clusterin null tubular epithelial}

cells

In order to investigate the molecular pathways specific for CLU functions in kidney cells, we used both CLU-expressing TEC-CLU ${ }^{\text {hCLU }}$ and CLU negative control TEC-CLU ${ }^{-/-}$cells from the same parent cells - CLU null TECs from a CLU KO mouse.

As shown by Western blot Figure 3.1, both uncleaved cCLU (top band) and mature sCLU (bottom band) were detected in protein extracts of TEC-CLU ${ }^{\text {hCLU }}$ cells, but not of TEC-CLU ${ }^{-}$ I- cells.

Confocal microscopic analysis revealed that CLU-GFP (secreted CLU) was exclusively localized in the cytoplasm of TECs, and some of this protein was expressed as large puncta, particularly surrounding the nucleus (Fig. 1B). The CLU-GFP expression in TECs under normoxia was not significantly different from that in those under hypoxia Figure 3.2. 


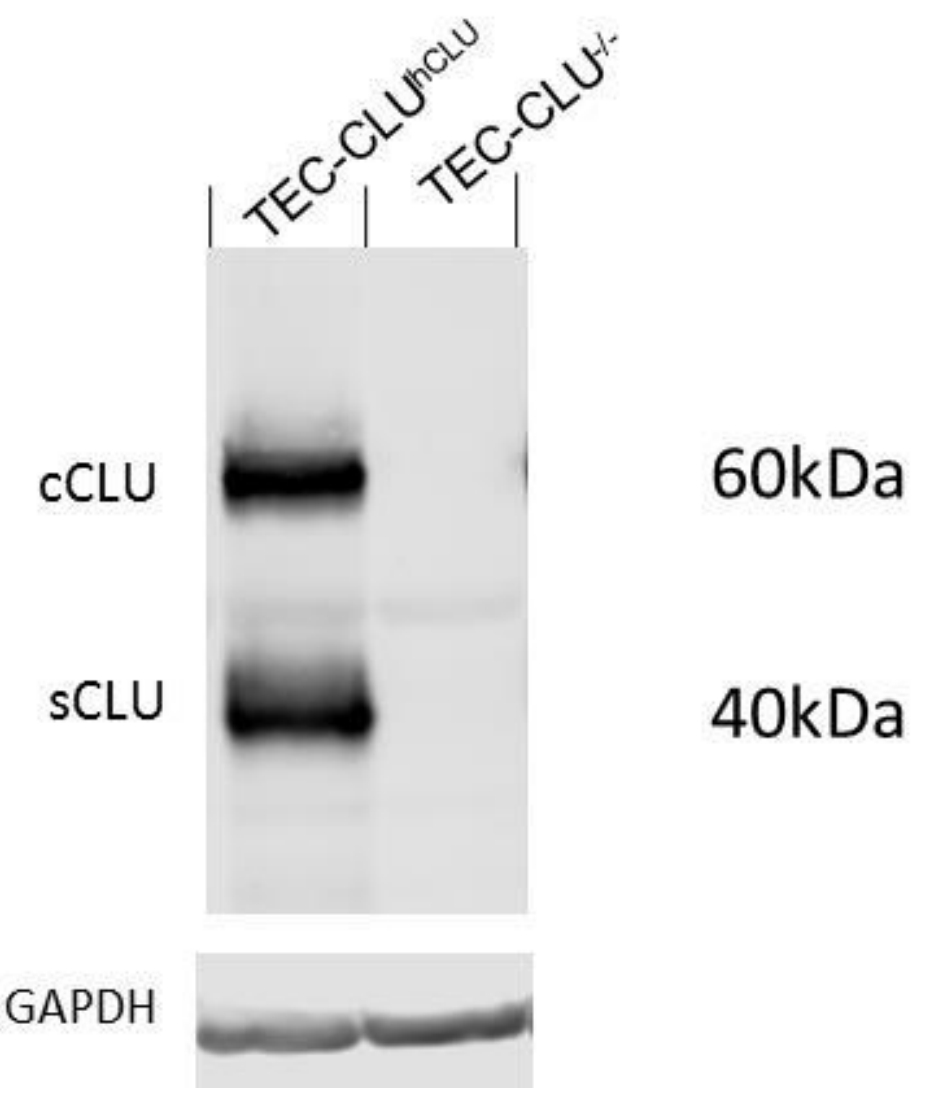

Figure 3.1 Ectopic expression of human clusterin isoform1 in tubular epithelial cells from clusterin knockout mouse

TEC-CLU $^{-/}$cells were stably expressing an empty pHEX6300 vector, and TEC$\mathrm{CLU}^{\mathrm{hCLU}}$ cells the pHEX6300 vector containing human CLU isoform 1 cDNA.The expression of CLU proteins (cCLU: cytoplasmic CLU; sCLU: secreted/mature CLU) in protein extracts of both cell lines was determined by Western blot analysis. GAPDH protein was reprobed with the antibodies on the same blot. Data were a representative of two separate experiments 

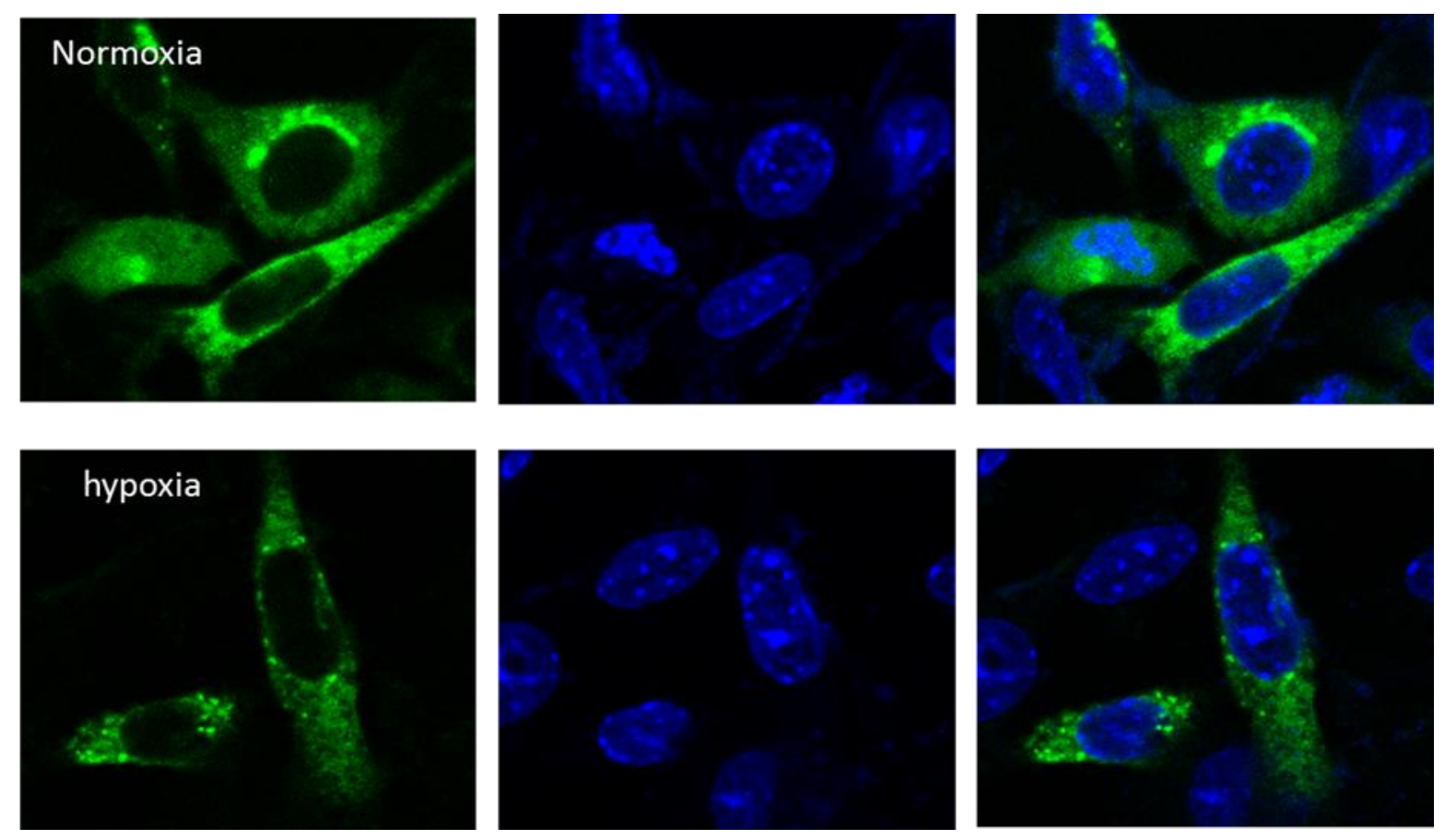

Figure 3.2 Cellular localization of clusterin in tubular epithelial cells under hypoxia and normoxia.

Cells were transfected with EGFP-N1 vector containing human CLU isoform 1 cDNA to express CLU-GFP fusion protein and then were incubated in normoxia or hypoxia $\left(1 \% \mathrm{O}_{2}\right)$ for $24 \mathrm{~h}$, followed by DAPI nuclear staining. The cellular localization of CLU-GFP was performed by using confocal microscopy. Green: CLU-GFP fusion protein; blue: DAPIstained nucleus. Data were presented as a typical microscopic image of CLU-GFPexpressing cells in normoxia or hypoxia from two separate experiments 


\subsection{Regulation of clusterin gene expression (transcriptome) by clusterin expression in tubular epithelial cells}

A comprehensive coverage of 60,000 transcripts in both TEC-CLU ${ }^{\mathrm{hCLU}}$ and TEC-CLU ${ }^{-/-}$cells in two different conditions - hypoxia and normoxia was examined using SurePrint G3 Mouse Gene Expression Microarray, so that two different databases using FC (fold change) $\geq 2.0$ and $\mathrm{p} \leq 0.05$ as a cut-off line were established: CLU functions in normoxia (TEC-CLU ${ }^{\text {hCLU }}$ versus TEC-CLU ${ }^{-/}$cells in normoxia), and CLU functions in hypoxia (TEC-CLU ${ }^{\text {hCLU }}$ versus TEC-CLU $^{-/}$cells in hypoxia). In normoxia, the expression of 3864 transcripts was significantly affected in TEC-CLU ${ }^{\text {hCLU }}$ cells (1893 or $48.99 \%$ up-regulated, and 1971 or $51.01 \%$ down-regulated) compared to TEC-CLU $^{-/-}$controls Figure3.3 .In hypoxia, the significantly-affected transcripts were reduced to 3670 (1925 or 52.45\% up-regulated, and 1745 or $47.55 \%$ down-regulated) Figure 3.3.Overlapping analysis showed that the number of

transcripts that was changed specifically in normoxia in TEC-CLU ${ }^{\text {hCLU }}$ cells compared to TEC-CLU $^{-/-}$controls was 1892 (939 or $49.63 \%$ up-regulated, and 953 or 50.37\% downregulated), and specifically in hypoxia was 1698 (971 or 57.19\% up-regulated, and 727 or $42.81 \%$ down-regulated). Taken together, these data clearly showed that although hypoxia suppressed the total transcription activities, ectopic expression of CLU significantly upregulated gene transcription in TEC specifically in response to hypoxia. 


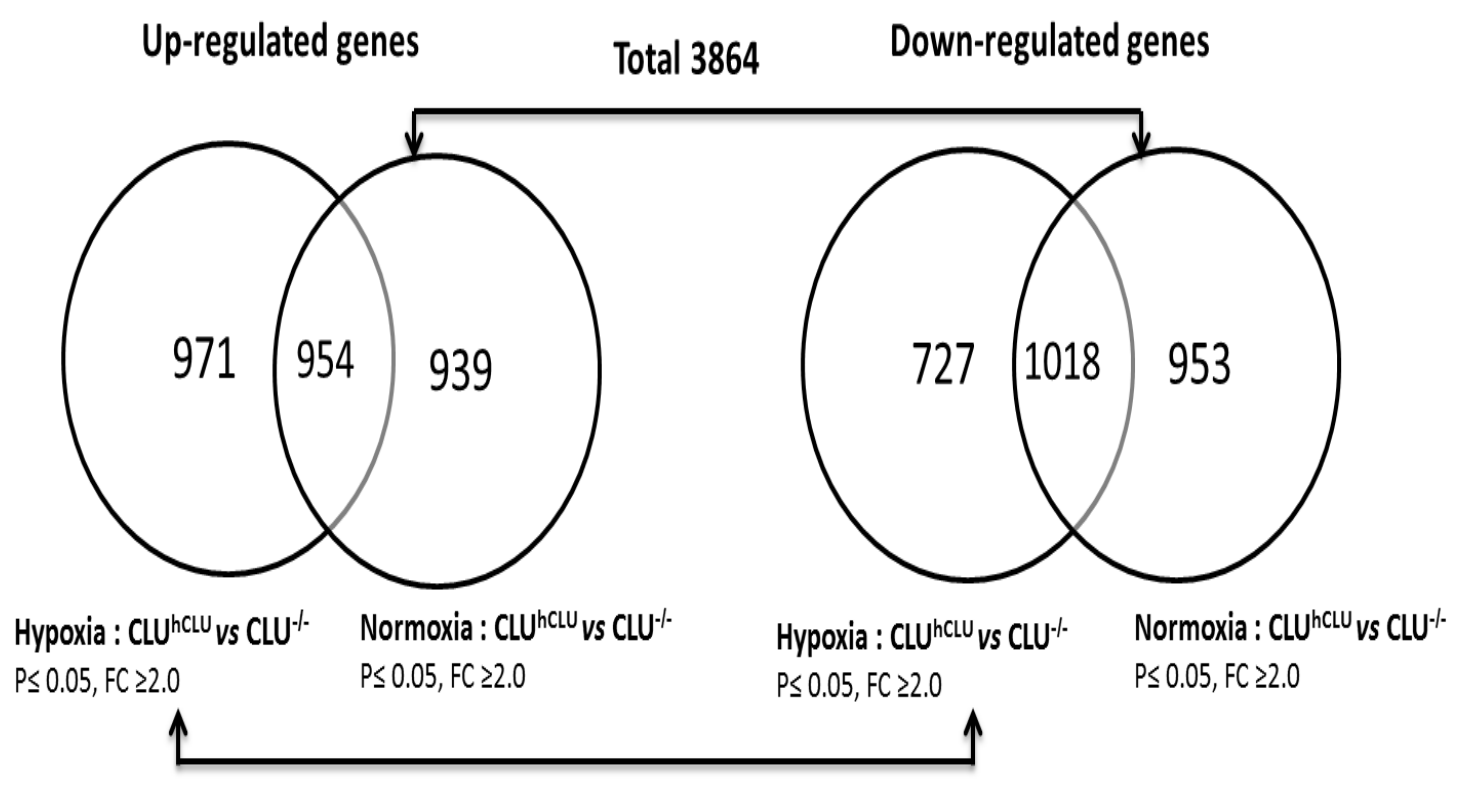

Total 3670

Figure 3.3 Clusterin -induced transcriptome of tubular epithelial cells in both normoxia and hypoxia

Venn diagram analysis of microarray data (three separate samples in each group, $n=3$ ) of TEC-CLU ${ }^{\text {hCLU }}$ (denoted by CLU ${ }^{\text {hCLU}}$ ) compared to those of TEC-CLU ${ }^{-/}$(denoted by $\mathrm{CLU}^{--}$) in both normoxia and hypoxia using the Agilent Gene Spring software. Only the transcripts in $\mathrm{CLU}^{\mathrm{hCLU}}$ cells that were significantly changed $(\mathrm{P} \leq 0.05 ; \mathrm{FC} \geq 2.0)$ as compared to CLU negative backgroup $\left(\mathrm{CLU}^{-/}\right)$were included and presented in this analysis. The numbers of the overlapped transcripts between normoxia and hypoxia were presented in the shared area of two circles. FC: fold change. 


\subsection{Signaling pathways mediating clusterin-dependent cell survival under normoxia}

As shown in Figure 3.4A, ectopic expression of CLU in CLU null TECs reduced cell apoptosis, particularly late apoptosis (double positive stained cell population - 7AAD/annexin-V) in normoxia, or increased cell survival from $86.5 \pm 4.85 \%$ in cultured TEC$\mathrm{CLU}^{-/-}$cells to $94.83 \pm 2.04 \%$ in TEC-CLU ${ }^{\mathrm{hCLU}}$ cells $(\mathrm{p}=0.0031$, two-tailed t-test, $\mathrm{n}=6$ ). The effect of CLU expression on cell survival was also confirmed by counting the cells using trypan blue stain to differentiate viable and dead cells Figure 3.4B. IPA analysis of cell survival/death signaling pathways in TEC-CLU ${ }^{\mathrm{hCLU}}$ cells compared to TEC-CLU ${ }^{-/-}$controls in normoxia showed that based on the p value, ERK/MAPK signaling was ranked first, followed by PI3K/AKT, STAT3, PTEN signaling and NF-kB signaling (Table3.1), and upregulation of AKT2 was the most common gene associating with these signaling pathways (PI3K/AKT, PTEN, VEGF, NF-кB, AMPK, JAK/STAT and Myc Mediated Apoptosis signaling), followed by the up-regulation of PPP2R2B in ERK/MAPK, PI3K/AKT and AMPK signaling and of both FGFR1 and FGFR4 in STAT3, PTEN and NF-KB signaling (Table 1). The association of CLU expression in TECs with the up-regulation of AKT2 was verified by Western blot, showed that the protein level of AKT2 in TEC-CLU ${ }^{\text {hCLU }}$ cells was higher than that in TEC-CLU ${ }^{-/-}$controls Figure 3.13. 


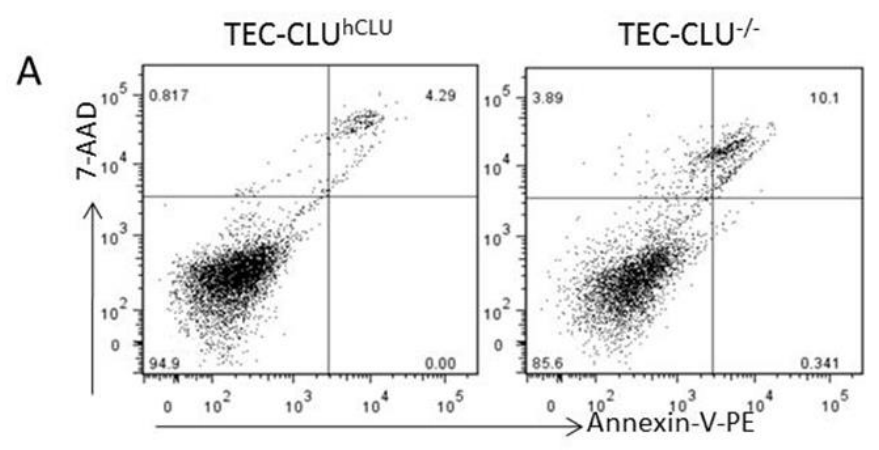

B

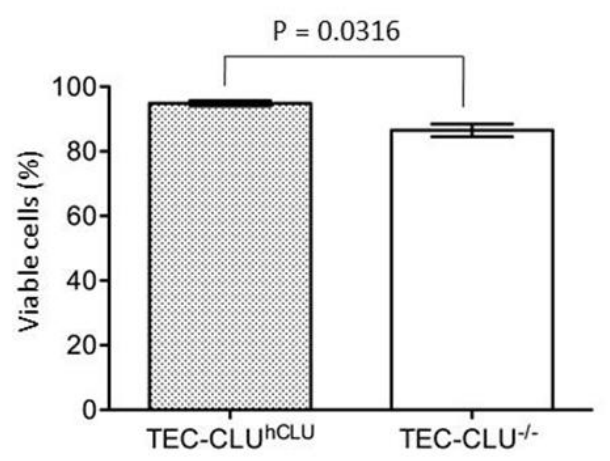

Figure 3.4 clusterin- induced cell survival in normoxia

TECs were grown in $\mathrm{K}^{+/+}$culture medium in 24-well plates. A. Cell viability or apoptosis was measured by FACS analysis with annexin-V-PE and 7-AAD staining after incubation for overnight. Cell viability represented the percentage of viable cells (doubleannexin-V-PE/7-AAD negative cells in lower left quadrant), and late apoptosis was indicated by the double-annexin-V-PE/7-AAD positive cells in upper right quadrant. Data are represented as a typical graph of three separate experiments. B. Cell viability was counted by using trypan blue exclusion assay. Data are presented as mean \pm standard deviation (SD) of six separate experiments. TEC-CLU ${ }^{\text {hCLU }}$ vs.TEC-CLU ${ }^{-{ }^{-}}, \mathrm{P}=0.0031$ (two-tailed $t$-test). 
Table 3.1 Cell survival/death pathways associated with clusterin expression in tubular epithelial cells in normoxia

\begin{tabular}{|c|c|c|c|}
\hline Canonical Pathway & $-\log (P$ value $)$ & Up regulated genes & Down regulated genes \\
\hline \multirow[t]{2}{*}{ ERK/MAPK signaling } & 8.5 & PPP2CA,CREB1,PRKCA,PPM1L,PAK3,CREBBP,PPP2R2B, & PLA2G4A,PLCG2,PAK6,PPP1R14D,PPP1R3D,DUSP2 ,PTK2B,HSPB1,RAPGEF3,E \\
\hline & & DUSP9 & LF3,PRKAR2B,RAC3,RRAS2,HSPB2,PRKCD,PPP2R5E,MRAS,ITGB1 \\
\hline \multirow[t]{2}{*}{ PIЗK/AKT } & 8.4 & AKT2,PPP2CA,GSK3B,MAP3K5,PPM1L,NOS3,NANOG & PRKCZ,PTGS2,SFN,IKBKE,GDF15,RRAS2,BCL2L1 \\
\hline & & ,PPP2R2B & ,IKBKB,PPP2R5E,MRAS,CDKN1A,ITGB1,JAK1 \\
\hline \multirow[t]{2}{*}{ STAT3 } & 7.5 & MAP3K12,FGFR4,FLT1,FGFR1 & MAPK13,NGFR,FLT4,PTPN6,SOCS2,TGFBR2, \\
\hline & & & RRAS2,MAPK12,MAP3K9,MRAS,CDKN1A \\
\hline \multirow[t]{2}{*}{ PTEN signaling } & 7.0 & AKT2, GSK3B,FGFR4,FLT1,FGFR1 & FOXG1,PRKCZ,NGFR,FLT4,IKBKE,TGFBR2, \\
\hline & & & RAC3,RRAS2,BCL2L1,IKBKB,MRAS,CDKN1A \\
\hline VEGF signaling & 6.5 & AKT2,ARNT,PRKCA,FLT1,NOS3 & PLCG2,FLT4,SFN,PTK2B,PTPN6,VCL,RRAS2,BCL2L1,MRAS,ROCK2 \\
\hline \multirow[t]{2}{*}{ Nfk B signaling } & 6.0 & AKT2,GSK3B,TLR2,CREBBP,BTRC, FGFR4,FLT1,FGFR1, & PRKCZ, PLCG2,NGFR,FLT4,IL1RN,IL1A,TGFBR2, \\
\hline & & & RRAS2,IKBKB,TGFA,CARD10,MRAS \\
\hline Death Receptor signaling & 4.3 & TNFRSF21,CASP6,MAP3K5,PARP14,TNFSF12 & HSPB1,IKBKE,CFLAR,BID,HSPB2,IKBKB,TNKS2 \\
\hline \multirow[t]{2}{*}{ AMPK signaling } & 3.2 & AKT2,SMARCE1,PPP2CA,PPM1L, & MAPK13, IRS2,PRKAR2B,MAPK12,PPP2R5E,MRAS, \\
\hline & & IRS1,ADRA1D,NOS3,PPP2R2B & \\
\hline JAK/STAT signaling & 3.0 & AKT2,STAT5A & PTPN6,SOCS2,RRAS2,BCL2L1,MRAS,CDKN1A,JAK1 \\
\hline Apoptosis signaling & 3.0 & CASP6,MAP3K5,PRKCA & PLCG2, IKBKE,BID,RRAS2,BCL2L1,IKBKB,MRAS \\
\hline $\begin{array}{l}\text { Myc Mediated Apoptosis } \\
\text { signaling }\end{array}$ & 2.4 & AKT2 & PRKCZ,SFN,BID,RRAS2,MAPK12,MRAS \\
\hline
\end{tabular}




\subsection{Signaling mediating clusterin-dependent cell proliferation in normoxia}

Cell proliferation in both cultured TEC-CLU ${ }^{\mathrm{hCLU}}$ cells and TEC-CLU ${ }^{-/-}$controls in normoxia was monitored by counting viable cells using both MTT assay and trypan blue exclusion for a period of $48 \mathrm{~h}$. Data showed that ectopic expression of CLU significantly enhanced cell growth, indicated by the more increased viable cells in TEC-CLU ${ }^{\text {hCLU }}$ cells compared to TEC-CLU ${ }^{-/}$controls by MTT assay $(\mathrm{p}<0.0001$, two-way ANOVA, $\mathrm{n}=12)$ Figure 3.5A, and as well by trypan blue exclusion $(\mathrm{p}=0.0002$, two-way ANOVA, $n=3)$ Figure 3.5B. The beneficial effects of CLU on cell growth were further confirmed by cell cycle distribution analysis, showing that there was a progressive shift of the cells from the G0/G1 to the $S$ and then $\mathrm{G} 2 / \mathrm{M}$ phases of the cell cycle following the time of incubation with serum and growth factors after starvation, which however was not observed in TEC-CLU ${ }^{-/-}$cells Figure 3.6. These data suggested that ectopic expression of CLU induced normal cell cycle progression and enhanced cell proliferation or growth in normoxia.

As shown in (Table 3.2), by IPA analysis the CLU functions in TEC proliferation were mediated by the similar pathways to those in cell survival, but ranked in a different order: VEGF signaling first, followed by PTEN, PI3K/AKT and ERK/MAPK signaling. In addition, both TGF-beta and EGF signaling were in the list for the CLU-dependent TEC proliferation. The most common gene that was up-regulated by the expression of CLU in cell proliferation-related pathways was still AKT2 (Table 3.2). In the analysis of signaling pathways for cell cycle progression, G1/S checkpoint regulation was ranked first, followed by PTEN, PI3K/AKT signaling/BTG family protein and G2/M DNA damage checkpoint regulation (Table 3.3). Up-regulation of GSK3B was commonly found in the top 3 signaling 
pathways mediating the CLU regulation of cell cycle progression (Table 3.3), and was confirmed by Western blot analysis Figure 3.13.

A

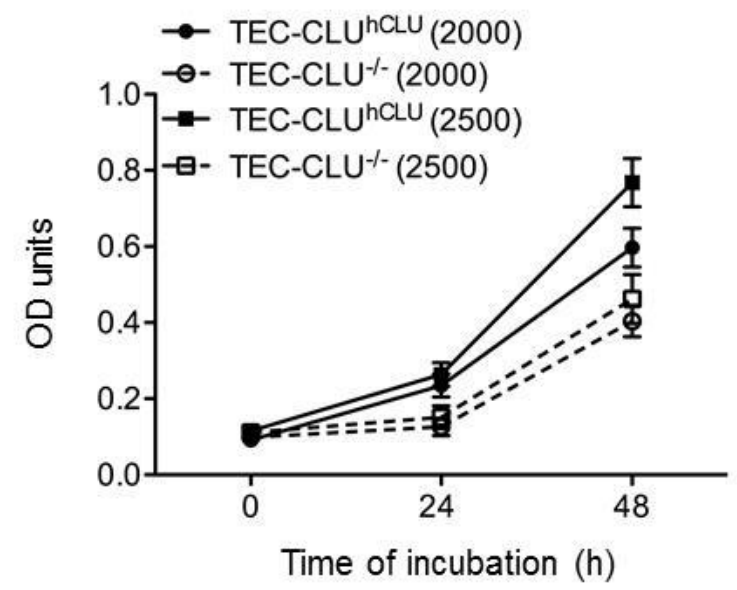

B

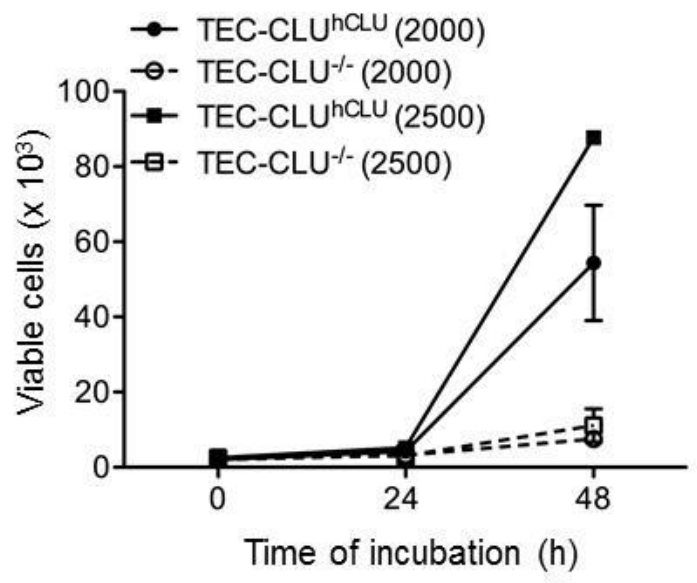

Figure 3.5 Clusterin-induced tubular epithelial cells growth or proliferation in normoxia

Cell growth of TECs (2000 or 2500 cells/well) in $\mathrm{K}^{+/+}$culture medium in 96-well plates was monitored using MTT assay (A) or trypan blue exclusion (B) at 0, 24 or $48 \mathrm{~h}$.

Data are presented as mean \pm SD at each time point in each group. TEC-CLU ${ }^{\text {hCLU }}$ vs. TEC-CLU ${ }^{-/-}$in MTT assay: $\mathrm{P}<0.0001$ (two-way ANOVA, $\mathrm{n}=12$ ); in trypan blue exclusion: $\mathrm{P}=0.0002(2000$ cells/well) or $\mathrm{P}<0.0001(2500$ cells/well) (two-way ANOVA, $\mathrm{n}=3$ ) 


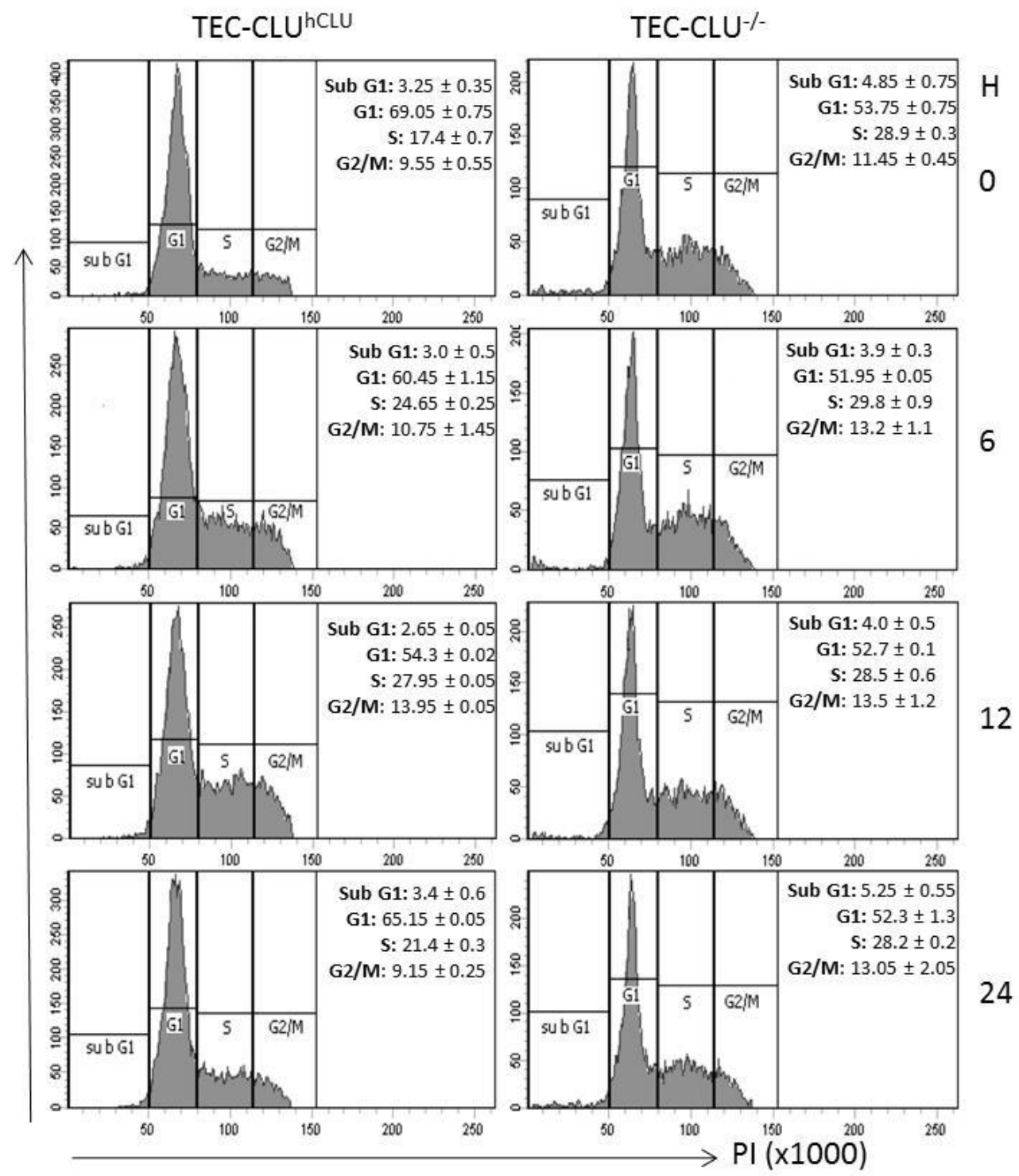

Figure 3.6 Clusterin-induced tubular epithelial cells division in normoxia

TECs were grown in $\mathrm{K}^{+/+}$medium(containing $5 \%$ bovine serum and growth factors) after overnight starvation in serum-growth factor free $\mathrm{K}^{-/-}$medium. The percentage of cells in $\mathrm{G}_{0} / \mathrm{G}_{1}, \mathrm{~S}$, and $\mathrm{G}_{2} / \mathrm{M}$ phases of the cell cycle in these cultured TECs was determined following the time of incubation with the $\mathrm{K}^{+/+}$medium from 0 to $24 \mathrm{hrs}$. Data are presented as a typical graph for the cell cycle distribution in FACS analysis of each group. 
Table 3.2 cell proliferation pathways associated with clusterin expression in tubular epithelial cells in normoxia

\begin{tabular}{|c|c|c|c|}
\hline $\begin{array}{l}\text { Canonical } \\
\text { Pathway }\end{array}$ & $\begin{array}{l}-\log (p \\
\text { value })\end{array}$ & Up regulated genes & Down regulated genes \\
\hline VEGF signaling & 8.0 & AKT2,ARNT,PRKCA,FLT1,NOS3,FIGF & PLCG2,FLT4,SFN,PIK3R5,PTK2B,PTPN6,VCL,RRAS2,BCL2L1,ACTN1,MRAS,ROCK2 \\
\hline \multirow[t]{2}{*}{ PTEN signaling } & 7.0 & AKT2,GSK3B,FGFR4,FLT1,FGFR1 & FOXG1,PRKCZ,NGFR,FLT4,PIK3R5,IKBKE,TGFBR2,RAC3 \\
\hline & & & ,RRAS2,BCL2L1,IKBKB,MRAS,CDKN1A,CDKN1A \\
\hline PIЗK/AKT & 7.0 & AKT2,PPP2CA,GSK3B,MAP3K5,NOS3,NANOG & PPP2R2C,PRKCZ,PTGS2,SFN,IKBKE,GDF15,RRAS2,BCL2L1 \\
\hline signaling & & & ,IKBKB,MRAS,CDKN1A,ITGB1,JAK1 \\
\hline ERK/MAPK & 5.5 & PPP2CA,CREB1,PRKCA,CREBBP,DUSP9 & PLA2G4A,PPP2R2C,PLCG2,DUSP2,PIK3R5,PTK2B,RAPGEF3 \\
\hline signaling & & & ,ELF3,PRKAR2B,RAC3,RRAS2,RPS6KA4,ELF1,PRKCD,MRAS,ITGB1, \\
\hline TGF B signaling & 4.9 & MAP4K1,CREBBP,TGFB3,RUNX3,PITX2,HNF4A & MAPK13,INHA,SERPINE1,TGFBR2,RRAS2,MAPK12,MRAS \\
\hline P38 MAPK & 4.3 & CREB1,MAP3K5,TIFA,MAP4K1,CREBBP, & PLA2G4A,MAPK13,IL1RL1,IL1RN,IL1A,TGFBR2,MAPK12,R \\
\hline signaling & & TGFB3 & PS6KA4 \\
\hline \multirow[t]{2}{*}{ AMPK signaling } & 4.0 & AKT2,SMARCE1,PPP2CA,AK4,IRS1,ADRA1D,NOS3,ADRA2A & PPP2R2C, MAPK13,PIK3R5,IRS2,PRKAR2B, \\
\hline & & & MAPK12,MRAS,PFKFB3 \\
\hline EGF signaling & 1.8 & AKT2,PRKCA & MAPK13, PIK3R5,MAPK12,JAK1 \\
\hline FAK & 1.4 & AKT2 & PLCG2, PIK3R5,VCL,RRAS2,MRASITGB1 \\
\hline
\end{tabular}


Table 3.3 Cell cycle pathways associated with clusterin expression in tubular epithelial cells in normoxia

\begin{tabular}{|c|c|c|c|}
\hline Canonical Pathway & $-\log (p$ value) & Up regulated genes & Down regulated genes \\
\hline Cell cycle:G1/S checkpoint regulation & 9.0 & ABL1,GSK3B,BTRC,TGFB3 & CCND2,GNL3,ATR,E2F4,CDKN1A,CCND3 \\
\hline PTEN signaling & 8.5 & GSK3B,FLT1,FGFR1 & $\begin{array}{l}\text { FOXG1,PRKCZ,NGFR,TGFBR2,RRAS2, } \\
\text { BCL2L1,IKBKB,ITGB1 }\end{array}$ \\
\hline PI3K/AKT signaling & 8.5 & PPP2CA,GSK3B,NANOG,PPP2R2B & $\begin{array}{l}\text { PRKCZ,PTGS2,SFN,RRAS2,BCL2L1,IKBKB,CDKN1A, } \\
\text { ITGB1 }\end{array}$ \\
\hline $\begin{array}{l}\text { Cell cycle:G2/M DNA damage checkpoint } \\
\text { regulation }\end{array}$ & 6.5 & ABL1, BTRC, & PRKCZ, SFN,ATR,CDKN1A,BORA \\
\hline Cell cycle regulation by BTG family protein & 2.5 & PPP2CA, PPP2R2B & $\mathrm{E} 2 \mathrm{~F} 4$ \\
\hline DNA damage induced 14-14-3 a signaling & 1.8 & & ATR,SFN \\
\hline
\end{tabular}




\subsection{Signaling pathways for inhibition of clusterin in cell migration in normoxia}

Consistent with our previous observation in wound healing assay ${ }^{7}$, CLU expression in CLU null TECs inhibited cell migration in response to serum and growth factors in RTCA assay, indicated by the fact that migration of TEC-CLU ${ }^{\text {hCLU }}$ cells was significantly slower than that of TEC-CLU ${ }^{-/-}$controls Figure 3.7A, which was further confirmed by the lower migration slopes of TEC-CLU ${ }^{\text {hCLU }}$ cells $\left(0.0287 \pm 0.00031 / \mathrm{h}\right.$ by $10^{4}$ seeded cells, or $0.0629 \pm 0.0006$ $1 / \mathrm{h}$ by $2 \times 10^{4}$ seeded cells, $\left.\mathrm{n}=4\right)$ than those $\left(0.0434 \pm 0.00041 / \mathrm{h}\right.$ by $10^{4}$ seeded cells, or $0.103 \pm 0.00071 / \mathrm{h}$ by $2 \times 10^{4}$ seeded cells, $\left.\mathrm{n}=4\right)$ of $\mathrm{TEC}-\mathrm{CLU}^{-/}$controls during the time period of 15 to $35 \mathrm{~h}$ ( $\mathrm{p}<0.0001$, two-tailed t-test), As shown in Figure 3.7B. IPA analysis revealed that, CLU expression was associated with the loss of the signaling pathways similar to those facilitating tumor cell migrations, particularly glioma invasiveness signaling, and affected FAK signaling (Table 3.4). 
A

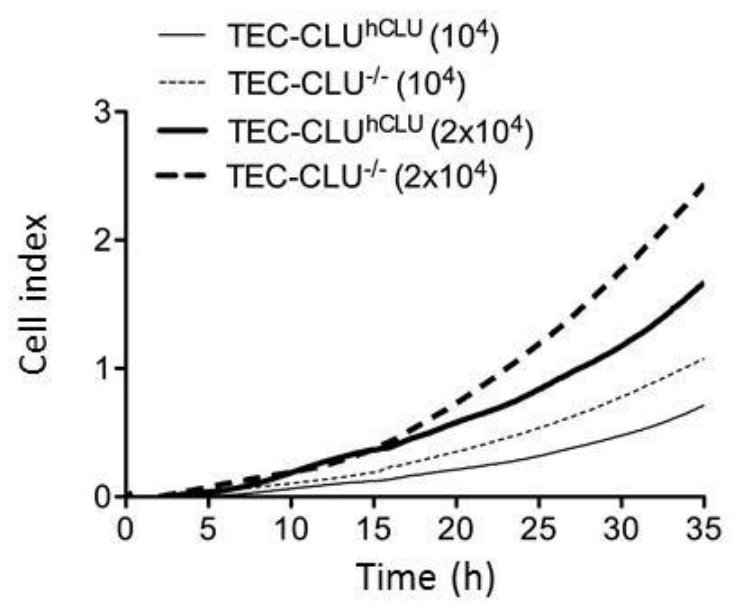

B

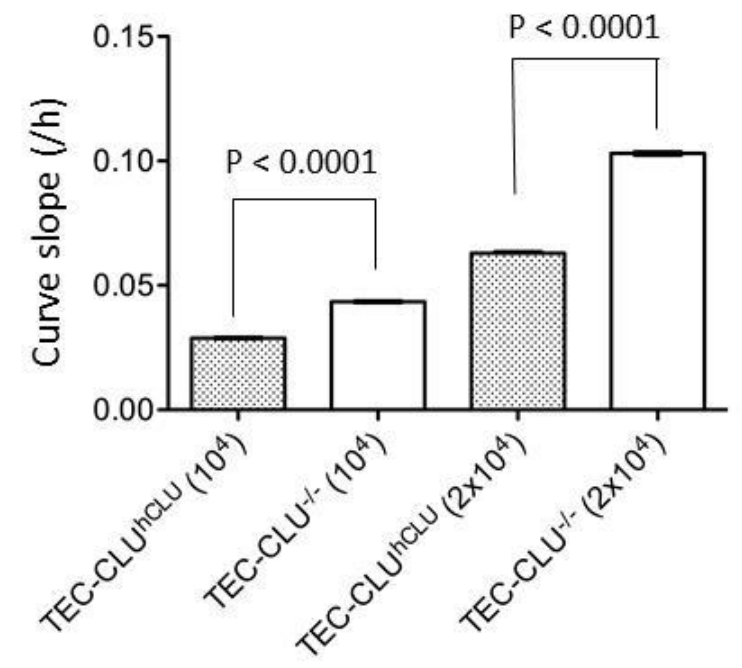

Figure 3.7 Clusterin-restrained tubular epithelial cells migration in normoxia

TECs $\left(10^{4}\right.$ or $2 \times 10^{4}$ cells/well $)$ were cultured in $\mathrm{K}^{+/+}$medium in the upper chamber of CIM-9 plate overnight, followed by incubation in serum- growth factor free $\mathrm{K}^{-/-}$medium (starvation) for $24 \mathrm{~h}$. The cell migration from the upper chamber to the $\mathrm{K} 1^{+/+}$mediumcontaining lower chamber was determined by real time cell analyzer. A. Cell index from 0 to $35 \mathrm{~h}$. B. Curve slope per hour was calculated based on the cell index during the time period of 15 to $35 \mathrm{~h}$. Data are presented as mean of four separate experiments. TEC$\mathrm{CLU}^{\text {hCLU }}$ vs. TEC-CLU ${ }^{-/-}, \mathrm{P}<0.0001$ (two-tailed $t$-test) 
Table 3.4 Cell migration pathways associated with clusterin expression in tubular epithelial cells in normoxia

\begin{tabular}{|c|c|c|c|}
\hline Canonical Pathway & $-\log (p$ value $)$ & Up regulated genes & Down regulated genes \\
\hline \multirow[t]{3}{*}{ Molecular Mechanism of Cancer } & 12.0 & AKT2,CDK5,ABL1,GSK3B,MAP3K5,WNT5A,PRKCA,IRS1, & PRKCZ,CDH1,PRKD1,PAK6,GNAO1,ARHGEF4 \\
\hline & & PAK3,FZD4,LRP1,TGFB3,WNT5B,GNAI1,LEF1,BMP6 & ,PIK3R5,RAPGEF3,TGFBR2,ARHGEF1,BID,RRAS2,MAPK \\
\hline & & & 12,PRKCD,MRAS,CDKN1A,ITGB1, RHOA,RAP2A,JAK1, \\
\hline FAK signaling & 4.5 & AKT2, TNS1,PAK3 & PLCG2,PAK6,PIK3R5,VCL,RRAS2,MRAS,ITGB1 \\
\hline Glioma Invasiveness signaling & 3.3 & & PLAU,CD44,PIK3R5,RRAS2,TIMP1,MRAS,RHOA \\
\hline
\end{tabular}




\subsection{Signaling pathways mediating clusterin-dependent cell survival in hypoxia}

CLU expression is required for prosurvival autophagy in TEC in the exposure to hypoxia ${ }^{96}$. However, whether or not the activation of prosurvival autophay is a primary pathway for CLU function mediating cell survival in hypoxia remains unknown. Figure 3.7A confirmed that there were more survived cells $(93.83 \pm 2.14 \%)$ in TEC-CLU ${ }^{\text {hCLU }}$ cells than those (75.17 $\pm 8.75 \%)$ in TEC-CLU ${ }^{-/-}$controls after $24 \mathrm{~h}$ of hypoxia $(\mathrm{p}=0.0005$, two-tailed t-test, $\mathrm{n}=6)$.

This result was also confirmed by trypan blue assay Figure 3.7B. IPA analysis of cell survival/death signaling of these TEC-CLU ${ }^{\mathrm{hCLU}}$ cells compared to TEC-CLU ${ }^{-/}$controls showed that PI3K/AKT signaling was ranked first, followed by HIF- $\alpha$, VEGF, PTEN, ERK/MAPK, STAT3 and Myc-mediated apoptosis signaling (Table 3.5), and the most common up-regulated genes are PIK3CD and MAPK1, followed by PPP2R2B, MAP3K5 and FOXO3 (Table 3.5). Indeed, the autophagy-related both endoplasmic reticulum (ER) stress and unfolded protein response (UPR) were found in the list with the p value of 2.4 and 2.0, respectively. It was very interested in noting that CLU-enhanced cell survival in hypoxia was associated with two groups of signaling pathways: PIK3CD and/or MAPK1-upregulated pathways (PI3K/AKT, HIF- $\alpha$, VEGF, PTEN, ERK/MAPK, STAT3, Myc-mediated apoptosis, SAPK/JNK and AMPK signaling) or PIK3CD and/or MAPK1-independent pathways (i.e. ER stress and UPR) (Table 5). Both ER stress and UPR were activated by CLU expression via exclusive up-expression of DDIT3, CEBPD, PPP1R15A, XBP1, ERN1 and MAP3K5 only (Table 3.5). 

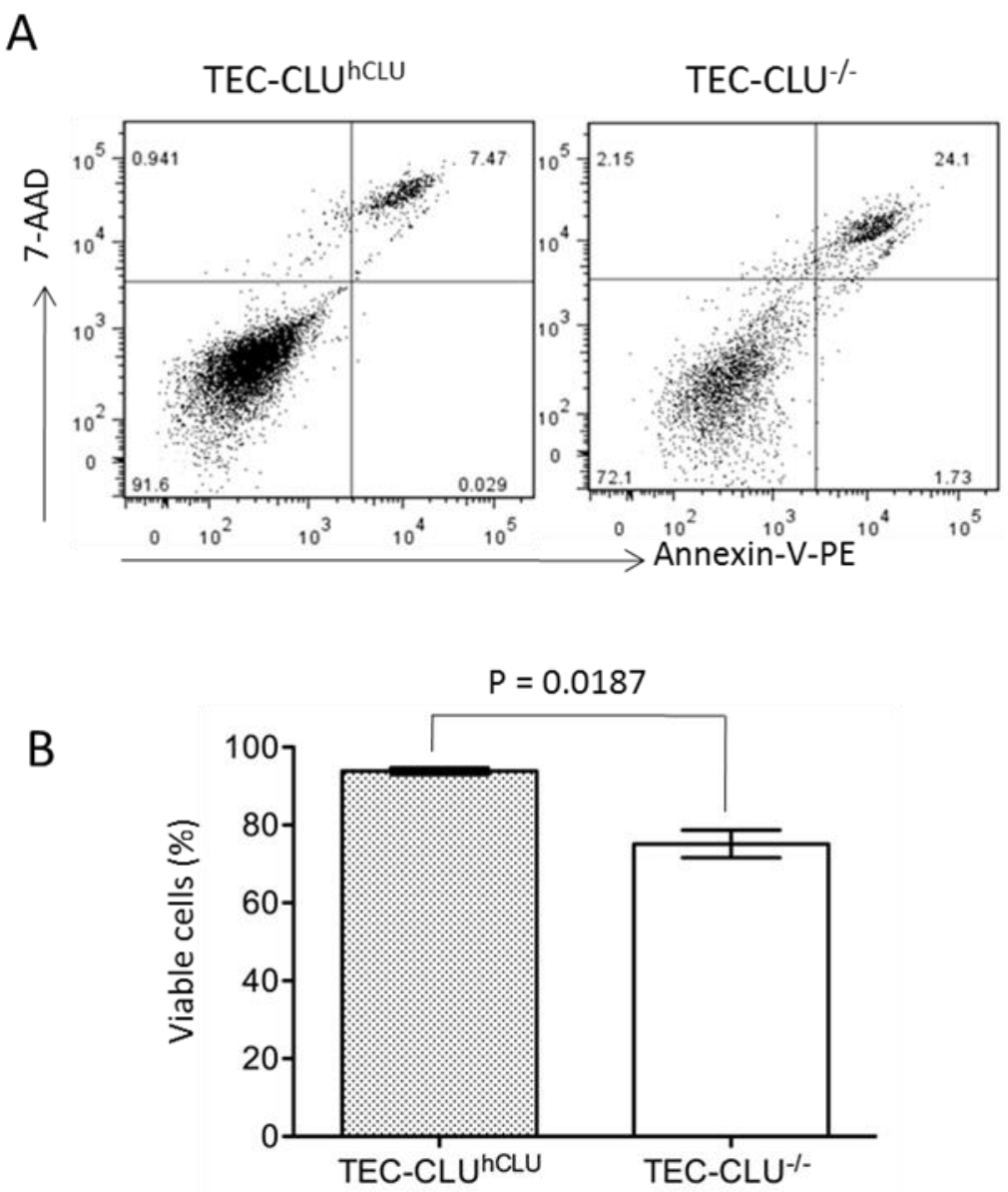

Figure 3.8 Clusterin-enhanced tubular epithelial cells survival in hypoxia

TECs were grown in $\mathrm{K}^{+/+}$culture medium in 24-well plates. A. Cell viability or apoptosis was measured by FACS analysis with annexin-V-PE and 7-AAD staining after incubation in hypoxia for $24 \mathrm{~h}$. Cell viability represented the percentage of viable cells (doubleannexin-V-PE/7-AAD negative cells in lower left quadrant), and late apoptosis was indicated by the double-annexin-V-PE/7-AAD positive cells in upper right quadrant. Data are represented as a typical graph of three separate experiments. B. Cell viability was counted by using trypan blue exclusion assay. Data are presented as mean $\pm \mathrm{SD}$ of six separate experiments. TEC-CLU ${ }^{\text {hCLU }}$ vs. TEC-CLU ${ }^{-/-}, \mathrm{P}=0.0005$ (two-tailed $t$-test) 
Table 3.5 Cell death/survival pathways associated with clusterin expression in tubular epithelial cells in hypoxia

\begin{tabular}{|c|c|c|c|}
\hline Canonical Pathway & $-\log (p$ value) & Up regulated genes & Down regulated genes \\
\hline PI3K/AKT signaling & 8.0 & $\begin{array}{l}\text { NFKBIB,MAPK1,FOXO3,TSC1,PPM1L,THEM4,PIK3CD,NOS3,N } \\
\text { ANOG,PPP2R2B }\end{array}$ & PRKCZ,SFN,PTGS2,JAK3,ITGB1,IKBKB,RRAS2,YWHAZ,MRAS \\
\hline HIF a signaling & 7.5 & MAPK1,MAPK9,MAPK15,ARNT,MMP7,NOS2,PIK3CD,NOS3 & MAPK13,SLC2A3,MMP13,EDN1,PGF,MMP14,SLC2A1,RRAS2,MARS \\
\hline VEGF signaling & 6.5 & MAPK1, ARNT,FOXO3,PIK3CD,FLT1,NOS3 & PLCG2,SFN,FLT4,PTK2B,PTPN6,PGF,VCL,RRAS2,MRAS \\
\hline PTEN signaling & 5.5 & MAPK1, FOXO3,PIK3CD,FLT1,FGFR4,FGFR1 & FOXG1,PRKCZ,FLT4,RAC3,NGFR,ITGB1 FGFR3,IKBKB,RRAS2,MRAS \\
\hline ERK/MAPK signaling & 5.3 & MAPK1, PPM1L,PAK3,PIK3CD,PPP2R2B,DUSP9 & $\begin{array}{l}\text { PLA2G4A,PLCG2,PAK6,PTK2B,HSPB1,,PRKCD,RRAS2,YWHAZ,MRAS } \\
\text { PPP1R14D,MYCN,RAC3,ELF3,ITGB1 }\end{array}$ \\
\hline $\begin{array}{l}\text { STAT3 } \\
\text { Myc mediated apoptosis } \\
\text { signaling }\end{array}$ & $\begin{array}{l}5.0 \\
3.7\end{array}$ & $\begin{array}{l}\text { MAPK1,MAPK9, FLT1,FGFR4,FGFR1 } \\
\text { MAPK9,IGF1,PIK3CD,FAS }\end{array}$ & $\begin{array}{l}\text { MAPK13,FLT4,PTPN6,NGFR,FGFR3, RRAS2,MRAS } \\
\text { PRKCZ, SFN,RRAS2,YWHAZ,MRAS }\end{array}$ \\
\hline ERK5 signaling & 3.5 & IL6ST,FOXO3,EGF & PRKCZ,SFN, CTF1,RRAS2,YWHAZ,MRAS \\
\hline JAK/STAT signaling & 2.5 & MAPK1,STAT5B,STAT5A,PIK3CD & PTPN6,JAK3,RRAS2,MRAS \\
\hline $\begin{array}{l}\text { Endoplasmic Reticulum } \\
\text { Stress }\end{array}$ & 2.4 & DDIT3,ERN1,MAP3K5,XBP1 & - \\
\hline $\begin{array}{l}\text { Unfolded Protein } \\
\text { Response }\end{array}$ & 2.0 & DDIT3, CEBPD,PPP1R15A,XBP1,ERN1,MAP3K5 & - \\
\hline SAPK/JNK signaling & 2.0 & MAPK9, MAP3K5,MAP4K1,PIK3CD & GNG2,RAC3,RRAS2,MRAS \\
\hline AMPK signaling & 1.7 & MAPK1,TSC1,PPM1L,PIK3CD,AK5,NOS3,PPP2R2B & MAPK13,SLC2A1,MRAS \\
\hline Death Receptor signaling & 1.5 & NFKBIB, MAP3K5,TNFSF12,FAS & HSPB1,CFLAR,IKBKB \\
\hline
\end{tabular}




\subsection{Interaction between genes mediating clusterin functions}

IPA was used to identify differentially expressed genes mediating specific clu functions (cell survival/death, proliferation, cell cycle and migration). Additionally, String database (http://string-db.org/) was used to map all these genes into a functional network based on known and predicted protein-protein interactions. Our conducted networks showed strong interactions and associations between these genes and most remarkable interactions were with AKT2, GSK3 $\beta, C R E B 1, P A K 3$, FGFRlunder normoxia (Figure 3.9, 3.10, 3.11, and 3.12). However, FOXO3, PTGS2, NO3, ERN1 and XPB1were also shown a strong interaction with other genes regulated by CLU under hypoxia (Figure 3.13).

In summary, based on our canonical pathways and networks analyses, the dominant genes were found to be affected and up-regulated by CLU were AKT2, GSK3 $\beta$, PAK3, while FOXO3 was a dominant gene was influenced by CLU and hypoxia. As shown in (Table 3.15), these genes were notably involved to regulate the most significant pathways as well as many pathways. This finding suggested the important role of candidate genes as key genes regulated by CLU and mediating cell functions. 


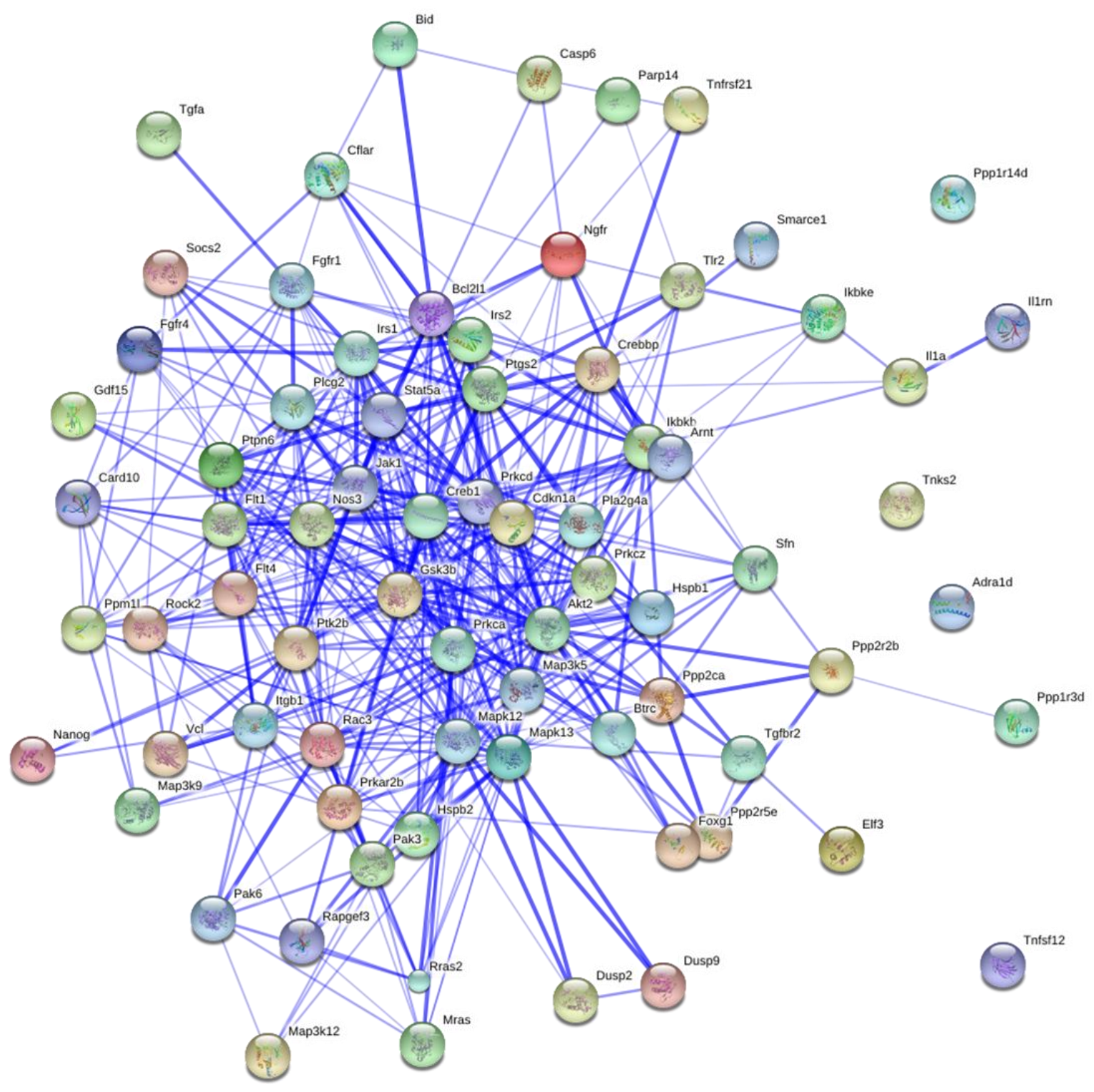

Figure 3.9 Network analysis of genes mediating clusterin cell survival function in normoxia

Networks generated using String software. Interactions between key genes(genes involved in many pathways) in normoxia can be visualized. Additional interaction between other protein can be visualized at the same time. Node colors have no meaning while thicker lines between the nods represent stronger association. 


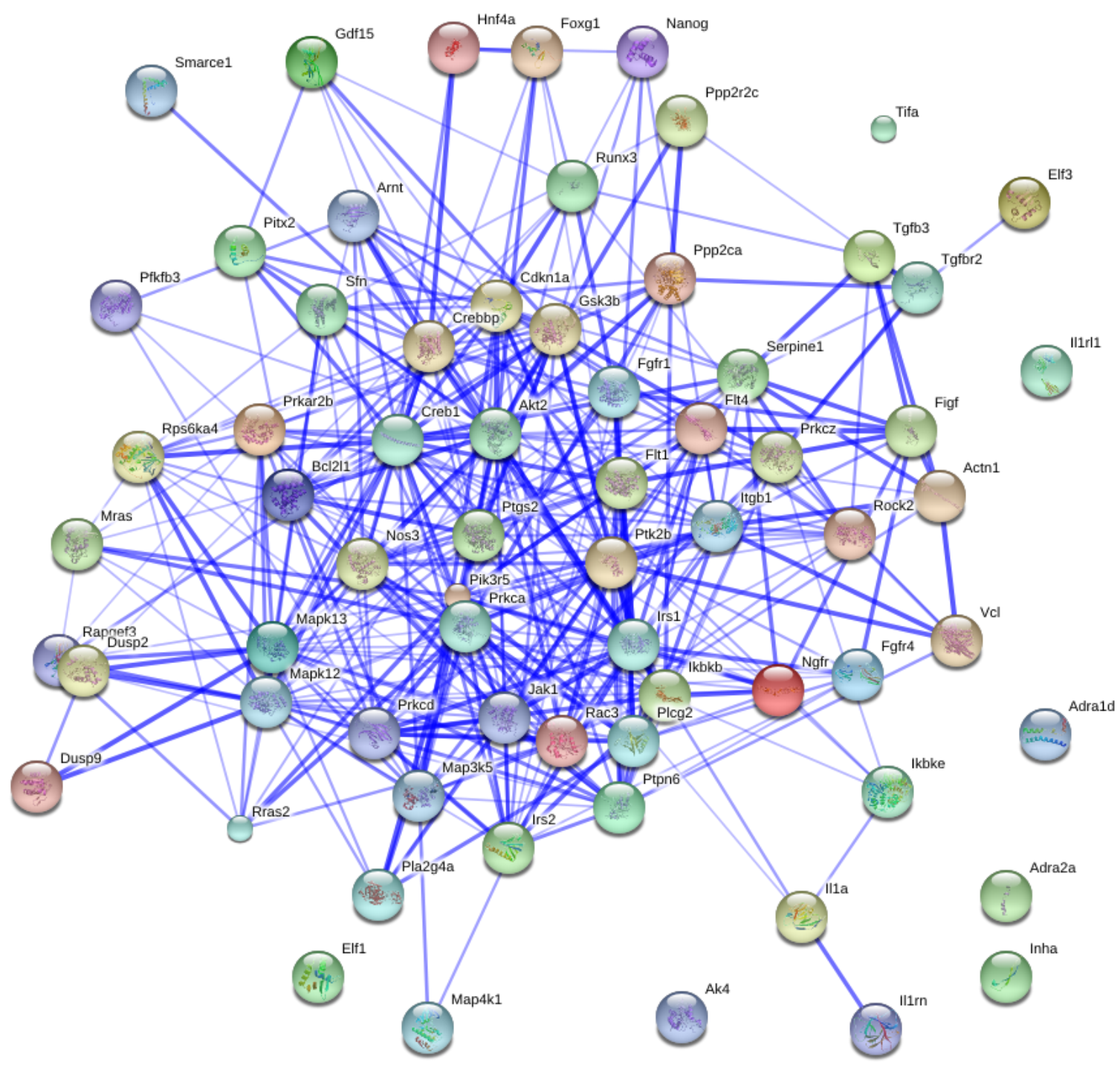

Figure 3.10 Network analysis of genes mediating clusterin cell prolifration function in normoxia 


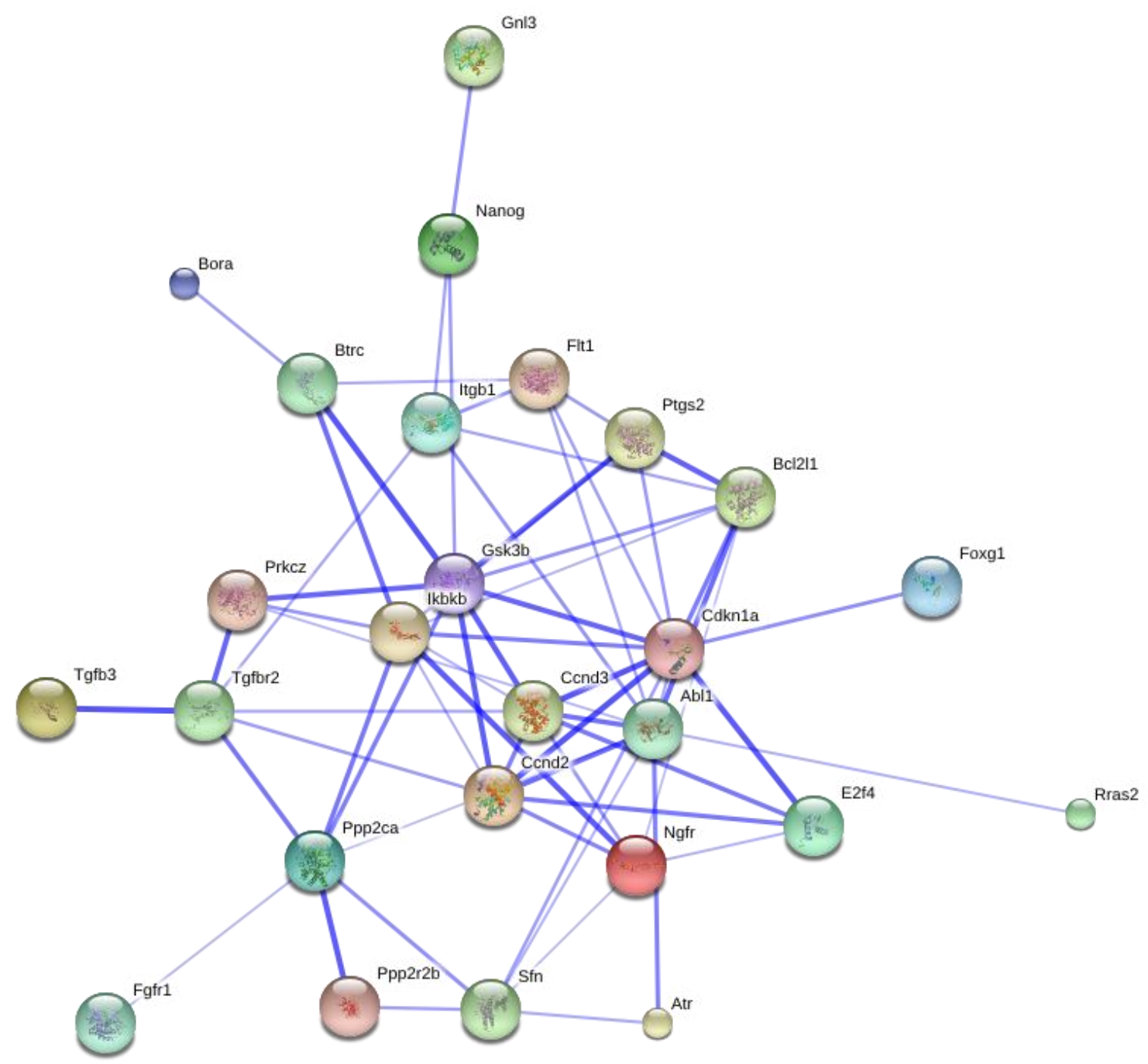

Figure 3.11 Network analysis of genes mediating clusterin cell cycle function in normoxia 


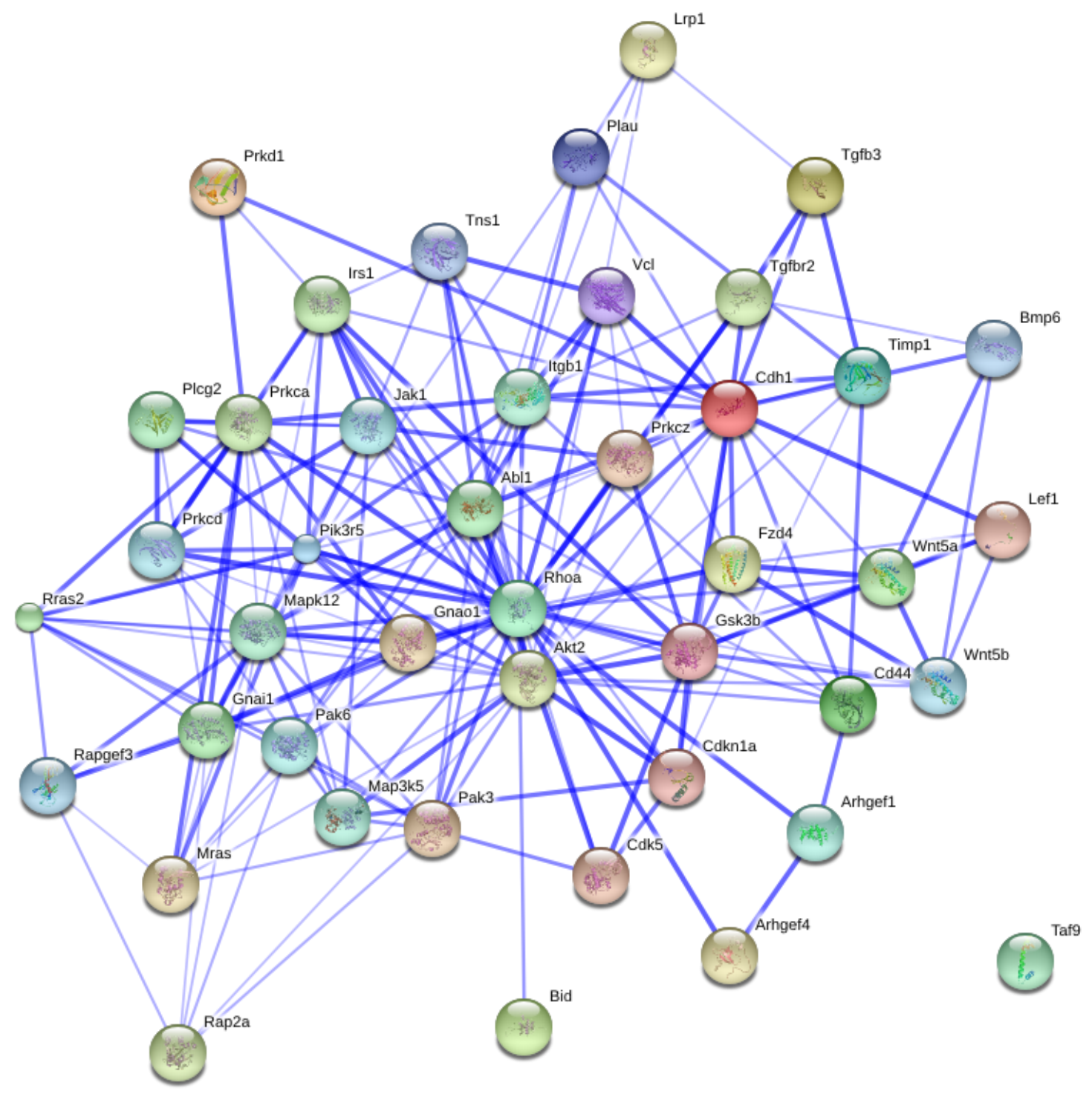

Figure 3.12 Network analysis of genes mediating clusterin cell migration function in normoxia 


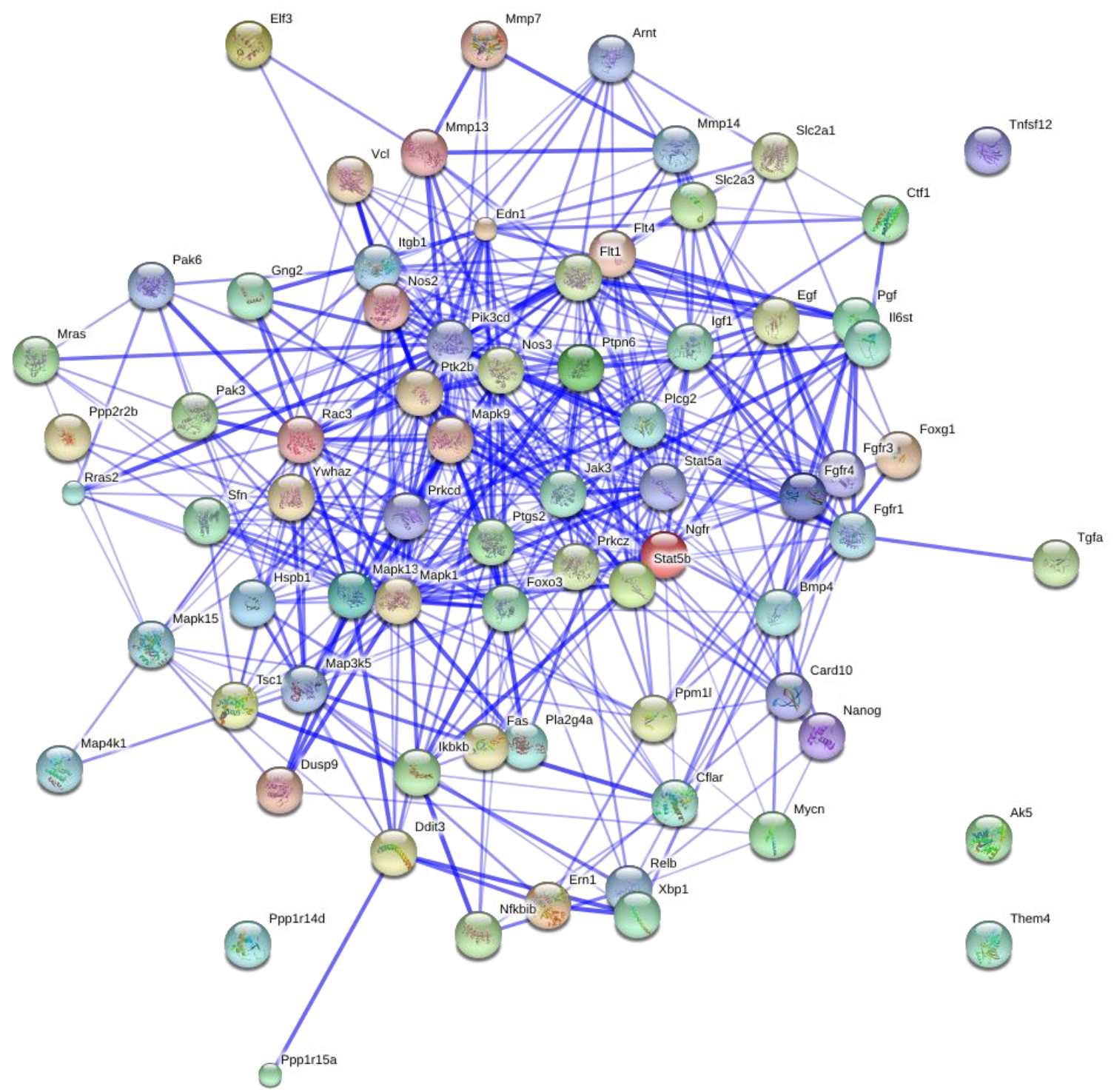

Figure 3.13 Network analysis of genes mediating clusterin cell survival function in hypoxia 


\subsection{Validation of protein product from selected genes}

For confirmation of selected dominant genes including AKT2 and GSK3B Western blot analysis of the protein expression of these genes was performed (see materials and methods).

As shown in Figure 3.14, protein expression of AKT2 and GSK3B and was significantly higher in TEC-CLU ${ }^{\mathrm{hCLU}}$ compared with those in TEC-CLU ${ }^{-/-}$under normal condition. Overall, there was an agreement between the microarray gene expression data and the western blot results. 


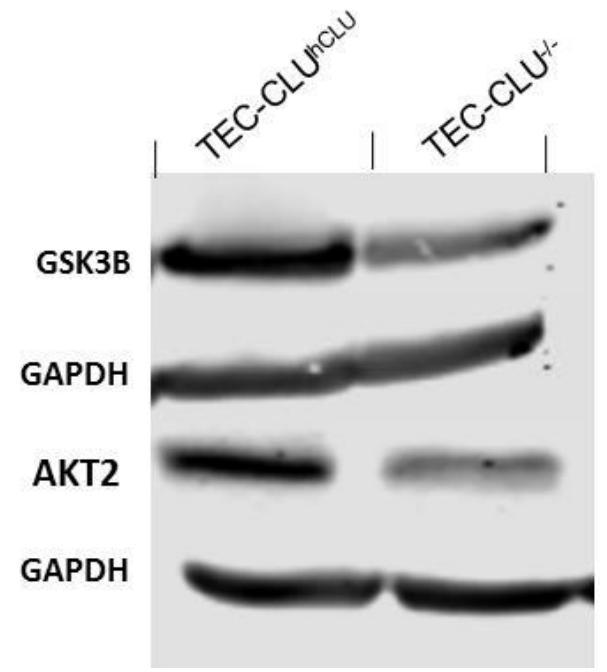

Figure 3.14 Confirmation of selected genes by western blot

Selected genes from microarray were verified by western blot. The expression of AKT2 and GSK3B proteins under normoxia in protein extracts of (TEC-CLU ${ }^{\text {hCLU }}$ vs. TEC-CLU ${ }^{-/-}$) was determined by Western blot analysis. GAPDH protein was reprobed with the antibodies on the same blot. 


\section{Chapter 4: Discussion and conclusion}

AKI is a common hospitalized problem, particularly among ICU patients, and is associated with a high rate of mortality and morbidity ${ }^{5}$. It can be caused by many insults, one of which is $\mathrm{IRI}^{97,98}$. IRI is defined as a sudden decrease in renal arterial blood pressure results in renal tissue hypoxia (deoxygenation), and following by reoxygenation (reperfusion) ${ }^{99}$. Up to date, the pathophysiological mechanisms of ischemic AKI are not well defined. There is no doubt nowadays that up-regulation of CLU in the kidney mediates resistance against IRI ${ }^{6}$. Thus, the understanding of molecular pathways by which CLU protects the kidney from IRI and rank those pathways may lead to the development of novel strategies to reduce the incidence of AKI and its related kidney disease in our community.

Our previous studies have demonstrated that compared to CLU KO mice, CLU-expressing mice are more resistant to renal IRI ${ }^{6}$, and kidneys from these mice are repaired or recovered faster after IRI ${ }^{7}$. In cultured TEC, both the present study and our previous study ${ }^{7}$ have shown that ectopic expression of CLU in TECs increases cell survival or reduces apoptosis, restores the progression of the cell cycle to promote cell proliferation and inhibits cell migration, an important function of CLU involved in the resistance to IRI and the improvement of tissue repair. The present study builds on our previous investigation using the same in vitro

experimental system - TECs ${ }^{7}$, and aims to explore the signaling pathways influenced by CLU expression under both hypoxia and normoxia. The signaling pathways mediating the cytoprotective activity of CLU has been studied using biochemical methods in different experimental systems, such as CLU inhibits cell apoptosis by interacting with BAX or 
GRP78 ${ }^{100-102}$, or promotes cell survival by activating Akt and NF- $\kappa \mathrm{B}$ pathway ${ }^{79,103}$ and prosurvival autophagy ${ }^{96}$. Previous study has determinted that that CLU can interact with GRP78, ER chaperon, in response to ER stress ${ }^{100}$. This interaction has been linked to sCLU re-translocation into cytosol and mediation of anti-apoptotic effects ${ }^{100}$. Here, we hypothesized that using transcriptome profile combined with bioinformatics tools would help us to understand more about the molecular pathways in the kidney for the cytoprotective effects of CLU. Microarray assay has been commonly used in multi different research fields to study the gene expression ${ }^{84}$, and this technique provides a wide image of the transcriptional activity in a biological sample, which may allow us to analyze the pathways specific for CLU functions in kidney cells on a large scale.

Cells in culture in a $5 \% \mathrm{CO}_{2}$ incubator (normoxia) are exposed to $20-21 \%$ of atmospheric oxygen that is much higher than that in arterial blood of the kidney $(4-12 \%)^{104,105}$, suggesting that cultured kidney cells in normoxia are under sublethal oxidative stress ${ }^{106}$. CLU expression in TECs enhanced cell survival and proliferation as well as suppressed cell migration under this normoxic condition ${ }^{7}$ (Fig. 3A, Fig. 4A and Fig.5A). IPA analysis revealed that the functions of CLU in TECs against the sublethal oxidative stress were mostly associated with AKT2 and/or GSK3B-dependent pathways, such as PI3k/AKT and PTEN signaling, and AKT2 and/or GSK3B-independent ERK/MAPK signaling. PI3K/AKT pathways are considered as a main signaling transduction pathways regulating cell survival, cell proliferation, cell migration as well as cell cycle ${ }^{107}$. Activation of this pathway has been reported to increase the cell survival by directly targeting the pro-apoptotic Bcl-2 related protein, Foxo through AKT, an principal mediator ${ }^{108}$. Also, increasing evidence supports a 
key roles of PI3K/AKT pathways in G1/S cell cycle progression through inactivation of GSK3B and inhibition of Foxo and increasing of Cyclin $\mathrm{D}^{109,110}$. Indeed, Our data in this study may be in agreement with evidence from literature, showing that the anti-apoptosis of CLU in TNF- $\alpha, \mathrm{H}_{2} \mathrm{O}_{2}$ or chemo-treated cells is mediated by activation of PI3k/AKT/GSK3B signaling ${ }^{78,79,111}$, and as well by ERK1/2 pathway ${ }^{111,112}$.

After prolongation of reduced $\mathrm{O}_{2}$ supply - hypoxia, cells activate adapting mechanisms for survival, including decreasing cellular ATP demand ${ }^{113}$, and the hypoxia-inducible factor (HIF) 1 , a heterodimer of HIF-1 $\beta$ (constitutively expressed) and HIF-1 $\alpha\left(\mathrm{O}_{2}\right.$-regulated), is a primary factor for these adapting mechanisms ${ }^{114}$. Hypoxia up-regulates CLU expression in kidney cells ${ }^{96}$ or tenocytes ${ }^{115}$, and HIF-1 binding hypoxia response elements (HRE) are identified in the CLU gene promoter ${ }^{63}$, suggesting that up-regulation of CLU may be part of survival mechanisms of cells in hypoxia. Indeed, our previous study has demonstrated that CLU expression is required for activation of prosurvival autophagy in the kidneys after IRI, and in cultured kidney cells in hypoxia that is associated with $\mathrm{UPR}^{96}$. Consistently, IPA analysis in current study also showed that as compared to CLU null controls, exclusive upregulation of UPR/ER stress-related transcripts was seen in TEC-CLU ${ }^{\text {hCLU }}$ cells (Table 5). The novel findings in this study were that in addition to this UPR-associated prosurvival autophagy as demonstrated previously ${ }^{96}$, which was confirmed by this study, CLU expression may also activated PIK3CD/MAPK1/Foxo3a-dependent signaling pathways, including HIF- $\alpha$, PI3K/AKT, VEGF, PTEN and ERK/MAPK signaling, which may together facilitate cell survival in hypoxia. A strong body of evidence has shown that induction of hypoxia in fibroblasts as well as breast cancer cells activates Foxo3a in a HIF 1-dependent 
manner to mediate cell survival ${ }^{116}$. In addition, another study has shown that Foxo3a, a transcription factor, plays a vital role in inducing or activating the expression of autophagy related genes (Atg) to mediate a cellular resistance under starvation ${ }^{117}$. In our IPA results, Foxo3 transcript was up regulated in $\mathrm{CLU}^{\mathrm{hCLU}}$ cells compare to $\mathrm{CLU}^{-/-}$under hypoxia (table5).

In conclusion, the CLU expression in kidney cells promotes cell survival and proliferation, but inhibits cell migration under either sublethal oxidative stress (normoxia) or hypoxia. Despite the limitation of sample size and the experimental time point as well as the need of detailed mechanistic of CLU expression on kidney TECs, this study illustrates that there is a complicated cascade network mediating the functions of CLU in the kidney TECs Figure.4.1, including AKT2/GSK3B -dependent PI3K/AKI, PTEN, VEGF and ERK/MAPK signaling in normoxia, and both UPR/ER stress and PIK3CD/MAPK1/FOXO3-dependent pathways (PI3K/AKI, HIF- $\alpha$, PTEN, VEGF and ERK/MAPK signaling) in hypoxia. Further studies of these pathways, especially in the kidney with IRI, are strongly needed and may provide a new strategy to reduce or prevent AKI. 
$\begin{array}{llllll}1 & 2 & 3 & 4 & 5 & \text { CLU functions : }\end{array}$

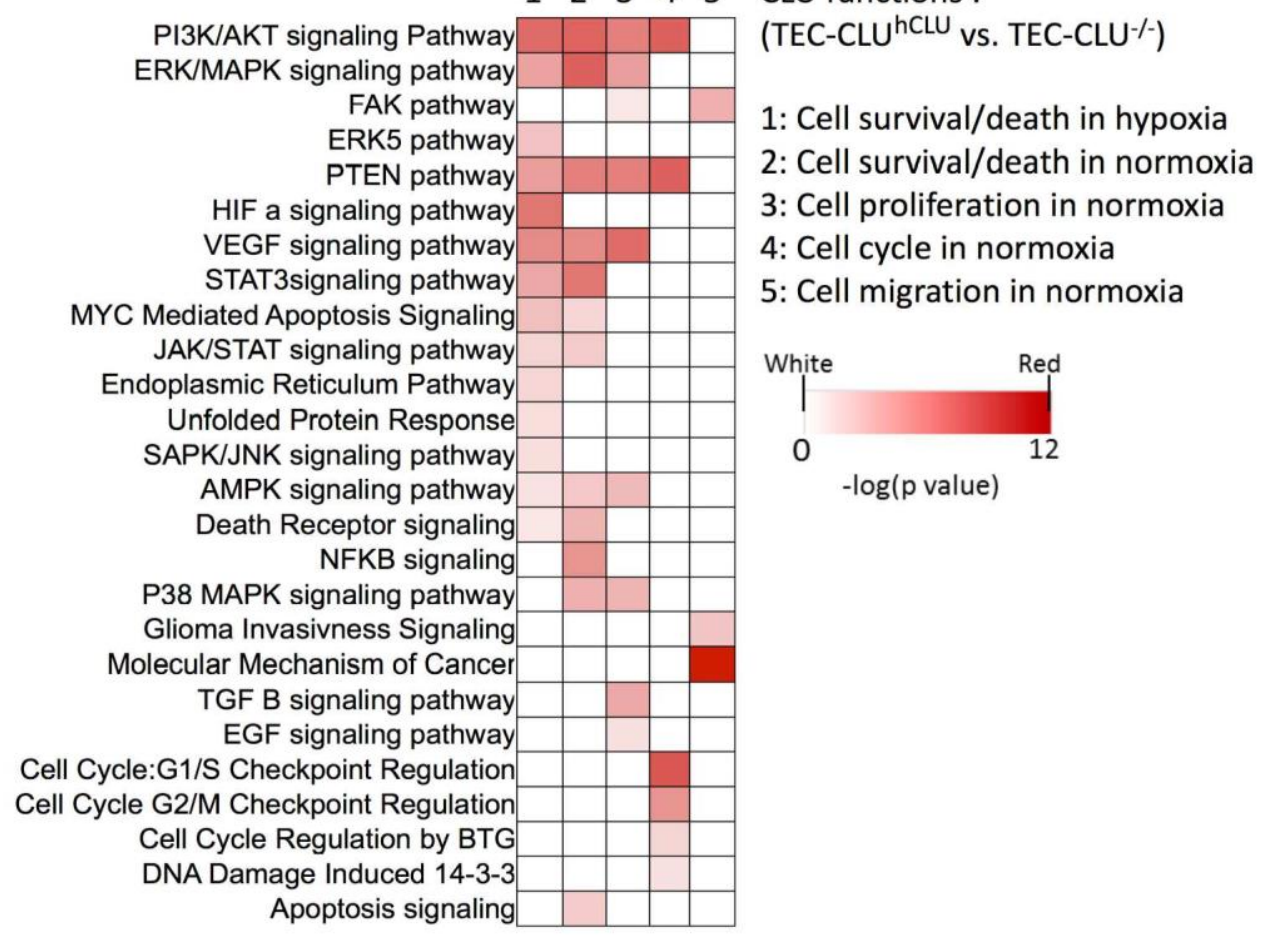

Figure 4.1 Association of clusterin functions with signaling pathways in TECs 


\section{Chapter 5: Questions for next studies}

Due to the wide range of transcriptome data generates by microarray, it has been used as a tool that assists to generate research hypothesis rather than to approve $\mathrm{it}^{85}$. From this point of view and based on our transcriptome data our next research hypothesis is illustrated in Figure.5.1.

Our next hypothesis is that up-regulation of retro-translocated sCLU in kidney cells in normoxia or sublethel condition to mediate cell survival, cell proliferation (cell cycle progression) and inhibit cell migration may be through PI3K-AKT. Our data shows that AKT2 and GSK3B may be commonly up-regulated in CLU-expressing TEC-CLU ${ }^{\text {hCLU }}$ cells compared with those CLU null TEC-CLU ${ }^{-/}$cells. So that whether or not sCLU mediates the cell survival through activation and phosphorylation of AKT/PI3K pathway in kidney TECs is not known, which still needs to be studied and confirmed. In contrast, up-regulation of sCLU under hypoxia has been associated with cell survival. Interestingly, our data shows that Foxo3and IRE1 mRNA were commonly up-regulated in TEC-CLU ${ }^{\text {hCLU }}$. So that whether or not the up regulation of sCLU under hypoxia mediates cell survival through activation of Foxo3-induced autophagy pathway is not known, which remains further investigation. 


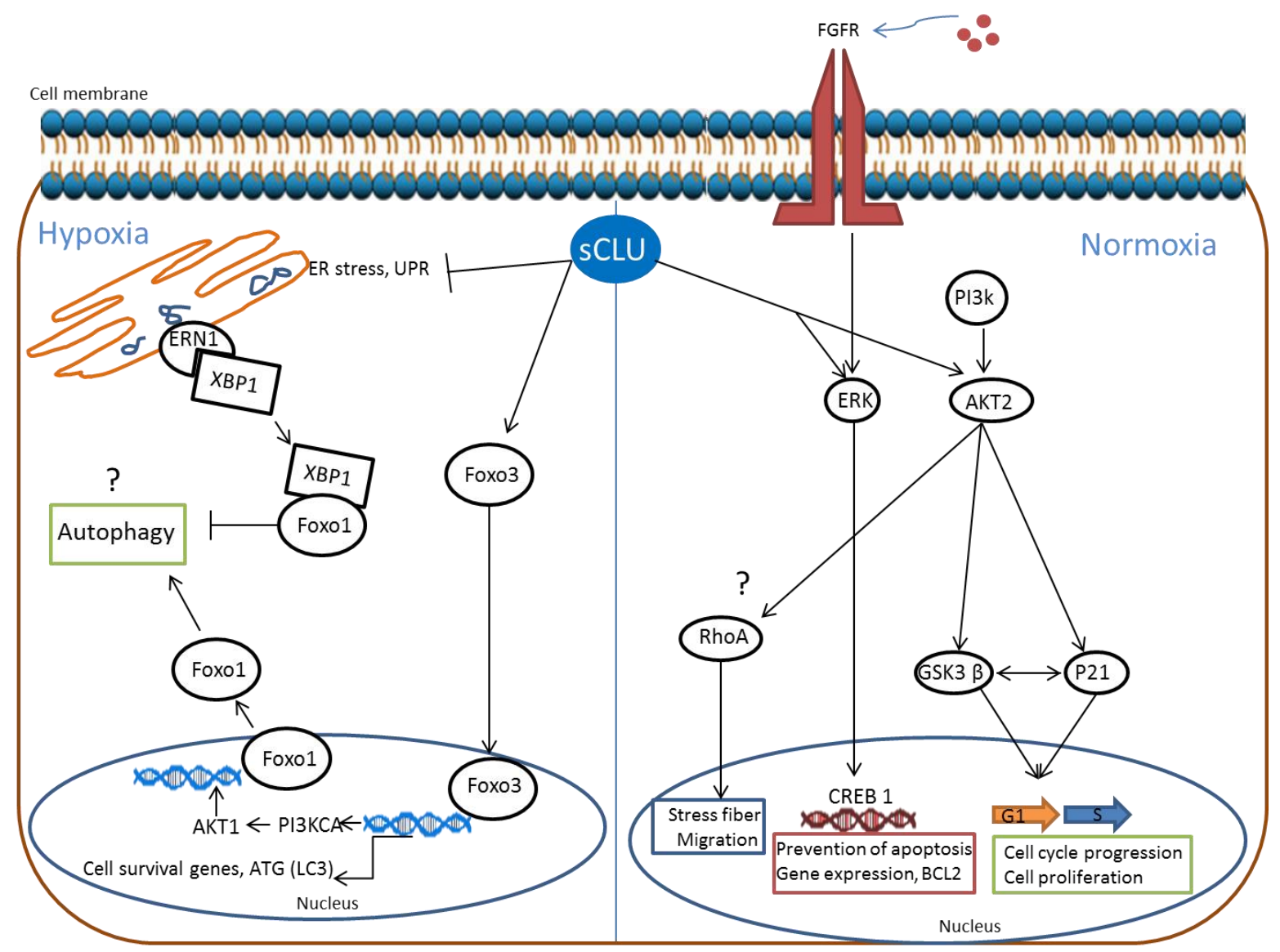

Figure 5.1 Schematic of next research hypothesis

Up regulation of sCLU under normoxia condition may activate Akt/PI3K signaling cascadesin kidney TECs to mediate cell cycle progression from G1to $\mathrm{S}$ phase through phosphorylation and inhibition of GSK3B and P21and cell migration inhibition by inhibite RhoA. As well as phosphorylation of ERK signaling pathways that leads to cell survival. In contrast, up regulation of sCLU inhibits ER stress and UPR in addition to activate Foxo3. Phosphorylated Foxo3 translocate to the nucleus and activates autophagy related gene (ATG) and Foxo1-induced autophagy. 


\section{Bibliography}

1. Semenza GL. HIF-1: mediator of physiological and pathophysiological responses to hypoxia. J Appl Physiol. 2000;88(4):1474-1480.

doi:10.1152/japplphysiol.00373.2011.

2. Kalogeris T, Baines CP, Krenz M, Korthuis RJ. Cell Biology of Ischemia/Reperfusion Injury. Vol 298.; 2012. doi:10.1016/B978-0-12-394309-5.00006-7.Cell.

3. Le Dorze M, Legrand M, Payen D, Ince C. The role of the microcirculation in acute kidney injury. Curr Opin Crit Care. 2009;15(6):503-508. doi:10.1097/MCC.0b013e328332f6cf.

4. Liaño F, Pascual J. Epidemiology of acute renal failure: a prospective, multicenter, community-based study. Madrid Acute Renal Failure Study Group. Kidney Int. 1996;50:811-818.

5. Ali T, Khan I, Simpson W, et al. Incidence and outcomes in acute kidney injury: a comprehensive population-based study. JAmSocNephrol. 2007;18:1292-1298.

6. Zhou W, Guan Q, Kwan CCH, et al. Loss of clusterin expression worsens renal ischemia-reperfusion injury. Am J Physiol Renal Physiol. 2010;298(30):F568-F578. doi:10.1152/ajprenal.00399.2009.

7. Nguan CYC, Guan Q, Gleave ME, Du C. Promotion of cell proliferation by clusterin in the renal tissue repair phase after ischemia-reperfusion injury. Am J Physiol Renal Physiol. 2014;306(7):F724-F733. doi:10.1152/ajprenal.00410.2013.

8. Bruce M. Carlson. Saint Louis Mosby. Human Embryology and Developmental Biology. 3rd ed.; 2004. 
9. Gerard J. Tortora BHD. Principles Of Anatomy And Physiology. 12th ed.; 2008.

10. Mehta RL, Kellum J a, Shah S V, et al. Acute Kidney Injury Network: report of an initiative to improve outcomes in acute kidney injury. Crit Care. 2007;11(2):R31. doi:10.1186/cc5713.

11. Bonventre J V, Yang L. Cellular pathophysiology of ischemic acute kidney injury. $J$ Clin Invest. 2011;121(11):4210-4221. doi:10.1172/JCI45161.

12. Wald R, Quinn RR, Luo J, et al. Chronic dialysis and death among survivors of acute kidney injury requiring dialysis. JAMA. 2009;302(11):1179-1185. doi:10.1001/jama.2009.1322.

13. Coca SG, Singanamala S, Parikh CR. Chronic kidney disease after acute kidney injury: a systematic review and meta-analysis. Kidney Int. 2012;81(5):442-448. doi:10.1038/ki.2011.379.

14. Triverio P-A, Martin P-Y, Romand J, Pugin J, Perneger T, Saudan P. Long-term prognosis after acute kidney injury requiring renal replacement therapy. Nephrol Dial Transplant. 2009;24(7):2186-2189. doi:10.1093/ndt/gfp072.

15. Pannu N, Gibney RN. Renal replacement therapy in the intensive care unit. Ther Clin Risk Manag. 2005;1(2):141-150. doi:10.2147/tcrm.1.2.141.62908.

16. Waikar SS, Wald R, Chertow GM, et al. Validity of International Classification of Diseases, Ninth Revision, Clinical Modification Codes for Acute Renal Failure. J Am Soc Nephrol. 2006;17(6):1688-1694. doi:10.1681/ASN.2006010073.

17. Uchino S, Bellomo R, Goldsmith D, Bates S, Ronco C. An assessment of the RIFLE criteria for acute renal failure in hospitalized patients. Crit Care Med. 2006;34(7):1913-1917. doi:10.1097/01.CCM.0000224227.70642.4F. 
18. Lafrance JP, Miller DR. Defining acute kidney injury in database studies: The effects of varying the baseline kidney function assessment period and considering CKD status. Am J Kidney Dis. 2010;56(4):651-660. doi:10.1053/j.ajkd.2010.05.011.

19. Fang Y, Ding X, Zhong Y, et al. Acute kidney injury in a chinese hospitalized population. Blood Purif. 2010;30(2):120-126. doi:10.1159/000319972.

20. Hoste E a J, Clermont G, Kersten A, et al. RIFLE criteria for acute kidney injury are associated with hospital mortality in critically ill patients: a cohort analysis. Crit Care. 2006;10(3):R73. doi:10.1186/cc4915.

21. Thakar C V, Christianson A, Freyberg R, Almenoff P, Render ML. Incidence and outcomes of acute kidney injury in intensive care units: a Veterans Administration study. Crit Care Med. 2009;37(9):2552-2558. doi:10.1097/CCM.0b013e3181a5906f.

22. Goldberg R, Dennen P. Long-Term Outcomes of Acute Kidney Injury. Adv Chronic Kidney Dis. 2008;15(3):297-307. doi:10.1053/j.ackd.2008.04.009.

23. Sancho-Martínez SM, López-Novoa JM, López-Hernández FJ. Pathophysiological role of different tubular epithelial cell death modes in acute kidney injury. Clin Kidney J. 2015;8(5):548-559. doi:10.1093/ckj/sfv069.

24. Kaufman J, Dhakal M, Patel B, Hamburger R. Community-acquired acute renal failure. Am J Kidney Dis. 1991;17(2):191-198. http://www.ncbi.nlm.nih.gov/pubmed/1992662.

25. Bonegio R, Lieberthal W. Role of apoptosis in the pathogenesis of acute renal failure. Curr Opin Nephrol Hypertens. 2002;11(3):301-308.

26. Havasi A, Borkan SC. Apoptosis and acute kidney injury. doi:10.1038/ki.2011.120.

27. Eltzschig HK, Eckle T. Ischemia and reperfusion - from mechanism to translation. 
Nat Med. 2011;17(11):1391-1401. doi:10.1038/nm.2507.

28. Al-Awqati Q, Oliver JA. Stem cells in the kidney. Kidney Int. 2002;61(2):387-395. doi:10.1046/j.1523-1755.2002.00164.x.

29. Lieberthal W, Rennke HG, Sandock KM, Valeri CR, Levinsky NG. Ischemia in the isolated erythrocyte-perfused rat kidney. Protective effect of hypothermia. Ren Physiol Biochem. 1988;11(1-2):60-69.

http://www.ncbi.nlm.nih.gov/entrez/query.fcgicmd=Retrieve \&db=PubMed\&dopt=Cit ation\&list_uids=3249834.

30. BA. M. Acute renal failure. Drugs Today (Barc). 1999;35:659-66([PubMed: 12973464]).

31. Kosieradzki M, Rowiński W. Ischemia/Reperfusion Injury in Kidney Transplantation: Mechanisms and Prevention. Transplant Proc. 2008;40(10):3279-3288. doi:10.1016/j.transproceed.2008.10.004.

32. Sugiyama S, Hanaki Y, Ogawa T, Hieda N, Taki K, Ozawa T. The effects of sun 1165, a novel sodium channel blocker, on ischemia-induced mitochondrial dysfunction and leakage of lysosomal enzymes in canine hearts. Biochem Biophys Res Commun. 1988;157(2):433-439. doi:10.1016/S0006-291X(88)80267-5.

33. K. Kako, M. Kato, T. Matsuoka AM. Depression of membrane-bound Na+-K+ATPase activity induced by free radicals and by ischemia of kidney. Am J Physiol Cell Physiol. 254 (2)(C330-C337).

34. Javadov S, Hunter JC, Barreto-Torres G, Parodi-Rullan R. Targeting the mitochondrial permeability transition: Cardiac ischemia-reperfusion versus carcinogenesis. Cell Physiol Biochem. 2011;27(3-4):179-190. doi:10.1159/000327943. 
35. Saikumar P, Venkatachalam $\mathrm{M}$ a. Role of apoptosis in hypoxic/ischemic damage in the kidney. Semin Nephrol. 2003;23(6):511-521. doi:10.1053/S0270-9295(03)00130X.

36. Hotchkiss RS, Strasser A, McDunn JE, Swanson PE. Cell death. N Engl J Med. 2009;361(16):1570-1583. doi:361/16/1570 [pii]ไr10.1056/NEJMra0901217.

37. Rosen S, Heyman SN. Difficulties in understanding human "acute tubular necrosis": Limited data and flawed animal models. Kidney Int. 2001;60(4):1220-1224. doi:10.1046/j.1523-1755.2001.00930.x.

38. Kelly KJ. P53 Mediates the Apoptotic Response to GTP Depletion after Renal Ischemia-Reperfusion: Protective Role of a p53 Inhibitor. J Am Soc Nephrol. 2003;14(1):128-138. doi:10.1097/01.ASN.0000040596.23073.01.

39. Weinberg JM, Venkatachalam MA. Guanine nucleotides and acute renal failure. 2001;108(9):1279-1281. doi:10.1172/JCI200114320.Sustained.

40. Zamzami N, Kroemer G. The mitochondrion in apoptosis: how Pandora's box opens. Nat Rev Mol Cell Biol. 2001;2(1):67-71. doi:10.1038/35048073.

41. Wang Y, Knowlton AA, Christensen TG, Shih T, Borkan SC. Prior heat stress inhibits apoptosis in adenosine triphosphate-depleted renal tubular cells. Kidney Int. 1999;55(6):2224-2235. doi:10.1046/j.1523-1755.1999.00476.x.

42. Wei Q, Yin X-M, Wang M-H, Dong Z. Bid deficiency ameliorates ischemic renal failure and delays animal death in C57BL/6 mice. Am J Physiol Renal Physiol. 2006;290(1):F35-F42. doi:10.1152/ajprenal.00184.2005.

43. Vanden Berghe T, Linkermann A, Jouan-Lanhouet S, et al. Regulated necrosis: the expanding network of non-apoptotic cell death pathways. Nat Rev Mol Cell Biol. 
2014;15(2):135-147. doi:10.1038/nrm3737.

44. Zhao J, Jitkaew S, Cai Z, et al. Mixed lineage kinase domain-like is a key receptor interacting protein 3 downstream component of TNF-induced necrosis. Proc Natl Acad Sci U S A. 2012;109(14):5322-5327. doi:10.1073/pnas.1200012109.

45. Linkermann A, Green DR. Necroptosis. N Engl J Med. 2014;370(5):455-465. doi:10.1056/NEJMra1310050.

46. Vandenabeele P, Declercq W, Van Herreweghe F, Vanden Berghe T. The role of the kinases RIP1 and RIP3 in TNF-induced necrosis. Sci Signal. 2010;3(115):re4. doi:10.1126/scisignal.3115re4.

47. Pasparakis M, Vandenabeele P. Necroptosis and its role in inflammation. Nature. 2015;517(7534):311-320. doi:10.1038/nature14191.

48. Linkermann A, Chen G, Dong G, Kunzendorf U, Krautwald S, Dong Z. Regulated Cell Death in AKI. J Am Soc Nephrol. 2014:1-13. doi:10.1681/ASN.2014030262.

49. Haase VH. Hypoxia-inducible factors in the kidney. Am J Physiol Ren Physiol. 2006;291(2):F271-F281. doi:10.1152/ajprenal.00071.2006.

50. Andringa KK. Role of Hypoxia-Inducible Factors in Acute Kidney Injury. 2014;35294:70-74. doi:10.1159/000363669.

51. Rizzi F, Coletta M, Bettuzzi S. Chapter 2 Clusterin (CLU). Vol 104. 1st ed. Elsevier Inc.; 2009. doi:10.1016/S0065-230X(09)04002-0.

52. Aronow BJ, Lund SD, Brown TL, Harmony J a, Witte DP. Apolipoprotein J expression at fluid-tissue interfaces: potential role in barrier cytoprotection. Proc Natl Acad Sci U S A. 1993;90(January):725-729. doi:10.1073/pnas.90.2.725.

53. Jones SE, Jomary C. Clusterin. Int J Biochem Cell Biol. 2002;34(5):427-431. 
doi:S1357272501001558 [pii].

54. Rizzi F, Bettuzzi S. The clusterin paradigm in prostate and breast carcinogenesis. Endocr Relat Cancer. 2010;17(1). doi:10.1677/ERC-09-0140.

55. Tobe T, Minoshima S, Yamase S, Choi NH, Tomita M, Shimizu N. Assignment of a human serum glycoprotein sp-40,40 gene (CLI) to chromosome 8. Cytogenet Genome Res. 1991;57(4):193-195. doi:10.1159/000133144.

56. Zoubeidi A, Chi K, Gleave M. Targeting the cytoprotective chaperone, clusterin, for treatment of advanced cancer. Clin Cancer Res. 2010;16(4):1088-1093. doi:10.1158/1078-0432.CCR-09-2917.

57. Prochnow H, Gollan R, Rohne P, Hassemer M, Koch-Brandt C, Baiersdörfer M. NonSecreted Clusterin Isoforms Are Translated in Rare Amounts from Distinct Human mRNA Variants and Do Not Affect Bax-Mediated Apoptosis or the NF- $\kappa B$ Signaling Pathway. PLoS One. 2013;8(9):1-15. doi:10.1371/journal.pone.0075303.

58. Leskov KS, Klokov DY, Li J, Kinsella TJ, Boothman DA. Synthesis and functional analyses of nuclear clusterin, a cell death protein. J Biol Chem. 2003;278(13):1159011600. doi:10.1074/jbc.M209233200.

59. Burkey BF, de Silva H V, Harmony JAK. Intracellular processing of apolipoprotein J precursor to the mature heterodimer. J Lipid Res. 1991;32(6):1039-1048.

60. Kapron JT, Hilliard GM, Lakins JN, et al. Identification and characterization of glycosylation sites in human serum clusterin. Protein Sci. 1997;6(10):2120-2133. doi:10.1002/pro.5560061007.

61. Nizard P, Tetley S, Le Dré An Y, et al. Stress-Induced Retrotranslocation of Clusterin/ApoJ into the Cytosol. Traffic. 2007;8:554-565. doi:10.1111/j.1600- 
0854.2007.00549.x.

62. Michel D, Chatelain G, North S, Brun G. Stress-induced transcription of the clusterin/apoJ gene. Biochem J. 1997;328 ( Pt 1:45-50.

63. Park J, Park SY, Shin E, et al. Hypoxia inducible factor-1 $\alpha$ directly regulates nuclear clusterin transcription by interacting with hypoxia response elements in the clusterin promoter. Mol Cells. 2014;37(2):178-186. doi:10.14348/molcells.2014.2349.

64. Jordan-Starck TC, Lund SD, Witte DP, et al. Mouse apolipoprotein J: characterization of a gene implicated in atherosclerosis. J Lipid Res. 1994;35(2):194-210.

65. Hatem A Alnasser QG. From Humans to Experimental Models: The Cytoprotective Role of Clusterin in the Kidney. Med Surg Urol. 2014;03(02). doi:10.4172/21689857.1000134.

66. Polihronis M, Paizis K, Carter G, Sedal L, Murphy B. Elevation of human cerebrospinal fluid clusterin concentration is associated with acute neuropathology. $J$ Neurol Sci. 1993;115(2):230-233. doi:10.1016/0022-510X(93)90230-V.

67. Choi-Miura NH, Oda T. Relationship between multifunctional protein "clusterin" and Alzheimer disease. Neurobiol Aging. 1996;17(5):717-722. doi:10.1016/S01974580(96)00106-6.

68. Dvergsten J, Manivel JC, Correa-Rotter R, Rosenberg ME. Expression of clusterin in human renal diseases. Kidney Int. 1994;45(3):828-835. doi:10.1038/ki.1994.109.

69. Fritz IB, Burdzy K, Sétchell B, Blaschuk O. Ram rete testis fluid contains a protein (clusterin) which influences cell-cell interactions in vitro. Biol Reprod. 1983;28(5):1173-1188. doi:10.1095/biolreprod28.5.1173.

70. Silkensen JR, Skubitz KM, Skubitz APN, et al. Clusterin promotes the aggregation 
and adhesion of renal porcine epithelial cells. J Clin Invest. 1995;96(6):2646-2653. doi:10.1172/JCI118330.

71. Murphy BF, Saunders JR, O’bryan MK, Kirszbaum L, Walker ID, D’apice AJF. SP40,40 is an inhibitor of C5b-6-initiated haemolysis. Int Immunol. 1989;1(5):551-554. doi:10.1093/intimm/1.5.551.

72. Tschopp J, Chonn A, Hertig S, French LE. Clusterin, the human apolipoprotein and complement inhibitor, binds to complement $\mathrm{C} 7, \mathrm{C} 8$ beta, and the b domain of C9. $J$ Immunol. 1993;151(4):2159-2165.

73. Jenne DE, Lowin B, Peitsch MC, Böttcher A, Schmitz G, Tschopp J. Clusterin (complement lysis inhibitor) forms a high density lipoprotein complex with apolipoprotein A-I in human plasma. J Biol Chem. 1991;266(17):11030-11036.

74. Karlsson H, Leanderson P, Tagesson C, Lindahl M. Lipoproteomics II: Mapping of proteins in high-density lipoprotein using two-dimensional gel electrophoresis and mass spectrometry. Proteomics. 2005;5(5):1431-1445. doi:10.1002/pmic.200401010.

75. Wyatt AR, Yerbury JJ, Berghofer P, et al. Clusterin facilitates in vivo clearance of extracellular misfolded proteins. Cell Mol Life Sci. 2011;68(23):3919-3931. doi:10.1007/s00018-011-0684-8.

76. Ma X, Bai Y. IGF-1 activates the P13K/AKT signaling pathway via upregulation of secretory clusterin. Mol Med Rep. 2012;6(6):1433-1437. doi:10.3892/mmr.2012.1110.

77. Santilli G, Aronowt BJ, Sala A. Essential Requirement of Apolipoprotein J (Clusterin) Signaling for IkB Expression and Regulation of NF- $\square$ B Activity*. 2003. doi:10.1074/jbc.C300252200.

78. Kim JH, Jun HO, Yu YS, Min BH, Park KH, Kim KW. Protective effect of clusterin 
from oxidative stress-induced apoptosis in human retinal pigment epithelial cells. Invest Ophthalmol Vis Sci. 2010;51:561-566. doi:10.1167/iovs.09-3774.

79. Ammar H, Closset JL. Clusterin activates survival through the phosphatidylinositol 3kinase/akt pathway. J Biol Chem. 2008;283(19):12851-12861. doi:10.1074/jbc.M800403200.

80. Graichen R, Lösch A, Appel D, Koch-Brandt C. Glycolipid-independent sorting of a secretory glycoprotein to the apical surface of polarized epithelial cells. J Biol Chem. 1996;271:15854-15857. doi:10.1074/jbc.271.27.15854.

81. Gobé GC, Buttyan R, Wyburn KR, Etheridge MR, Smith PJ. Clusterin expression and apoptosis in tissue remodeling associated with renal regeneration. Kidney Int. 1995;47(2):411-420. doi:10.1038/ki.1995.54.

82. Charnay Y, Imhof A, Vallet PG, et al. Clusterin expression during fetal and postnatal CNS development in mouse. Neuroscience. 2008;155(3):714-724. doi:10.1016/j.neuroscience.2008.06.022.

83. B. Alberts, A. Johnson, J. Lewis, K.Roberts M. Raff and PW. Molecular Biology of the Cell. Garland,

84. Allison DB, Cui X, Page GP, Sabripour M. Microarray data analysis: from disarray to consolidation and consensus. Nat Rev Genet. 2006;7(1):55-65. doi:10.1038/nrg1749.

85. Tarca AL, Romero R, Draghici S. Analysis of microarray experiments of gene expression profiling. Am J Obstet Gynecol. 2006;195(2):373-388. doi:10.1016/j.ajog.2006.07.001.

86. Kurella M, Hsiao LL, Yoshida T, et al. DNA microarray analysis of complex biologic processes. Jasn. 2001;12(5):1072-1078. 
87. Miller MB, Tang YW. Basic concepts of microarrays and potential applications in clinical microbiology. Clin Microbiol Rev. 2009;22(4):611-633. doi:10.1128/CMR.00019-09.

88. Iyer VR, Eisen MB, Ross DT, et al. The transcriptional program in the response of human fibroblasts to serum. 1999;283(5398):83-87.

89. DeRisi JL. Exploring the Metabolic and Genetic Control of Gene Expression on a Genomic Scale. Science (80- ). 1997;278(5338):680-686. doi:10.1126/science.278.5338.680.

90. MacPhee DJ. Methodological considerations for improving Western blot analysis. $J$ Pharmacol Toxicol Methods. 2010;61(2):171-177. doi:10.1016/j.vascn.2009.12.001.

91. Hosseini-Beheshti E, Pham S, Adomat H, Li N, Tomlinson Guns ES. Exosomes as Biomarker Enriched Microvesicles: Characterization of Exosomal Proteins Derived from a Panel of Prostate Cell Lines with Distinct AR Phenotypes. Mol Cell Proteomics. 2012;11(10):863-885. doi:10.1074/mcp.M111.014845.

92. Fang Y, Zhu X, Wang J, Li N, Li D, Sakib N. MiR-744 functions as a proto-oncogene in nasopharyngeal carcinoma progression and metastasis via transcriptional control of ARHGAP5. 2015;6(15):13164-13175.

93. Roshan Moniri M, Young A, Reinheimer K, Rayat J, Dai LJ, Warnock GL. Dynamic assessment of cell viability, proliferation and migration using real time cell analyzer system (RTCA). Cytotechnology. 2014:1-8. doi:10.1007/s10616-014-9692-5.

94. Ingenuity Pathway Analysis system.

95. Szklarczyk D, Franceschini A, Wyder S, et al. STRING v10: protein-protein interaction networks, integrated over the tree of life. Nucleic Acids Res. 
2015;43(Database issue):D447-D452. doi:10.1093/nar/gku1003.

96. Alnasser HA, Guan Q, Zhang F, Gleave M, Nguan CYC, Du C. Requirement of clusterin expression for prosurvival autophagy in hypoxic kidney tubular 1 epithelial cells 2 3. Am J Physiol Ren Physiol. 2015. doi:10.1152/ajprenal.00304.2015.

97. Wang HE, Muntner P, Chertow GM, Warnock DG. Acute kidney injury and mortality in hospitalized patients. Am J Nephrol. 2012;35(4):349-355. doi:10.1159/000337487.

98. Maioli M, Toso A, Leoncini M, Gallopin M, Musilli N, Bellandi F. Persistent renal damage after contrast-induced acute kidney injury: Incidence, evolution, risk factors, and prognosis. Circulation. 2012;125:3099-3107. doi:10.1161/CIRCULATIONAHA.111.085290.

99. Rajakumar S, Dwyer K. Ischaemia Reperfusion Injury in Kidney Transplantation. 1998.

100. Li N, Zoubeidi a., Beraldi E, Gleave ME. GRP78 regulates clusterin stability, retrotranslocation, and mitochondrial localization under ER stress in prostate cancer. Cancer Res. 2012;72(8 Supplement):3261-3261. doi:10.1158/1538-7445.AM20123261.

101. Wang C, Jiang K, Gao D, et al. Clusterin Protects Hepatocellular Carcinoma Cells from Endoplasmic Reticulum Stress Induced Apoptosis through GRP78. PLoS One. 2013;8(2):1-9. doi:10.1371/journal.pone.0055981.

102. Zhang H, Kim JK, Edwards C a, Xu Z, Taichman R, Wang C-Y. Clusterin inhibits apoptosis by interacting with activated Bax. Nat Cell Biol. 2005;7(9):909-915. doi:10.1038/ncb1291.

103. Zoubeidi A, Ettinger S, Beraldi E. Clusterin facilitates COMMD1 and I-kB 
degradation to enhance NF-kB activity in prostate cancer. Mol Cancer Res. 2011;8(1):119-130. doi:10.1158/1541-7786.MCR-09-0277.Clusterin.

104. Panchision DM. The role of oxygen in regulating neural stem cells in development and disease. J Cell Physiol. 2009;220(3):562-568. doi:10.1002/jcp.21812.

105. Ivanovic Z. Hypoxia or in situ normoxia: The stem cell paradigm. J Cell Physiol. 2009;219(2):271-275. doi:10.1002/jcp.21690.

106. Halliwell B. Oxidative stress in cell culture: An under-appreciated problem FEBS Lett. 2003;540(1-3):3-6. doi:10.1016/S0014-5793(03)00235-7.

107. Franke TF. PI3K/Akt: getting it right matters. Oncogene. 2008;27(50):6473-6488. doi:10.1038/onc.2008.313.

108. Downward J. PI 3-kinase, Akt and cell survival. Semin Cell Dev Biol. 2004;15(2):177182. doi:10.1016/j.semcdb.2004.01.002.

109. Liang J, Slingerland JM. Multiple Roles of the PI3K/PKB (Akt) Pathway in Cell Cycle Progression. Cell Cycle. 2003;2(4):336-342. doi:10.4161/cc.2.4.433.

110. Chang F, Lee JT, Navolanic PM, et al. Involvement of PI3K/Akt pathway in cell cycle progression, apoptosis, and neoplastic transformation: a target for cancer chemotherapy. Leukemia. 2003;17(3):590-603. doi:10.1038/sj.leu.2402824.

111. Zhang B, Zhang K, Liu Z, et al. Secreted Clusterin gene silencing enhances chemosensitivity of A549 cells to cisplatin through AKT and ERK1/2 pathways in vitro. Cell Physiol Biochem. 2014;33(4):1162-1175. doi:10.1159/000358685.

112. Tang Y, Liu F, Zheng C, Sun S, Jiang Y. Knockdown of clusterin sensitizes pancreatic cancer cells to gemcitabine chemotherapy by ERK1/2 inactivation. J Exp Clin Cancer Res. 2012;31:73. doi:10.1186/1756-9966-31-73. 
113. Heerlein K, Schulze A, Hotz L, Brtsch P, Mairburl H. Hypoxia decreases cellular ATP demand and inhibits mitochondrial respiration of A549 cells. Am J Respir Cell Mol Biol. 2005;32(1):44-51. doi:10.1165/rcmb.2004-0202OC.

114. Ke Q, Costa M. Hypoxia-inducible factor-1 (HIF-1). Mol Pharmacol. 2006;70(5):1469-1480. doi:10.1124/mol.106.027029.

115. Millar NL, Reilly JH, Kerr SC, et al. Hypoxia: a critical regulator of early human tendinopathy. Ann Rheum Dis. 2012;71(2):302-310. doi:10.1136/ard.2011.154229.

116. Bakker WJ, Harris IS, Mak TW. FOXO3a Is Activated in Response to Hypoxic Stress and Inhibits HIF1-Induced Apoptosis via Regulation of CITED2. Mol Cell. 2007;28(6):941-953. doi:10.1016/j.molcel.2007.10.035.

117. Mammucari C, Milan G, Romanello V, et al. FoxO3 Controls Autophagy in Skeletal Muscle In Vivo. Cell Metab. 2007;6(6):458-471. doi:10.1016/j.cmet.2007.11.001. 